\title{
La población de la provincia de Cádiz en los siglos XVII y XVIII (1)
}

\author{
MANUEL BUSTOS RODRIGUEZ \\ ALICIA BUZON MUÑOZ \\ ISABEL GOMEZ MIIAN \\ ARTURO MORGADO GARCIA \\ DOLORES NUINEZ GAIIEGO \\ MERCEDES RODRIGUEZ RAMIREZ
}

Nunca ha tenido sentido considerar la provincia de Cádiz como una unidad geográfica y socioeconómica, y menos aún durante el Antiguo Régimen. Dividida desde el punto de vista administrativo entre las intendencias de Sevilla y Granada, desde el punto de vista eclesiástico entre las diócesis de Cádiz, Sevilla y Málaga, y desde el punto de vista jurisdiccional entre los territorios de realengo y entre aquéllos donde el poder señorial dejaba hacer sentir su peso, todo ello nos muestra que referirse a la provincia como un todo es algo que solamente tiene justificación desde nuestra perspectiva actual. Es obvio, sin embargo, que tal diversidad de estructuras debía reflejarse también en el terreno demográfico; de ahí que nuestra intención haya sido ofrecer una visión de conjunto acerca de los rasgos poblacionales de las localidades que hoy componen la provincia de Cádiz, y de su trayectoria demográfica a lo largo de los siglos XVII y XVIII: No hemos pretendido ni mucho menos agotar todas las posibilidades ofrecidas por una cuestión que requeriría numerosos trabajos de carácter mono-

(1) Este trabajo es el resultado de la actividad investigadora realizada por el grupo Lantery, dirigido por los profesores Manuel Bustos Rodríguez y Arturo Morgado Garcia, cuya constitución fue posible gracias a una ayuda económica otorgada por la Dirección General de Universidades e Investigación de la Junta de Andalucía. 
gráfico, sino tan sólo ofrecer un punto de partida (y nunca de llegada) para futuras investigaciones, a lo que nos ha animado la ausencia casi total de estudios acerca de esta zona.

\section{FUENTES Y METODOLOGIA}

Casi todos los investigadores están de acuerdo en señalar cómo los censos confeccionados a lo largo del Antiguo Régimen carecen de credibilidad, al menos hasta el siglo XVIII (2), por lo que nos parecía en gran medida inútil acudir a los archivos nacionales a fin de consultar estas fuentes. Nuestra opción ha sido recoger la información contenida en las versiones publicadas de los censos de 1591 (3) y 1787 (4), al estar situados al inicio y al final del marco cronológico de nuestra investigación, llenando las etapas intermedias con los datos ofrecidos por P. Ponsot (5). Se ha descartado la consulta de padrones municipales y señoriales, ya que desde un principio nuestro propósito fue ofrecer una visión de conjunto, de ahí que no abordemos la recogida sistemática de información referida a localidades concretas cuyos totales poblacionales, al datar las fuentes de años diversos, no fuesen homologables con los de las restantes localidades de nuestro marco espacial.

El núcleo de este trabajo viene dado por las series parroquiales. Contábamos ya con algunas de ellas, como las de Cádiz (6), San Fernando (7), Chipiona (8) y El Puerto de Santa María (9), por lo que la

(2) Vid. MARTIN GALAN, M., "Fuentes y métodos para el estudio de la demografía castellana durante la Edad Moderna". Hispania, 148, 1981, p.p. 231-325.

(3) GONZALEZ, T., Censo de la población de las provincias y partidos de la Corona de Castilla en el siglo XVI. Madrid, 1829, reeditado recientemente por el I.N.E.

(4) Censo de 1787 "Floridablanca" Cádiz, Madrid, I.N.E., 1986.

(5) PONSOT, P., Atlas de bistoria económica de la Baja Andalucía (siglos $X V I-X I X)$. Sevilla, 1986, pp. 91-99 y 104-116.

(6) PORQUICHO MOYA, I., Cádiz, población y sociedad (1596-1650). Las series parroquiales (Sevilla, Tesis de Licenciatura inédita, 1984); PEREZ SERRANO, J., La población de Cádiz a fines del Antiguo Régimen. Su estructura y mecanismos de renovaciôn (1775-1800) (Cádiz, 1989); PONCE CORDONES, F., "Dos siglos claves en la demografía gaditana" (Breve estudio sobre la evolución de la población de Cádiz en las centurias XVII y XVIII). Gades, 11, 1983, pp. 417-453, construido este último a partir de los libros indice, y no de las series parroquiales, por lo que los resultados ofrecen un grado de fiabilidad mucho menor.

(7) MOLINA MARTINEZ, J.M., San Fernando, demografía y sociedad (1656-1750). Cádiz, 1985. Tesis de Licenciatura inédita.

(8) PONSOT, P., op. cit., PP. 155-156.

(9) Ibídem, pp. 170-171. 
Bahía gaditana se encontraba de antemano bien representada, lo què nos ha movido a volcarnos hacia las localidades del interior, si bien el problema radicaba en seleccionar las mismas. Desde un principio parecía evidente que Jerez de la Frontera, segunda población en importancia de la provincia según el censo de 1787, no podía quedar descartada: Era necesario, además, comprender en la muestra los núcleos serranos, eligiendo a Olvera (al encontrarse su documentación en el Archivo Diocesano de Jerez, lo que facilitaba el acceso a la misma) y Bornos. Arcos hubiese sido la solución ideal, pero las condiciones en que se encuentra su archivo parroquial no son las más aptas para desarrollar una tarea investigadora.

Las zonas de la Campiña situadas al sur del río Guadalete han sido cubiertas por medio del estudio de Chiclana y Alcalá de los Gazules, en tanto Sanlúcar de Barrameda (que a finales del siglo XVIII era la quinta población más populosa de la provincia) y Conil permitirian completar la banda costera. Más problemático, por el contrario, ha sido elegir alguna población representativa del Campo de Gibraltar, puesto que no se conserva la documentación de Jimena ni de Castellar de la Frontera, en tanto que los archivos parroquiales de Tarifa se encuentran prácticamente vedados al público por falta de personal. Optamos por la solución menos mala, cual era el estudio de Gibraltar (cuyo término municipal englobaba los de las actuales Algeciras, San Roque y Los Barrios), y cubrir el siglo XVIII por medio del estudio de San Roque, al constituir esta población el lugar de asentamiento de los calpenses tras la conquista inglesa del Peñón.

En total, la muestra comprende ocho poblaciones, que constituyen el $21 \%$ del total de términos municipales existentes en la provincia a finales del Antiguo Régimen, concentrando el 29,2\% de la población de la misma.

El segundo problema a dilucidar era la metodología. Desde un principio se descartó la utilización del método francés, o de reconstrucción de familias, tarea imposible en nuestra provincia dada la intensidad de las corrientes migratorias y el elevado volumen de habitantes de sus principales localidades. Nos parecía mucho más racional optar por el método inglés, o de recuentos globales, cuyo empleo ha alcanzado elevados niveles de sofisticación en los últimos trabajos publicados (10), si bien aun así era evidente que la ingente cantidad 
de documentación disponible (11) provocaba la imposibilidad de realizar un análisis exhaustivo. Por tales motivos, resolvimos abordar la investigación mediante un doble sistema:

a) Hacer un recuento anual y mensual de las series de bautismos, matrimonios y defunciones de todas las poblaciones y todas las parroquias objeto de nuestro estudio, a fin de obtener un perfil completo de la evolución de dichas variables y de las variaciones estacionales existentes en el período comprendido entre 1600 y 1799.

b) Se confeccionaron catas correspondientes a los años de $1595-1600,1645-1650,1695-1700,1745-1750$ y $1795-1800$, en las cuales se estudiaban cuestiones más específicas: relación de masculinidad, estudio de la ilegitimidad, importancia de las segundas nupcias, análisis de la inmigración y de la estructura por edad y sexo de las defunciones. Dichas catas cubren todas las localidades, aunque en aquéllas con un elevado número de parroquias se eligió la que nos pareció $a$ priori la más representativa: así, la de San Juan Bautista para el caso de Chiclana, y las de Santiago y San Dionisio por lo que se refiere a Jerez de la Frontera.

En líneas generales, las series de bautismos están completas y, salvo algunas excepciones, las de matrimonios. El gran problema viene ofrecido por las series de defunciones, que a su escasa fiabilidad (12) añaden el agravante de no iniciarse hasta finales del siglo XVII en la mayoría de las ocasiones, presentando además ciertas lagunas en algunas localidades.

Los archivos consultados fueron los siguientes:

-Archivo Parroquial de San Jorge (Alcalá de los Gazules).

-Archivo Parroquial de Santo Domingo (Bornos).

-Archivo Parroquial de Santa Catalina (Conil).

-Archivo Parroquial de San Juan Bautista (Chiclana), contiene además la documentación de la parroquia castrense, iniciada en 1765.

-Archivo Parroquial de San Sebastián (Chiclana). Las series se inician en 1788.

-Archivo Parroquial de Santa Maria la Coronada (San Roque). Contiene además los libros correspondientes a la Iglesia Mayor de Gibraltar.

-Archivo Diocesano de Jerez de la Frontera:

a) Parroquias de San Dionisio, San Juan de los Caballeros, San Lucas, San Marcos, San Mateo, San Miguel, San Salvador y Santiago de Jerez de la Frontera.

b) Parroquia de Nuestra Señora de la Encarnación de Olvera.

c) Parroquia de Nuestra Señora de la O de Sanlúcar de Barrameda.

(12) PEREZ MOREDA, V., Las crisis de mortalidad en la España interior (siglos $X V T-X(X)$. Madrid, 1980, pp. 29-33. 


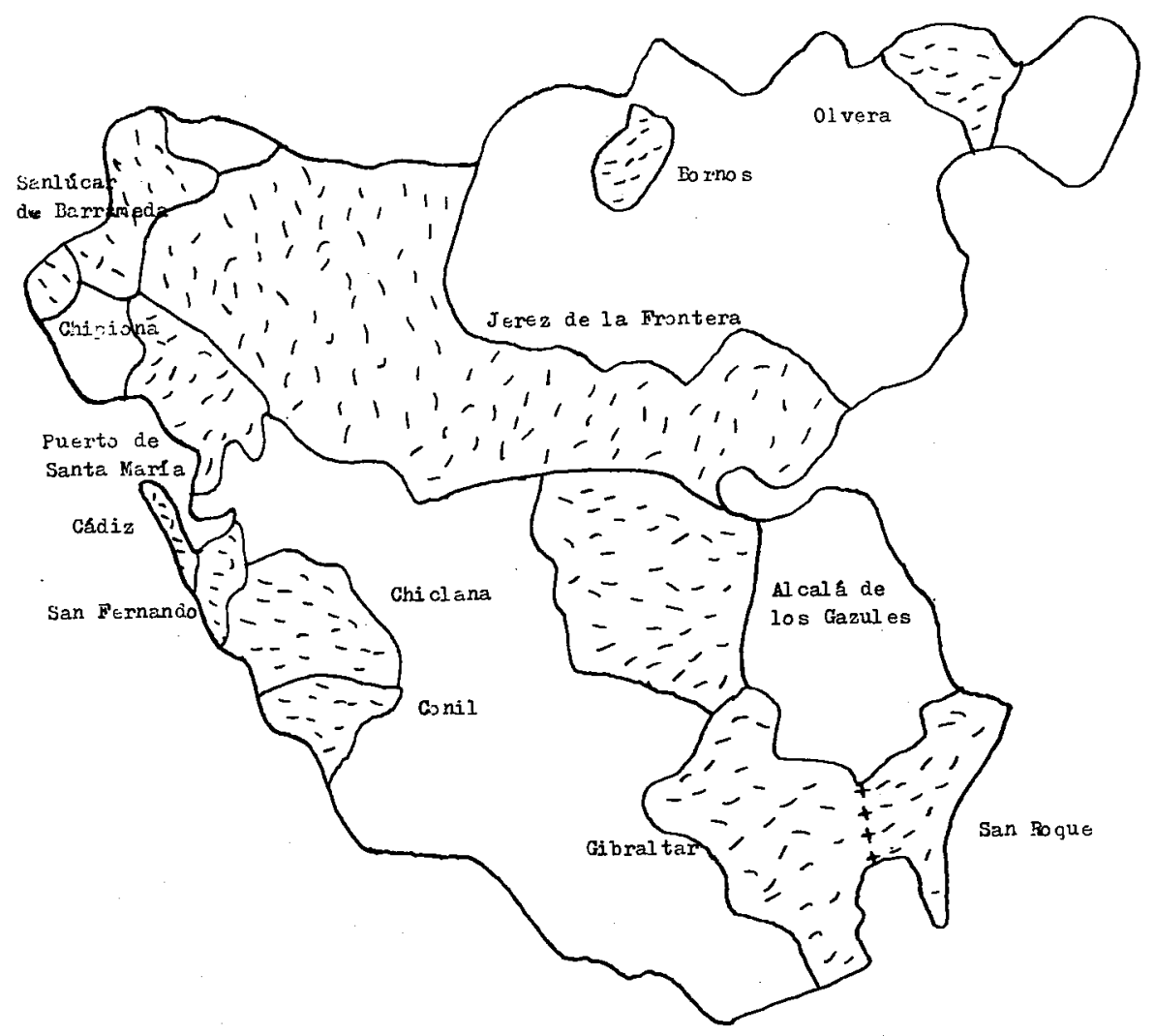


Deseamos manifestar desde estas páginas nuestro agradecimiento al personal de los archivos parroquiales y diocesanos consultados, que en muchas ocasiones nos han brindado más facilidades de las que les imponía el estricto cumplimiento de sus obligaciones. Es de justicia señalar que sin su desinteresada y amable colaboración, el llevar a buen término este trabajo hubiese supuesto mucho más tiempo y esfuerzo.

\section{LA NATALIDAD}

\subsection{Las tasas}

A lo largo del Antiguo Régimen, las tasas de natalidad se caracterizan por un volumen mucho más elevado que las obtenidas en las poblaciones de los países desarrollados de nuestros días (13), e idéntica es la situación que se observa en nuestra provincia, tal como nos revelan estos datos referidos a 1785-1789:

$\begin{array}{ll}\text { Alcalá de los Gazules } & 43,3 \text { por mil } \\ \text { Bornos } & 42,7 \\ \text { Cádiz } & 33,1 \\ \text { Conil } & 46,5 \\ \text { Chiclana } & 43,0 \\ \text { Olvera } & 38,7 \\ \text { El Puerto de Santa María } & 43,4 \\ \text { Sanlúcar de Barrameda } & 37,7 \\ \text { San Roque } & 40,6\end{array}$

De hecho, en la mayoría de las localidades se obtienen tasas anormalmente elevadas que superan con mucho el 40 por mil, pero ello no excluye la existencia de situaciones caracterizadas por unos índices más reducidos, como los observados en Cádiz, para la cual ya se ha establecido un modelo explicativo coherente (14). En las zonas

(13) Suelen oscilar entre el 38 y el 40 por mil en la parroquia sevillana de Santa Ana (ALVAREZ SANTALO, L.C., "La población de Sevilla en las series parroquiales: siglos XVI-XIX". Actas de los II Coloquios de Historia de Andalucía. Andalucía Moderna, tomo 1. Córdoba, 1983, p.8.

(14) Vid. PEREZ SERRANO, J., op. cit., p. 134. 
rurales, por el contrario, la inexistencia de un elevado volumen de inmigrantes desarraigados (15) y la presencia de una estructura social más estable, que requiere ante todo brazos para la agricultura, provocaría una actividad reproductora más intensa, facilitada además por la posibilidad de encontrarnos en estos años con una coyuntura económica positiva, si bien no tenemos pruebas de ello. No se debe descartar, sin embargo, el hecho de que las cifras ofrecidas por el Censo de Floridablanca pequen por defecto en ciertos casos.

\subsection{La relación de masculinidad}

Una norma de universal cumplimiento y que obedece meramente a las leyes de la naturaleza radica en el hecho de que siempre nacen más niños que niñas, y la provincia de Cádiz no constituye ninguna excepción en este sentido:

$\begin{array}{ll}\text { Alcalá de los Gazules } & 106,8 \\ \text { Bornos } & 102,3 \\ \text { Cádiz (1775-1800) } & 106 \\ \text { Conil } & 104,8 \\ \text { Chiclana (San Juan Bautista) } & 100,6 \\ \text { Gibraltar } & 109,9 \\ \text { Jerez F. (Santiago) } & 107,6 \\ \text { Olvera } & 105,4 \\ \text { Sanlúcar de Barrameda } & 104,4 \\ \text { San Fernando (1656-1750) } & 104 \\ \text { San Roque } & 104,4\end{array}$

En la mayoria de las ocasiones los índices se sitúan en torno a 104-105, que según L. Henry son los valores más normales (17), no contando con ninguna explicación a la hora de establecer las causas de las anómalas tasas obtenidas en Bornos, Chiclana y Gibraltar.

(15) Sharlin ha puesto de relieve cómo en las ciudades de la Modernidad el índice de natalidad es más reducido entre los inmigrantes que en el seno de los naturales de las mismas, ya que aquéllos se caracterizan por unas precarias condiciones de vida y un mayor grado de desarraigo (SHARLIN, A., "Natural decrease in Early Modern cities: a reconsideration". Past and Present, 79, 1978).

(16) Fuente: MOLINA MARTINEZ, J.M., op. cit., p. 32 (San Fernando); PEREZ SERRANO, J., op. cit., p. 153 (Cádiz), series parroquiales de 1595-1600, 1645-1650, 1695-1700, 1745-1750-1795-1800 (restantes poblaciones).

(17) HENRY, L., Manual de Demografía Histórica. Barcelona, 1983, p. 78. 


\subsection{La estacionalidad}

La estacionalidad de los bautismos (cuadros 1 y 2) se corresponde en todas las localidades con un modelo muy bien definido, que apenas difiere de lo que ya sabíamos con anterioridad (18):

a) Los meses con un mayor número de nacimientos son los de enero y febrero, que comparten esta posición con los de marzo (Alcalá de los Gazules, Bornos, Jerez y Olvera) y diciembre (Conil, Chiclana, Gibraltar y Sanlúcar), lo que responde obviamente a concepciones producidas entre marzo y junio. Tan sólo Chiclana, con un volumen relativamente numeroso de nacimientos en noviembre; y Sanlúcar, en la cual mayo ocupa una posición destacada, ofrecen alguna nota original. El siglo XVIII presenta un perfil prácticamente idéntico, manteniéndose la hegemonía de los meses de enero y febrero, seguidos por los de marzo y noviembre. Tal y como sucedía en la anterior centuria, las concepciones acaecidas durante la primavera ofrecen la nota dominante.

b) Por lo que se refiere a los meses en los cuales el número de nacimientos es menor, en el siglo XVII los mismos son los de junio, julio, agosto y, a cierta distancia, abril, situación que prácticamente se mantiene a lo largo del Siglo de las Luces. A tenor de estos datos, el período de tiempo comprendido entre septiembre y noviembre debe ser menos proclive a las concepciones.

Mayor número de concepciones en primavera, y menor en otoño, es el comportamiento que está presente en todas partes: ¿¿A qué se debe dicho modelo, el cual, por otra parte, es el que encontramos en casi todas las localidades andaluzas? (19). Los imperativos religiosos, según los cuáles se proscribían las relaciones sexuales durante la Cuaresma, no juegan ningún papel; de ser así, durante los meses de noviembre y diciembre, el número de nacimientos sería muy reducido, situación que no se da en modo alguno. Los ritmos del trabajo agríco-

(18) Vid. MOLINA MARTINEZ, J.M., op. cit., p. 42; PORQUICHO MOYA, I., op. cit., p. 82; PEREZ SERRANO, J., op. cit., p. 157.

(19) Vid. CAMACHO RUEDA, E., Propiedad y explotación agrarias en el Aljarafe sevillano: el caso de Pilas (1760-1925). Sevilla, 1984, pp. 60-61; SANZ SAMPELAYO, J.F., Granada en el siglo XVII. Granada, 1980, p. 359; GARCIA-BAQUERO LOPEZ, G., Estudio demográfico de la parroquia de San Martín de Sevilla (1551-1 749). Sevilla, 1982, pp 135 ss; GARCIA JIMENEZ, B., Demografia rural andaluza: Rute en el Antiguo Régimen, Córdoba, 1987, p. 59. 
la, que provocarían un menor número de concepciones durante los períodos de siembra y recolección, tienen en todas partes una gran incidencia. La fecha de salida y llegada de las flotas hacia América juega en ciertos casos un papel relevante: así, en Sanlúcar de Barrameda, el elevado número de concepciones que tiene lugar en agosto durante el siglo XVII parece estar relacionado con el hecho de que precisamente en este mes del año zarpaban los Galeones de Tierra Firme. Pero, y siguiendo a J. Pérez Serrano, estamos de acuerdo en afirmar que los factores biológicos son los preponderantes (20), si bien hay autores que niegan el papel jugado por este misterioso "ciclo vital»" (21).

\subsection{La ilegitimidad}

La proporción de nacimientos ilegítimos con respecto al total ofrece tasas muy dispares en la provincia de Cádiz, tanto geográfica como cronológicamente (cuadro 3). Todo parece indicar que las mismas son más elevadas en aquellas poblaciones que presentan una estructura social más compleja y una vida económica más diversifica$\mathrm{da}$, pudiendo aplicarse, en líneas generales, el modelo explicativo aducido para el Cádiz finidieciochesco (22). Así, en Sanlúcar de Barrameda, todo lo determina la presencia de las actividades comerciales y portuarias (23); en San Roque, la existencia de una importante guarnición militar establecida con la finalidad de hacer frente a una potencial amenaza inglesa; en Chiclana, la cercanía a Cádiz y la posible influencia de los modos más libres de la capital (24); y en Jerez de la Frontera, su carácter de metrópoli de cierta importancia, si bien los reducidos niveles observados en esta población durante el siglo XVIII nos

(20) PEREZ SERRANO, J., op. cit., p. 160.

(21) Vid. SANCHEZ LORA, J.L., "Ayamonte 1600-1800. El ciclo vital anual", Actas II Coloquios... tomo 1, Córdoba, 1983, pp. 127-134.

(22) Vid. PEREZ SERRANO, J., op. cit., pp. 204-206.

(23) Esta población se benefició mucho en el siglo XVII del monopolio del comercio colonial detentado por la urbe hispalense, e incluso en 1664 se dispuso que las flotas partieran de dicha ciudad (GARCIA BAQUERO, A., "Las mudanzas del condicionamiento americano". Historia de Andalucía, vol. VI. Barcelona, 1981, p. 262). Todavía en el siglo XVIII el comercio mantenía cierta actividad (DEMERSON, P. Sanlúcar de Barrameda en la corriente de la Ilustración, Cádiz, 1976, pp. 39-40), llegando a fundarse un Consulado en 1798.

(24) Muchos comerciantes adinerados mantenían residencias campestres en esta localidad. 
parece no deben corresponder a la realidad: es posible que durante esta centuria la tipología ilegítima más frecuente sea la de "expósito en la Cuna" y, al estar situada la misma en otra parroquia, la proporción de ilegítimos fuese más reducida en las restantes colaciones de la ciudad.

Las tasas de ilegitimidad ofrecen además grandes diferencias cronológicas, y a lo largo del período objeto de nuestro estudio las mismas conocen un gran descenso: en Bornos, el mismo se produce en la primera mitad del siglo XVII; en Alcalá de los Gazules, Chiclana, Gibraltar, Conil, Olvera y Jerez de la Frontera, en la segunda, si bien en Sanlúcar de Barrameda esta ruptura es mucho menos perceptible. Es muy probable que este descenso de la actividad sexual extramaritat haya que relacionarla con la creciente penetración de los modos de comportamiento que la Reforma Católica pretendió inculcar (25), pero lo cierto es que a mediados del siglo XVIII las tasas son muy reducidas, y solamente en Chiclana, San Roque y Sanlúcar se supera el 30 por mil, si bien sin alcanzarse jamás niveles como los observados en la urbe gaditana (26). En algunas ocasiones se produce un cierto incremento de las tasas a finales del Siglo de las Luces, tal como sucede en Alcalá de los Gazules, Chiclana, la parroquia jerezana de San Dionisio y San Roque, que posiblemente deba relacionarse con un creciente rechazo de la moral sexual católica o con la nefasta coyuntura económica vivida durante los difíciles años noventa (27).

No parece que los datos reunidos acerca de la relación de masculinidad existente en el seno de la población ilegítima y acerca de la estacionalidad de la misma tengan mucha credibilidad, dado el volumen relativamente reducido de la muestra en algunos casos, pero, por lo que se refiere a las tipologías ilegítimas (cuadro 4), el aspecto sin duda alguna más interesante, las mismas presentan ciertas notas comunes en todas las localidades, que a nuestro entender son las siguientes:

(25) Vid. SOLE, J., L'amour en Occident à l'epoque moderne, Eruselas, 1984, pp. 27 ss. Un ejemplo local de esta creciente moralización en ROSSIAUD, J., "Prostitución, sexualidad y sociedad en las ciudades francesas del siglo XV", ARIES, P., BEJIN, A., y FOUCAULT, M., Sexualidades Occidentales, Barcelona, 1987.

(26) El 22,6\% de los nacimientos en 1596-1650 (PORQUICHO MOYA, I., op. cit., p. 87 y el 15,4\% en $1775-1800$ (PEREZ SERRANO, J., op. cit., p. 199).

(27) Sobre las causas de este aumento de la ilegitimidad a fines del siglo XVIII, vid. ANDERSON, M., Approaches to the History of the Western Family 1500-1914, reimp., Hong Kong, 1984, pp. 56-57; y FLINN, M.W., El sistema demográfico europeo (1500-1820). Bolonia, 1983, p. 121. 
a) Los "hijos de esclavos" experimentan un descenso numérico continuo debido a la progresiva decadencia que atraviesa esta institución a lo largo del siglo XVII (28): de hecho, su presencia en el siglo XVIII es excepcional.

b) Los "hijos de padres solteros", fruto de relaciones extramaritales relativamente estables, conocen, quizás como consecuencia de la creciente moralización de la vida cotidiana impuesta por la Reforma Católica, un fuerte descenso, y son muy raros en el siglo XVIII.

c) Los "hijos de padres desconocidos" pueden deberse a una intención tácita o explícita de los padres por mantenerse en el anonimato, pero sin que ello implique forzosamente un abandono del recién nacido. Exceptuando los casos de Bornos y Olvera, en el siglo XVIII esta categoría prácticamente se ha desvanecido, quizás porque ese deseo de anonimato impuesto por las circunstancias sea cada vez más difícil de mantener ante las crecientes presiones eclesiásticas (29).

d) Finalmente, los "expósitos" o "hijos de la Iglesia" (30), términos que nos indican una clara voluntad por parte de los progenitores de abandonar a su suerte al recién nacido, tienden a aumentar de importancia (31) a medida que transcurre el período objeto de nuestro estudio. Ello puede estar relacionado con una creciente implantación de las Casas-Cuna (32), o bien con factores de carácter psicológico: es probable que el concebir un hijo resultado de una relación sexual extramarital se convierta en un hecho tan vergonzante, que la única alternativa existente para los padres fuese el abandono sistemático de todos aquellos niños nacidos como consecuencia de relaciones pecaminosas.

(28) La urbe gaditana, no obstante, constituye una excepción. Vid. MORGADO GARCIA, A., y NUÑEZ GALLEGO, D., "La esclavitud en el Cádiz de la segunda mitad del siglo XVII", I Coloquio de Historias locales, Cádiz, 1989.

(29) Vid. PEREZ SERRANO, J., op. cit., pp. 225-226.

(30) Sobre los expósitos vid. ALVAREZ SANTALO, L.C., Marginación social y mentalidad en Andalucia Occidental. Expósitos en Sevilla (1613-1910). Sevilla, 1980; FERNANDEZ CARRION, T., "Comportamientos demográficos marginales. Aproximación metodológica al estudio de la ilegitimidad en la Baja Andalucía a fines del Antiguo Régimen". Actas de los II Colloquios... tomo 1; y GOMEZ MARTINEZ, E., Los niños expósitos en Anduijar. Córdoba, 1987.

(31) Lo mismo sucede en la Granada de la Modernidad. Vid. CORTES PEÑA, A.L., y VINCENT, B., Historia de Granada, tomo III. La época moderna. Siglos XVI, XVII y XVII. Granada, 1986, p. 253.

(32) Desconocemos, sin embargo, la cronología de fundación de las casas-cuna en la provincia de Cádiz. 


\section{LA NUPCIAIIDAD}

\subsection{Las tasas}

Las tasas de nupcialidad observadas en nuestra provincia en 1785-1789 no difieren demasiado de las obtenidas en otras localidades andaluzas (33):

$\begin{array}{ll}\text { Alcalá de los Gazules } & 8,9 \text { por mil } \\ \text { Bornos } & 8,7 \\ \text { Cádiz } & 7,6 \\ \text { Conil } & 9,8 \\ \text { Chiclana } & 10,2 \\ \text { Olvera } & 7,1 \\ \text { El Puerto de Santa María } & 10,5 \\ \text { Sanlúcar } & 8,5 \\ \text { San Roque } & 9,1 \quad(34)\end{array}$

En algunas localidades de la provincia se obtienen incluso tasas anormalmente elevadas, como Chiclana y El Puerto de Santa María, donde, debido quizás a la prosperidad de estos años, se supera el 10 por mil. Tan sólo Cádiz y Olvera ofrece un comportamiento anómalo, en raźón de sus muy reducidos niveles de nupcialidad (35).

\subsection{La estacionalidad}

A diferencia de lo sucedido con los bautismos, el ritmo estacional de los matrimonios (cuadros 5 y 6) no conoce una concentración tan acusada en un período concreto del año, y cabría hablar, más que de uno, de dos máximos anuales: el primero, y más evidente, en los meses de septiembre y octubre (anticipado en el siglo XVIII hasta agosto); y el segundo, más difuminado en el Siglo de las Luces, en torno a febrero o mayo, según las localidades, jugando en algunos casos el mes de diciembre un papel preponderante. Por lo que se refiere a los mínimos, los comportamientos son más unánimes, y a lo largo de los dos siglos objeto de nuestro estudio suelen situarse en marzo, junio, julio, y, de manera más secundaria, en noviembre.

Vid. SANZ SAMPELAYO, J.F., op. cit., p. 345; y GARCIA-BAQUERO LOPEZ, G., op. cit.

(34) Fuente: Censo de 1787 y series parroquiales.

(35) Vid. PEREZ SERRANO, J., op. cit., pp. 125-127. 
a) En primer lugar, el calendario religioso (36), según el cual se prohibía la celebración de los matrimonios entre Adviento y Epifanía y la Cuaresma y el Domingo de Cuasimodo, lo que explica el escaso número de enlaces celebrados durante los meses de noviembre en ciertas poblaciones y en marzo, fecha en que tiene lugar la Semana Santa, en todas las localidades estudiadas por nosotros. Es lógico pensar que antes o después de estos períodos de abstinencia el número de matrimonios se dispara, y ello explica la importancia de las nupcias contraídas durante diciembre (al final del Adviento) y febrero (inmediatamente antes de la Cuaresma).

b) Los ritmos laborales (37): la concentración de las labores agrícolas en verano determina el escaso número de esponsales contraídos a lo largo de junio y julio, en tanto que finalizadas aquéllas el volumen de matrimonios aumenta, lo que explica el alza producida durante los meses de agosto, septiembre y octubre. La única excepción está constituida por la localidad de Sanlúcar de Barrameda, cuyo carácter comercial y portuario más acentuado provoca una menor vinculación del ritmo estacional de los matrimonios con la actividad agrícola.

c) La influencia del "ciclo vital" al que aludiamos en el caso de los bautismos, lo que provoca que el mes de mayo, asociado con la fertilidad y la renovación de la vida, sea en ciertos lugares una fecha especialmente proclive para contraer matrimonio.

\subsection{La estructura matrimonial}

Como consecuencia de las elevadas tasas de mortalidad existentes en el seno de las poblaciones del Antiguo Régimen, un fenómeno muy corriente será la elevada proporción de individuos que en algún momento de su existencia contrae segundas nupcias (38), y ello estará también presente en nuestra provincia (cuadro 7). La posibilidad más

(36) En algunas localidades como San Fernando (MOLINA MARTINEZ, J.M., op. cit., p. 57) o Medina del Campo (MARCOS MARTIN, A., Auge y declive de un núcleo mercantil y financiero de Castilla La Vieja. Euolución demográfica de Medina del Campo durante los stglos XVI y XVII, Valladolid, 1978, p. 153) jugaría el papel principal.

(37) En Rute constituye el factor primordial (GARCIA JIMENEZ, B., op. cit., p. 67), e incluso en ciertas zonas como la comarca gallega de La Ulla anularía la importancia del componente reliogioso (REY CASTELAO, O., Apraximación a la bistoria rural de la comarca de La Ulla (siglos XVII y XVIII). Santiago de Compostela, 1981, p. 48).

(38) Vid. GARCIA-BAQUERO LOPEZ, G., op. cit., p. 158; MOLINA MARTINEZ, J.M., op. cit., p. 60; PORQUICHO MOYA, I., op. cit., p. 138. 
común, en líneas generales, será el enlace entre soltera y viudo (39), muy posiblemente por la precariedad de la situación económica de unas viudas cargadas de hijos en muchos casos, lo que dificultaría en muchas ocasiones la contracción de un segundo matrimonio, en tanto que quizás la proliferación de viudos casados con solteras responda a enlaces habidos entre varones maduros y con una cierta posición económica y jóvenes. Solamente Sanlúcar de Barrameda (y hasta mediados del siglo XVII) presenta una proporción excepcionalmente reducida de matrimonios donde ambos cónyuges son solteros.

Hay que resaltar, además, cómo hay una cierta tendencia al aumento de las nupcias contraídas entre solteros, que posiblemente responda a la creciente importancia concedida al matrimonio por amor, lo que provocaría de rebote un cierto rechazo de las nupcias celebradas por motivos de interés, más factibles en los matrimonios donde uno de los cónyuges es viudo, ya que en éstos, la necesidad de protección económica o de asegurar el cuidado de los hijos pueden jugar un cierto papel (40).

\section{LA MORTAIIDAD}

\subsection{Las tasas}

La escasa fiabilidad de los libros de defunciones, determinada por la exclusión de la mayoría de los párvulos fallecidos, provoca que las tasas de mortalidad deducidas a partir de éstos no se correspondan en absoluto con la realidad. Solamente podemos ofrecer datos fiables referidos a la mortalidad de párvulos (entendiendo como tal la que afecta a los niños con una edad comprendida entre los 0 y los 7 años), que en todas las poblaciones de la provincia ofrecía unos índices muy elevados en 1787 :

$\begin{array}{ll}\text { Alcalá de los Gazules } & 490 \text { por mil } \\ \text { Bornos } & 543 \\ \text { Cádiz } & 434 \\ \text { Conil } & 424\end{array}$

(39) Vid. GARCIA-BAQUERO LOPEZ, G., op. cit., p. 158; GARCIA JIMENEZ, B., op. cit., p. 71; MOLINA MARTINEZ, J.M., op. cit., p. 60; si bien en el Cádiz de la primera mitad del siglo XVII son más corrientes los matrimonios contraídos entre solteros y viudas, quizás "debido a la enorme cantidad de foráneos que se casan con viudas de eierto nivel de asentamiento en la ciudad" (PORQUICHO MOYA, I., op. cit., p. 140).

(40) Vid. ANDERSON, M., op. cit., pp. 45-49, que ofrece una visión de conjunto acerca de esta cuestión. 
En casi todas partes se supera la tasa del 400 por mil (y en San Roque y Bornos se sitúa por encima del 500 por mil, quizás por una excepcional insalubridad o una atención médica especialmente precaria en estas poblaciones), constituyendo Sanlúcar de Barrameda la única excepción. Parafraseando a Goubert, harán falta dos nacimientos para producir un adulto (41), si bien es preciso tener en cuenta que la incidencia de la epidemia de fiebre amarilla de 1785-1786 puede haber provocado una mortalidad excepcionalmente elevada de párvulos

\subsection{La estacionalidad}

La estructura estacional de las defunciones (cuadro 8) es muy estable en las localidades objeto de nuestro estudio: en casi todas ellas los meses más proclives a los fallecimientos son los de agosto-diciembre, debido a las infecciones gástricas provocadas por el consumo de a'gua y verdura en malas condiciones durante el verano, y las irregularidades climáticas del otoño (42). En muy pocas ocasiones se observa una mayor acumulación de defunciones en los meses invernales ante la relativa benignidad de dicha estación en nuestra provincia. Los meses de febrero-junio, por el contrario, suelen conocer un índice de mortalidad más reducido. Es curioso señalar cómo en San Roque los niveles de mortalidad de párvulos en los meses de julio-noviembre son excepcionalmente elevados.

\subsection{Estructura por edad y sexo}

La práctica ausencia de noticias contenidas en los libros de defunciones acerca de la edad de los fallecidos y la sistemática exclusión de los párvulos en la mayoría de las ocasiones, provocan que la

(41) GOUBERT, P., Beauvais et le Beauvaisis de 1600 a 1730. París, 1982, p. 39.

(42) Idéntico comportamiento se observa en otras zonas. Vid. PEREZ MOREDA, V., op. cit., pp. 210-212; y CORTES CORTES, F., La población de Zafra en los siglos XVI y XVII. Badajoz, 1983, p. 52. 
información con la que contamos acerca de la estructura de las defunciones sea bastante escasa, a pesar de lo cual es interesante señalar algunas conclusiones (cuadros 9 y 10):

a) En primer lugar, el hecho de cómo son los primeros años los más críticos de la existencia, y cómo pasado el umbral de los 465 años aumentan en gran medida las posibilidades de sobrevivir: en San Roque, por ejemplo, los niños con menos de un año suponen el 21,1 $\%$ de los fallecimientos, proporción casi idéntica a quienes tienen entre uno y cuatro años de edad en el momento de morir $(23,9 \%)$, en tanto que en Conil, los fallecidos con menos de un año representan el $25,1 \%$ de las defunciones, y con 1-7 años el $27,6 \%$.

b) En segundo término, la presencia de una elevada relación de masculinidad en el total de fallecimientos, lo que se debe ante todo al hecho de que nos encontramos con localidades que acogen una fuerte inmigración de varones. La relación de masculinidad, no obstante, es bastante variable según las edades: en Conil, por ejemplo, de los 0 a los 7 años oscila en torno a 108, ligeramente superior a la obtenida en el momento del nacimiento; a partir de los 20 años la relación de masculinidad se dispara (200 a los 20-29, 225 a los 30-39) (43), como consecuencia de la tantas veces mencionada mayor debilidad biológica masculina (44), y muy probablemente por la fuerte incidencia de la inmigración de varones en edades intermedias; si bien, a medida que nos vamos acercando a edades más avanzadas la relación de masculinidad va lentamente disminuyendo: 146 a los 50-59, 110 a los 60-69, 52 en la población con una edad superior a los 70 años. San Roque sigue un comportamiento similar, si bien parece que en esta población es mayor la sobremortalidad femenina como consecuencia del parto (la relación de masculinidad es de 92 a los 20-29 años).

\subsection{La principales crisis de mortalidad}

Las grandes conmociones que azotaron la España de la Modernidad también afectaron, como no podía ser menos, a la provincia de Cádiz. Es muy difícil, no obstąnte, reflejar de manera fiable cuáles fue-

(43) No se observa, sin embargo, una sobremortalidad femenina en las edades intermedias como consecuencia de las dificultades del parto, a diferencia de lo sucedido en la parroquia sevillana de San Martín (GARCIA-BAQUERO LOPEZ, G., op. cit., p. 232) o San Fernando (MOLINA MARTINEZ, J.M., op. cit., p. 89).

(44) Insistimos en la relatividad de todos estos datos, ante la escasa fiabilidad de los libros de defunciones. 
ron las grandes crisis de mortalidad, ya que las series se inician en la mayoría de las poblaciones a fines del siglo XVII, y suelen presentar un grado de credibilidad bastante reducido al omitir a los párvulos. En cualquier caso, el panorama que podemos deducir es el siguiente (vid. cuadros 20 y 23):

a) Las consecuencias de la epidemia de peste de 1676-1685 (45) solamente se reflejan en Sanlúcar y la parroquia jerezana de San Miguel. En esta última, el número de defunciones aumenta de manera desorbitada a lo largo del verano de 1678 , al igual que en Sanlúcar: la epidemia seguirá así un esquema básicamente veraniego, algo ya universalmente constatado.

b) Por lo que se refiere a la crisis de subsistencias de 1709-1710, derivada de las malas cosechas de estos años y de la fuerte presión fiscal provocada por la Guerra de Sucesión Española (46), sus efectos fueron prácticamente universales. A excepción de Chiclana (donde la mortandad se centra especialmente en el segundo semestre de 1708 y los meses de mayo-octubre de 1709) y Alcalá de los Gazules (en la cual la crisis se inicia en septiembre de 1708 y finaliza en diciembre del año siguiente), en todas las localidades objeto de nuestro estudio fue 1709 el año apocalíptico, debido a la catastrófica cosecha de 1708, cuya gravedad podemos deducirla atendiendo al brusco descenso que experimentan las rentas decimales percibidas en especie por el obispo y el Cabildo catedralicio gaditanos en dicho año (47). Las reservas alimenticias debieron agotarse paulatinamente durante el primer semestre de 1709 , de ahí que en la primavera de dicho año el número de defunciones se disparase en todas partes.

c) La crisis de subsistencias de 1737-1738 (48) tuvo, por el contrario, menor gravedad, dejando hacer sentir sus efectos principalmente en 1739 , como consecuencia, una vez más, de la pésima cosecha recogida dicho año (49). En Jerez de la Frontera, los años de

(45) Vid. PEREZ MOREDA, V., op. cit.; KAMEN, H., La España de Carlos II, Barcelona. 1981; y CALVO POYATO, J., "La última crisis de Andalucía en el siglo XVII: 1680-1685". Hispania, 164, 1986.

(46) Vid. DOMINGUEZ ORTIZ, A., Sociedad y Estado en el siglo XVIII español, reimpr., Barcelona, 1981; y CALVO POYATO, J., La Guerra de Sucesión en Andalucía. Córdoba, 1982.

(47) Vid. MORGADO GARCIA, A., Iglesia y Sociedad en el Cádiz del siglo XVIII. Cádiz, 1989, pp. 252 y 259.

(48) DOMINGUEZ ORTIZ, A., "La población de la Baja Andalucía". Historia de Andalucía, vol. Vl. Barcelona, 1981, p. 139.

(49) Vid. MORGADO GARCIA, A., Iglesia..., pp. 253 y 260. 
1736-1738 se caracterizaron en su conjunto por un brusco aumento de la mortandad.

d) La última gran crisis que atraviesa la provincia en el siglo XVIII (puesto que queda fuera del marco de nuestro trabajo la epidemia de fiebre amarilla de 1800) (50) vino provocada por la epidemia de tercianas o de paludismo de 1785-1786, cuya difusión fue también bastante desigual: Alcalá de los Gazules se vio afectada en julio-noviembre de 1786; Bornos, en agosto-noviembre del mismo año; Chiclana, en agosto-diciembre de 1786; Jerez de la Frontera, entre agosto de 1786 y enero de 1787; Olvera, en agosto-noviembre de 1787; y Sanlúcar de Barrameda, en julio de 1786-enero de 1787: predomina básicamente un ritmo veraniego-otoñal, algo que ya era bien conocido (51).

Las guerras apenas afectaron directamente a nuestra provincia durante este período, y solamente en San Roque las series de mortalidad se disparan en 1727 y 1780-1782, como consecuencia de los asedios de Gibraltar que tuvieron lugar en dichos años.

\section{LA INMIGRACION}

Hace mucho tiempo que se conoce la fuerte incidencia que tuvo la inmigración en la Bahía gaditana: en el Cádiz de la primera mitad del XVII los cónyuges inmigrantes suponen el 45,1\% del total (52), y en el San Fernando de 1656-1750, el 49,7\% (53), en tanto que en uno de los barrios de El Puerto de Santa María el $28,7 \%$ de la población del mismo era foránea (54). Estas cifras son más elevadas que las obtenidas en otras localidades andaluzas (55), aunque las poblacionestudiadas por nosotros (cuadro 11) presentan unas tasas más cercanas a la media regional ante su carácter rural más acentuado. Las únicas excepciones serán las de Sanlúcar y San Roque: la primera, por con-

(50) Vid. PEREZ MOREDA, V., op. cit., IGLESIAS RODRIGUEZ, J.J., La epidemia gaditana de fiebre amarilla de 1800, Cádiz, 1987; y RODRIGUEZ CARRION, J., Jerez 1800 epidemia de fiebre amarilla, Jerez de la Frontera, 1980.

(51) Vid. PEREZ MOREDA, V., op. cit.

(52) PORQUICHO MOYA, I., op. cit., pp. 147 ss.

(53) MOLINA MARTINEZ, J.M., op. cit., p. 63.

(54) GONZALEZ BELTRAN, J.M., "El Puerto de Santa María a fines del siglo XVIII: una visión demográfico-ocupacional según el Padrón de 1771", Anales de la Universidad de Cádiz, V-VI, 1988-1989, p. 106.

(55) El 21,6\% en la sevillana parroquia de San Martín (GARCIA-BAQUERO LOPEZ, G., op. cit., p. 169) y menos del $10 \%$ en Rute (GARCIA JIMENEZ, B., op. cit., p. 69). 
servar una cierta importancia a lo largo de este período como localidad marinera y portuaria (más acentuada, obviamente, en el siglo XVII); la segunda, por ser una población fundada ex novo. Pero es raro que la proporción de cónyuges inmigrantes supere en las restantes poblaciones el $20 \%$ del total, y tan sólo en Sanlúcar de Barrameda nos encontramos con una tendencia evolutiva coherente, dándose en esta localidad un proceso de continua pérdida de importancia del componente inmigrante como consecuencia de la decadencia comercial de esta población.

El perfil del inmigrante (cuadro 12) suele ser bastante similar en todas partes: la inmigración es básicamente masculina, y cuanto más nos alejemos de la localidad en cuestión mayor será el predominio de los varones, lo que, por otro lado, es algo que está universalmente constatado. Se trata, en segundo término, de una inmigración ceñida básicamente a las fronteras de la actual provincia gaditana, si bien en ciertas localidades como Sanlúcar de Barrameda y San Roque el componente andaluz tiene una gran importancia, como consecuencia de la venida de numerosos sevillanos y malagueños, respectivamente. La presencia de individuos oriundos de otras regiones españolas o del extranjero, solamente tendrá cierta incidencia en Jerez de la Frontera, Sanlúcar de Barrameda, El Puerto de Santa María (56), Cádiz (57) y San Fernando (58), las poblaciones con una vida económica más intensa y un mayor grado de urbanización.

La procedencia de los inmigrantes (cuadro 13) es muy variada debido a la gran diversidad de la inmigración provincial, ya que, como es obvio, cada localidad se surte básicamente de contingentes humanos llegados de las poblaciones vecinas, pero una vez cruzadas las fronteras provinciales nos encontramos en casi todas partes con un

(57) Sobre los extranjeros en Cádiz, por no citar más que algunos ejemplos, vid. BODDAERT, N., "Presencia extranjera en el Cádiz del siglo XVIII. Las mujeres", Cádiz en su bistoria. III Jornadas de Historia de Cádiz, Cádiz, 1984; COLLADO VILLALT, P., Las colonias de extranjeros en el Cádiz de la Edad Moderna, Sevilla, 1977, Tesis doctoral inédita; SANCHO DE SOPRANIS, H., Los genoveses en Cádiz antes de 1600, Larache, 1939; SOLIS, R., El Cädiz de las Cortes, Barcelona, 1978; OZANAM, D., "La colonie française de Cadix au XVIII e siécle", Melanges de la Casa de Velázquez, IV, 1968; ESPINOSA DE GODOS, E., Cádiz lonja europea en el XVIII. Población y sociedad. Sevilla, 1984, Tesis doctoral inédita.

(58) MOLINA MARTINEZ, J.M., op. cit. 
modelo muy similar. Así, la inmigración regional se nutre sobre todo de contingentes sevillanos o malagueños, en función únicamente de la situación geográfica de la población en cuestión: los sevillanos predominarán en casi todas partes, a excepción de Gibraltar y San Roque, donde los malagueños constituyen el contingente principal, en tanto los onubenses solamente abundan en Sanlúcar, y la presencia de otras provincias andaluzas es más bien testimonial. Por lo que se refiere al resto de España, normalmente las dos Castillas, Galicia y Extremadura son las que ofrecen las principales aportaciones, en función de la mayor proximidad de Castilla y Extremadura al territorio andaluz, la saturación demográfica de Galicia y las tradicionales vinculaciones de los santanderinos con nuestra provincia en función de su actividad marinera. Las únicas notas originales vendrán dadas por la presencia de ceutíes en Gibraltar (una vez más, la proximidad lo marca todo), catalanes en San Roque, mallorquines y catalanes en San Fernando (no olvidemos la importante actividad comercial que desempeña Cataluña en el siglo XVIII, y la presencia de catalanes en localidades con un fuerte carácter militar puede deberse al hecho de que el ejército constituye un mercado consumidor de grandes posibilidades) (59) y vascos en Cádiz, dada su fuerte presencia en la Carrera de Indias. Los extranjeros, finalmente, suelen estar representados por los portugueses, aunque desde mediados del siglo XVII su presencia se difumina con rapidez debido a la independencia de este país con respecto a la Monarquía Hispánica. Conil conocerá una cierta venida de italianos, Chiclana de franceses e italianos, al igual que El Puerto; San Fernando y Cádiz de italianos, especialmente genoveses, aunque en esta última población la presencia de franceses en el siglo XVIII será bastante destacada.

\section{LA EVOLUCION DE LA POBLACION}

\subsection{El siglo XVII}

No es nada nuevo señalar cómo la pretendida crisis del siglo XVII

(59) Sobre esta actividad catalana vid. MARTINEZ SHAW, C., "Las relaciones económicas entre Cataluña y la Baja Andalucía en el siglo XVIII. Un intento de interpretación", Actas del I Congreso de Historia de Andalucía. Andalucía Moderna (siglo XVIII). Córdoba, 1978. 
presenta en España numerosos matices regionales (60), siendo un lugar común indicar que la Bahía gadicense constituye una de las escasas excepciones a la misma ante su creciente papel en el control del comercio colonial americano, señalándose incluso cómo el crecimiento poblacional de la urbe gaditana coincide cronológicamente con el declive sevillano (61). No obstante, conviene matizar esta afirmación, puesto que la provincia de Cádiz jamás ha constituido una unidad geográfica ni socioeconómica, y los comportamientos demográficos experimentados por sus distintas comarcas son bastante dispares.

Comencemos por la observación de los datos que nos ofrecen los recuentos poblacionales realizados en la Corona castellana en 1591, 1646 y 1693-1694 (cuadro 14), si bien las informaciones que nos proporcionan hay que contemplarlas siempre con bastante prevención. En cualquier caso, los modelos de comportamiento que podemos vislumbrar son bastante dispares:

a) Algunas localidades conocen un crecimiento ininterrumpido a lo largo de todo el siglo XVII, situación en la que se encuentran Alcalá de los Gazules, Conil, y, sobre todo, Cádiz, y El Puerto de Santa María: tomando como base 100 el año 1591, a finales del siglo XVII Cádiz alcanza un índice de 625, y El Puerto de 230.

b) Otras, por el contrario, contemplan un descenso continuo de sus efectivos durante todo el siglo, siendo éste el caso de Bornos, Chipiona, y, especialmente, Jerez de la Frontera $(1591=100$, finales del siglo XVII $=57$ ).

c) Finalmente, tendríamos aquellas poblaciones que se caracteri-

(60) Vid. DOMINGUEZ ORTIZ, A., El Antiguo Régimen: los Reyes Católicos y los Austrias, Madrid, 1988, pp. 263-273; y NADAL, J., "La población española durante los siglos XVI, XVII y XVIII: un balance a escala regional"; PEREZ MOREDA, V., y SVEN-REHR, D., Demografía bistórica en España, Madrid, 1988, pp. 39-54. Sobre la evolución demográfica andaluza vid. ALVAREZ SANTALO, L.C., "La población ...", FORTEA PEREZ, J.I., "La evolución demográfica de Córdoba en los siglos XVI y XVII", Actas del Primer Congreso de Historia de Andalucía, vol. 1, Córdoba, 1978; CORONAS TEJADA, L., "Estudio demográfico de la ciudad de Jaén en el siglo XVII", Actas del Primer Congreso..., MONTAÑO REQUENA, M.I., "La población de Carmona en las series parroquiales: siglos XVI-XIX", Archivo Hispalense, 213, 1987; SANCHEZ LORA, J.L., Demografía y análisis bistórico. Ayamonte 1600-1860, Huelva, 1987; VALLE BUENESTADO, N., "Notas sobre la evolución demográfica de la comarca de Los Pedroches (1530-1807)", Actas I Congreso..., SANCHEZ MONTES, F., La población de Granada en el siglo XVII, Granada, 1989; GARCIA JIMENEZ, B., op. cit., y las series recogidas en PONSOT, P., op. cit.

(61) DOMINGUEZ ORTIZ, A., Historia de Andalucía, vol. VI, Barcelona, 1981, p. 147. 
zan por la disparidad de su evolución demográfica en cada una de las dos mitades de la centuria: para Jimena, Rota y Villamartín, la primera parte del siglo se sitúa bajo el signo de la depresión, en tanto que en la segunda se constatará una recuperación de los efectivos poblacionales; mientras que en Arcos, Chiclana, Isla de León (actual San Fernando), Medina Sidonia, Puerto Real, Sanlúcar y Vejer, el crecimiento demográfico persiste en la primera mitad del siglo XVII y se ve severamente truncado a partir de mediados de dicha centuria.

Esta información debe ser complementada y contrastada con los datos ofrecidos por las series parroquiales (cuadro 15), según las cuales los modelos de comportamiento se caracterizarían, una vez más, por su disparidad. En líneas generales, para los núcleos de las costa atlántica la centuria fue bastante positiva, y ésta será la situación de Cádiz (62), San Fernando (63), El Puerto de Santa María, Conil y Chipiona (aunque en estas dos últimas localidades los años de 1630-1659 se sitúan bajo el signo de la depresión), y en todas ellas, exceptuando el caso gaditano, el crecimiento será más intenso en la segunda mitad del siglo, justo el momento en que la Bahía gaditana centraliza el tráfico colonial. La única excepción a esta positiva coyuntura costera vendrá dada por Sanlúcar de Barrameda, localidad que nunca podrá recuperarse del hundimiento padecido en los años cincuenta: la recuperación, que se inicia inmediatamente, será incapaz de curar las heridas. Todo ello revela el auge del complejo gaditano-portuense (cuya prosperidad alcanzaría de rebote a Conil, la Isla de León y Chipiona, que cumplirían el papel de abastecer de productos agrícolas y ser lugar de reposo de los adinerados comerciantes gaditanos) en detrimento del eje Sevilla-Sanlúcar (64).

La Campiña, por el contrario, conoce evoluciones divergentes: Chiclana, tras una primera mitad del siglo bastante mediocre, atraviesa una fuerte recuperación en la segunda, ya que esta población vivirá también los beneficios económicos del complejo gaditano-portuense, y es posible que una parte del aumento de las exportaciones vitícolas tracia América a través del puerto gaditano se deba a los caldos de esta localidad (65). Alcalá de los Gazules no se verá afectada por gra-

(62) Vid. PORQUICHO MOYA, I., op. cit.; y PONCE CORDONES, F., op. cit.

(63) Vid. MOLINA MARTINEZ, J.M., op. cit.

(64) Una buena sintesis en GARCIA BAQUERO, A., Andalucía y la Carrera de Indias (1492-1824), Sevilla, 1986, pp. 88 ss.

(65) Vid. GARCIA FUENTES, L., El comercio español con América (1650-1700), Sevilla, 1980 , p. 264 : 
ves crisis, si bien la primera mitad del siglo fue mejor que la segunda. Jerez de la Frontera vive bajo el signo del estancamiento durante toda la centuria debido quizás a motivos económicos: los diezmos de vino de la prestamera de San Marcos nos revelan el hundimiento de la producción (66), lo que sería especialmente grave en una localidad volcada desde muy antiguo hacia este producto.

En los núcleos serranos los perfiles son sumamente dispares, contrastando el acentuado incremento poblacional de Bornos con la prolongada atonía de una Olvera que sigue un comportamiento muy similar al jerezano. Finalmente, en Gibraltar la crisis se inicia en el decenio de 1630 , toca fondo en la década de 1650 , y en los años noventa la recuperación habrá sido completa. Probablemente la coyuntura agraria se encuentre en la raíz de este declive: en una población relativamente cercana, Jimena, el precio de los arrendamientos experimenta un acusado descenso en los años de 1640-1669, y una cierta recuperación desde entonces (67).

La incidencia de la crisis, como vemos, ha sido bastante desigual, y su consecuencia más evidente ha sido trastocar los equilibrios económicos existentes en el interior de la provincia: el eje sanluqueño-jerezano, la zona más dinámica durante el siglo XVI, ha sido sustituido por el complejo gaditano-portuense. Por lo que se refiere a las tierras del interior, no podemos indicar con seguridad las razones de su comportamiento demográfico en tanto no conozcamos mejor la evolución de la producción agraria durante este período ( $67 \mathrm{bis})$.

(66) PONSOT, P., op. cit., pp. 337-338.

(67) Ibídem, pp. 617-621.

(67) (bis) Sólo contamos con TRAVERSO RUIZ, F., Riqueza y producción agraria en Cádiz durante los siglos XVI y XVII. Cádiz 1987. 


\subsection{El siglo XVIII}

Tal como sucedía en la anterior centuria, la evolución de los ritmos poblacionales en las distintas localidades es muy variable (68) (cuadro 14):

a) Algunas localidades conocen un crecimiento continuo, siendo ésta la situación de Alcalá de los Gazules, Bornos, Cádiz, Conil, Chiclana, Chipiona, Isla de León (San Fernando), Jerez de la Frontera, Medina Sidonia, Puerto Real, Rota, Sanlúcar de Barrameda y Villamartín.

b) En las restantes poblaciones se observa un crecimiento en la primera mitad de la centuria y un leve descenso en la segunda, que solamente en Arcos supera el 10\%, en tanto que en Jimena, El Puerto de Santa María y Vejer oscila en torno al $5 \%$.

Por lo que se refiere al panorama mostrado por las series parroquiales (cuadro 15), Cádiz (69) y San Fernando (70) prosiguen con su alza poblacional, si bien en la primera a finales de la centuria se inicia ya la crisis (71). Pero hasta entonces, la buena marcha del comercio colonial (72) garantizará este aumento. En Sanlúcar de Barrameda y El Puerto de Santa María, los altibajos son muy numerosos y nunca se superan los niveles de fines del siglo XVII, habiendo que esperar hasta finales del XVIII para encontrarnos con un crecimiento medianamente sostenido, presentando Chipiona un perfil muy similar.

Las poblaciones vecinas de Conil y Chiclana ofrecen, como es lógico, una tendencia evolutiva idéntica: a partir de 1720 , salvadas las dificultades provocadas por la Guerra de Sucesión Española, se superan siempre los niveles de finales del siglo XVII, si bien los altibajos son continuos (1720-29, 1740-59, 1780-99, alza; 1730-39, 1760-79, depresión). En Jerez de la Frontera predomina una tónica secular de

(68) Sobre la evolución demográfica andaluza en el XVII, amén de algunas de las obras indicadas en la nota 60, vid. SANZ SAMPELAYO, J.F., op. cit:; GAMEZ AMIAN, M.A., Transformaciones económicas y sociales en el reino de Granada. Siglo XVIII, Málaga, 1986; y NUÑEZ ROLDAN, F., En los confines del reino. Huelva en la segunda mitad del siglo XVIII. Sevilla, 1987. Una visión de conjunto en GARCIA BAQUERO, A., "Andalucía en el siglo XVIII. El perfil de un crecimiento ambiguo". FERNANDEZ, R., España en el siglo XVIII. Homenaje a Pierre Vilar, Barcelona. 1985.

(69) Vid. PONCE CORDONEZ, F, op. cit.

(70) Vid. MOLINA MARTINEZ, J.M., op. cit.

(71) Vid. PEREZ SERRANO, J., op. cit.

(72) Vid. GARCIA BAQUERO, A., Cádiz y el Atlántico (1717-1778), reed., Cádiz, 1988. 
estancamiento con altibajos hasta que en los noventa se inicie el crecimiento, si bien normalmente se superan las cifras de bautismos obtenidas en la década de 1690 . Alcalá de los Gazules, tras el máximum de los años veinte, se caracteriza por un estancamiento continuo del número de bautismos que se prolonga hasta el decenio de 1760, a partir del cual se inicia un crecimiento sostenido. En Bornos las fluctuaciones son continuas, si bien la tendencia es al alza. Por lo que se refiere a Olvera, nos encontramos con un crecimiento lento del número de bautismos, interrumpido tan sólo en los decenios de 1710 y 1750 , y que se afirma en los años noventa. Finalmente, San Roque, población fundada ex novo, conoce un aumento explosivo de sus efectivos poblacionales que se prolonga hasta la década de 1750 , asistiéndose a partir de entonces a un cierto estancamiento.

En líneas generales, el siglo XVIII se caracterizaría por la presencia de un crecimiento irregular afectado por numerosos altibajos, conociéndose los peores tiempos durante los decenios de 1700-19 y 1760-79, y solamente en los años noventa se asiste a un crecimiento decidido. Normalmente, a partir de la década de 1720 se superan las cifras de bautismos de los años noventa del siglo XVII, si bien en Sanlúcar de Barrameda y El Puerto de Santa María nunca ocurrirá esto (lo que puede explicar el estancamiento poblacional de la primera y el leve descenso de la segunda entre 1751 y 1787) y, en Chipiona, no hasta los años noventa.

¿A qué se debe todo esto? Muy posiblemente a las fluctuaciones de la producción agraria, pero ignoramos casi por completo su comportamiento durante este período. Las series decimales del obispado gaditano nos muestran que en los años cuarenta y cincuenta la producción agraria ha alcanzado sus máximos niveles, que solamente volverán a ser superados (y no sabemos si de forma definitiva) en los ochenta (73). Los hacimientos de pan terciado de Jerez de la Frontera nos revelan un panorama similar, caracterizado por un aumento de la producción hasta los años veinte, un descenso en las décadas siguientes y un estancamiento con leve tendencia al alza desde mediados de la centuria (74). Todo parece indicar que nos encontramos ante un equilibrio población-recursos sumamente inestable, que explicaría las fluctuaciones.

(73) Vid. MORGADO GARCIA, A., op. cit., pp. 252-254 y 259-262.

(74) PONSOT, P., op. cit., PP. 235-237. 


\subsection{La población de la provincia de Cádiz a fines del siglo XVII}

En 1787 (cuadro 16) la población de la provincia de Cádiz ascendía a un total de 306.051 habitantes, si bien su distribución era muy desigual: Cádiz, con una población superior a las 70.000 almas, era la urbe más poblada, reuniendo más de la quinta parte de los efectivos totales, siendo seguida por Jerez de la Frontera, San Fernando, Arcos de la Frontera, Medina Sidonia, El Puerto de Santa María y Sanlúcar de Barrameda, únicas localidades que superaban los 10.000 habitantes. Otras 26 contaban entre 10.000 y 1.000 habitantes, en tanto que cinco no superaban el millar, siendo éste el caso de Castellar de la Frontera, El Gastor, Paterna de Rivera, Puerto Serrano y Torre Alháquime, esta última la población con menor número de habitantes (396) de todo el ámbito provincial. Todo ello nos configura una red urbana caracterizada por un elevado grado de concentración en las zonas litorales (aquí se sitúan cuatro de las siete localidades que superaban los 10.000 habitantes) debido al dinamismo económico generado por el comercio colonial, complementada por la existencia de algunas poblaciones, que si alcanzan un número de habitantes importante lo deben al hecho de estar situadas en el seno de comarcas agrícolas de cierta riqueza (Jerez, Arcos y Medina).

La densidad media provincial ascendía a 41,4 habitantes por $\mathrm{Km}^{2}$, cifra muy superior a la media andaluza y nacional, y que se acerca bastante a los niveles gallegos (una densidad media de 45) (75), pero las diferencias locales son imprestonantes: las densidades obtenidas en la Bahía gaditana son muy elevadas (106,3 en El Puerto, 944,2 en San Fernando, 6705,6 en Cádiz), bastante altas (entre 50 y 99,9) en Sanlúcar de Barrameda, Rota, Algeciras, Paterna y los núcleos serranos de Benaocaz, Bornos, Grazalema y Ubrique; pero frente a ello también existen zonas con un grado muy reducido de ocupación humana, siendo ésta la situación de Alcalá de los Gazules, Los Barrios, Castellar de la Frontera y Villamartín, donde la densidad es inferior a 10.

En líneas generales, el litoral noratlántico es la zona más poblada de la provincia, donde se encuentran las principales localidades y donde la densidad supera siempre los $25 \mathrm{~h} / \mathrm{Km}^{2}$, situación que se debe a la práctica del comercio colonial, la construcción naval, la pesca y el desarrollo de una agricultura especulativa cuyo objetivo es el aprovisionamiento de la urbe gaditana. En el resto de la provincia es

ROMERO DE SOLIS, P., La población española en los siglos XVII y XIX. Madrid, 1973, p. 137. 
raro que la densidad supere el nivel de 25 , siendo las excepciones San Roque, Algeciras (en ambas las necesidad de establecer un limes fronterizo frente a Gibraltar lo condiciona todo), Jerez de la Frontera (centro de una rica comarca agrícola), Paterna de Rivera, Bornos y las localidades serranas de Grazalema, Benaocaz, Ubrique, Algodonales, El Gastor, Villaluenga y El Bosque, alguna de ellas sede de una actividad artesanal relativamente importante. En el resto de la provincia, debido a la pobreza del medio (la Sierra) o la práctica de una agricultura extensiva que deja amplios espacios sin cultivar, susceptibles tan sólo de ser aprovechados por una ganadería que requiere escasa mano de obra (gran parte de la Campiña), la densidad es muy reducida.

Los 306.051 habitantes de la provincia se descomponían en 156.934 varones y 149.117 mujeres (cuadro 17 ), resultando una tasa de masculinidad de 0,51 y una relación de masculinidad de 105,2; índice bastante elevado, si tenemos en cuenta que en España era por aquel entonces de 99,2 y en Andalucía de 100,5 (76). Ello se debe al flujo migratorio provocado por la prosperidad de ciertas poblaciones de la provincia, pero hablamos de medias, ya que podemos distinguir entre zonas donde la relación de masculinidad es bastante elevada (así sucede en numerosas localidades serranas, Alcalá de los Gazules, Los Barrios, Castellar, Jerez de la Frontera, y gran parte de costa nordatlántica: Rota, Chipiona, Cádiz, San Fernando, El Puerto de Santa María y Conil se encontrarían en esta situación) y entre aquéllas en las que, por el contrario, la relación es inferior a 100 (el resto de la provincia). El flujo migratorio es en gran medida el responsable de estas variaciones: de hecho, en la mayoría de las localidades donde la relación de masculinidad es superior a 100, en el grupo de edades comprendidas entre los 25 y los 40 años la misma se eleva a más de 105, llegándose a casos extremos como el de San Fernando, donde la relación asciende a 194 ante el carácter acentuadamente militar de esta localidad.

Por lo que se refiere a la distribución por edades, es necesario advertir previamente que el censo de 1787 solamente recoge esta información por lo que se refiere a los individuos residentes en "viviendas familiares", dejando de lado a la población que habita en conventos, hospitales y hospicios. Sea como fuere, en 1787 el 15,4\% de los gaditanos tenía menos de 7 años, el $15,8 \%$ de 7 a 16 , el $16,6 \%$ de 16 a 25 , el $25,3 \%$ de 25 a 40 , el $11,9 \%$ de 40 a 50 y el $14,7 \%$ más de 50 . Si compa-

(76) LIVI BACCI, M.A., "Fertility and nuptiality changes in Spain from the late XVIII th to the XX th century (II) ${ }^{n}$, Population Studies, XXII, 2, 1968, p. 215. 
ramos estos resultados con la media española (77), observaremos cómo en la provincia tiene un mayor peso el grupo de edades comprendido entre los 16 y los 40 años.

Podemos, siguiendo los criterios establecidos por L. Henry (78), considerar como jóvenes (0-19 años) al 380 por mil de la población, como adultos (20-59) al 564 por mil, y como ancianos (60 ó más) al 55 por mil. Todo ello nos muestra una estructura demográfica caracterizada por una reducida esperanza de vida y con un porcentaje de población joven relativamente bajo, constituyendo los adultos un volumen muy importante del total de los efectivos. El resultado será una pirámide muy semejante a la de la población madrileña (79), cuya estructura viene marcada por la incidencia del flujo migratorio, aunque es probable que sea necesario introducir otros factores cuyo alcance no es posible medir con exactitud, como un descenso de la fecundidad en los años anteriores a la confección del censo, o una mayor incidencia de la mortalidad infantil como consecuencia de la epidemia de 1786.

Las disparidades regionales (cuadro 17) son bastante grandes, y por ello carece de sentido confeccionar una pirámide de edades común a toda la provincia, siendo más útil el estudio de las variaciones de las relaciones de masculinidad en las distintas edades. La provincia no sigue el modelo tipo (80) de relación de masculinidad, ya que la inmigración lo trastoca todo: a los 0-7 años la misma es de 107; a los 7-16, de 104; a los 16-25, de 101; a los 25-40, de 113; a los 40-50, de 104, y en el seno de la población con más de 50 años, de 88. Se observa la intensidad de la corriente migratoria, cuya incidencia se hace notar especialmente en la población comprendida entre los 25 y los 50 años de edad, disminuyendo fuertemente desde entonces, lo que nos puede indicar que en muchos casos se trata de una migración temporal: comerciantes extranjeros asentados durante algunos años, soldados o marinos cumpliendo con sus tareas de guarnición, jornaleros agrícolas, etc.

Hablamos nuevamente de medias que nos encubren las grandes

(78) HENRY, L., op. cit., pp. 23 s.

(79) CARBAJO ISLA, M.F., La población de la villa de Madrid desde finales del siglo XVI basta mediados del siglo XIX. Madrid, 1987, p. 191.

(80) HENRY, L., op. cit., p. 28. 
variaciones regionales existentes, ya que si en Alcalá del Valle, Algodonales, Los Barrios, El Bosque, Cádiz, Castellar, Conil, Chiclana, Chipiona, Espera, El Gastor, Jerez de la Frontera, Olvera, Rota, San Fernando, Ubrique y Vejer la relación de masculinidad es superior a 105, en Algeciras, Benaocaz, Paterna, San Roque, Trebujena y Villamartín, la misma no llega a 95 (cuadro 17).

Los datos del censo de 1787, como es sabido, solamente indican el estado civil de la población residente en viviendas familiares, que ofrece los siguientes resultados: 562 por mil solteros, 353 por mil casados y 83 por mil viudos, siendo estas proporciones del 605,350 y 44 por mil para los varones, y del 518, 357 y 123 por mil para las mujeres. En relación a otras regiones españolas (81), la provincia de Cádiz presenta unas tasas muy altas de viudedad femenina, debido a la fuerte sobremortalidad masculina, y una proporción muy elevada de solteros, lo que podemos atribuir a la inmigración y a la existencia de numerosos jornaleros sin medios económicos para contraer matrimonio, como revela el elevado grado de celibato definitivo masculino existente, situado en torno al 213 por mil (82).

La información proporcionada por el Censo de Floridablanca acerca de la estructura socioprofesional de la población es muy rudimentaria (83), si bien podemos decir, en líneas generales, que en casi toda la provincia el porcentaje de la población activa dedicada al sector primario (en el que incluiriamos a labradores, jornaleros (84), hacendados, ganaderos y pescadores) supera el $60 \%$ del total; siendo las únicas excepciones Sanlúcar de Barrameda, Cádiz, San Fernando, Puerto Real, Chiclana, Jerez de la Frontera, Ubrique y Grazalema. Como es natural, predominan básicamente los jornaleros desprovistos de tierra, y solamente en Alcalá de los Gazules, Trebujena, Jimena, Castellar, Olvera, Zahara, El Boque y Ubrique los labradores superan el $20 \%$ de la población incluida en el sector primario.

En líneas generales, el sector secundario tiene escasa importancia,

(81) Vid. CARBAJO ISLA, M.F., op. cit., p. 192; y GARCIA JIMENEZ, B., op. cit., p. 380.

(82) Sobre la definición de este concepto PEREZ SERRANO,J., op. cit., p. 72.

(83) Una crítica en Ibídem, p. 75.

(84) Sobre su adscripción al sector primario vid. ARIAS DE SAAVEDRA ALIAS, I., "La población del reino de Jaén en el siglo XVII", Actas II Coloquios de Historia de Andalucía. Andalucía Moderna, vol. 1. Córdoba, 1983, pp. 30-31. 
existiendo por aquel entonces 1.102 fabricantes y 17.030 artesanos, lo que nos muestra que nos encontramos ante una industria básicamente vinculada a los marcos gremiales (85), constituyendo más del $20 \%$ de la población activa tan sólo en Cádiz, Sanlúcar, Puerto Real, San Fernando, Algodonales, Grazalema, Zahara y Ubrique. En Cádiz y Sanlúcar se trataría de una industria muy diversificada y estrechamente vinculada a los marcos gremiales, con la finalidad de cubrir la demanda de núcleos populosos (Cádiz, Sanlúcar y Jerez); en Puerto Real y San Fernando será la construcción naval la que marque la pauta; en los núcleos serranos se trataría de actividades textiles, peleteras y curtidoras.

La variedad caracteriza al sector terciario, formado por nobles, clérigos, estudiantes, abogados, notarios, funcionarios, militares, comerciantes y criados, que supone más del $20 \%$ de la población activa en Jerez de la Frontera, Torre Alháquime, Sanlúcar, Cádiz, San Fernando, Chiclana, Tarifa y Algeciras. En la mayoría de las localidades, básicamente agrarias, su composición no presenta ninguna originalidad, limitándose a la presencia de algunos clérigos, funcionarios y comerciantes, pero en los núcleos anteriormente mencionados su estructura marca el talante de cada uno de ellos: Cádiz y San Fernando (tengamos en cuenta que el censo no incluye en este caso el personal vinculado a la Armada) se configuran como ciudades eminentemente comerciales; en Algeciras; marineros y criados marcan la pauta; Jerez, Sanlúcar y Tarifa presentan una estructura propia de poblaciones parasitarias de su hinterland agrario, con numerosos clérigos, criados y nobles, en tanto que en Chiclana, la población con fuero militar es la que marca la pauta.

(85) Vid. BERNAL, A.M., COLLANTES DE TERAN, A., y GARCIA BAQUERO, A., "Sevilla de los gremios a la industrialización", Estudios de historia social, 5-6, 1978. 


\section{CUADRO 1}

Estacionalidad de los bautismos. Siglo XVII. Cifras en tanto por mil

$\begin{array}{lrrrrrrrrrrrr}\text { Bautismos } & \mathbf{E} & \mathbf{F} & \mathbf{M} & \mathbf{A} & \mathbf{M} & \mathbf{J} & \mathbf{J} & \mathbf{A} & \mathbf{S} & \mathbf{O} & \mathbf{N} & \mathbf{D} \\ \text { Concep. } & \mathbf{A} & \mathbf{M} & \mathbf{J} & \mathbf{J} & \mathbf{A} & \mathbf{S} & \mathbf{0} & \mathbf{N} & \mathbf{D} & \mathbf{E} & \mathbf{F} & \mathbf{M} \\ \text { Alcala G. } & \mathbf{1 1 6} & \mathbf{1 0 3} & \mathbf{9 8} & \mathbf{6 6} & \mathbf{8 3} & \mathbf{6 7} & \mathbf{6 0} & \mathbf{6 3} & \mathbf{7 2} & \mathbf{7 9} & \mathbf{9 4} & \mathbf{8 8} \\ \text { Bornos } & \mathbf{1 0 6} & \mathbf{1 0 6} & \mathbf{9 1} & \mathbf{7 6} & \mathbf{7 7} & \mathbf{6 5} & \mathbf{6 0} & \mathbf{6 3} & \mathbf{7 8} & \mathbf{8 3} & \mathbf{9 9} & \mathbf{9 0} \\ \text { Conil } & \mathbf{1 0 8} & \mathbf{9 5} & \mathbf{8 6} & \mathbf{7 7} & \mathbf{8 5} & \mathbf{6 9} & \mathbf{6 9} & \mathbf{7 0} & \mathbf{7 3} & \mathbf{8 1} & \mathbf{9 0} & \mathbf{9 1} \\ \text { Chiclana } & \mathbf{1 1 3} & \mathbf{9 5} & \mathbf{9 2} & \mathbf{7 8} & \mathbf{7 9} & \mathbf{6 1} & \mathbf{6 6} & \mathbf{6 8} & \mathbf{7 4} & \mathbf{8 1} & \mathbf{9 4} & \mathbf{9 4} \\ \text { Gibraltar } & \mathbf{1 0 8} & \mathbf{9 5} & \mathbf{9 4} & \mathbf{5 8} & \mathbf{9 6} & \mathbf{6 7} & \mathbf{6 2} & \mathbf{6 8} & \mathbf{6 9} & \mathbf{8 7} & \mathbf{9 4} & \mathbf{9 5} \\ \text { Jerez F. } & \mathbf{1 0 5} & \mathbf{9 8} & \mathbf{1 1 6} & \mathbf{8 2} & \mathbf{8 1} & \mathbf{6 5} & \mathbf{6 1} & \mathbf{6 4} & \mathbf{6 8} & \mathbf{8 0} & \mathbf{8 6} & \mathbf{8 8} \\ \text { Olver2 } & \mathbf{1 0 3} & \mathbf{1 0 7} & \mathbf{9 9} & \mathbf{5 5} & \mathbf{9 4} & \mathbf{7 3} & \mathbf{5 9} & \mathbf{6 6} & \mathbf{8 3} & \mathbf{8 8} & \mathbf{8 4} & \mathbf{8 3} \\ \text { Sanlúcar } & \mathbf{1 0 4} & \mathbf{9 5} & \mathbf{9 4} & \mathbf{5 8} & \mathbf{9 6} & \mathbf{6 7} & \mathbf{6 2} & \mathbf{6 8} & \mathbf{6 9} & \mathbf{8 7} & \mathbf{9 4} & \mathbf{9 5}\end{array}$

\section{CUADRO 2}

Estacionalidad de los bautismos. Siglo XVIII

$\begin{array}{lrrrrrrrrrrrr}\text { Bautismos } & \mathbf{E} & \mathbf{F} & \mathbf{M} & \mathbf{A} & \mathbf{M} & \mathbf{J} & \mathbf{J} & \mathbf{A} & \mathbf{S} & \mathbf{O} & \mathbf{N} & \mathbf{D} \\ \text { Concep. } & \mathbf{A} & \mathbf{M} & \mathbf{J} & \mathbf{J} & \mathbf{A} & \mathbf{S} & \mathbf{O} & \mathbf{N} & \mathbf{D} & \mathbf{E} & \mathbf{F} & \mathbf{M} \\ \text { Alcalk G. } & \mathbf{1 0 6} & \mathbf{9 7} & \mathbf{9 0} & 71 & \mathbf{6 8} & \mathbf{6 5} & \mathbf{6 3} & \mathbf{6 8} & \mathbf{8 1} & \mathbf{8 5} & \mathbf{1 1 1} & \mathbf{9 0} \\ \text { Bornos } & 103 & \mathbf{1 0 8} & \mathbf{9 0} & \mathbf{7 3} & \mathbf{7 8} & \mathbf{7 3} & \mathbf{6 3} & \mathbf{6 8} & \mathbf{8 3} & \mathbf{7 3} & \mathbf{9 7} & \mathbf{8 8} \\ \text { Conil } & \mathbf{1 0 6} & \mathbf{9 4} & \mathbf{9 1} & \mathbf{8 2} & \mathbf{7 9} & \mathbf{6 8} & \mathbf{6 3} & \mathbf{6 9} & \mathbf{7 8} & \mathbf{7 7} & \mathbf{9 5} & \mathbf{9 1} \\ \text { Chiclana } & \mathbf{1 0 7} & \mathbf{9 7} & \mathbf{9 7} & \mathbf{8 0} & \mathbf{7 8} & \mathbf{6 7} & \mathbf{6 7} & \mathbf{7 0} & \mathbf{7 5} & \mathbf{7} & \mathbf{8 9} & \mathbf{8 7} \\ \text { Jerez F. } & \mathbf{1 0 9} & \mathbf{9 7} & \mathbf{8 9} & \mathbf{7 6} & \mathbf{7 6} & \mathbf{6 2} & \mathbf{6 5} & \mathbf{7 0} & \mathbf{7 5} & \mathbf{8 2} & \mathbf{9 8} & \mathbf{9 7} \\ \text { Olvera } & \mathbf{9 8} & \mathbf{1 0 1} & \mathbf{9 6} & \mathbf{7 2} & \mathbf{8 6} & \mathbf{7 6} & \mathbf{6 1} & \mathbf{6 7} & \mathbf{8 1} & \mathbf{8 2} & \mathbf{9 0} & \mathbf{8 4} \\ \text { Sanlúcar } & \mathbf{1 1 1} & \mathbf{9 7} & \mathbf{9 4} & \mathbf{8 0} & \mathbf{8 0} & \mathbf{6 4} & \mathbf{6 7} & \mathbf{7 0} & \mathbf{7 0} & \mathbf{8 0} & \mathbf{8 8} & \mathbf{9 2} \\ \text { San Roque } & \mathbf{1 0 5} & \mathbf{9 2} & \mathbf{9 5} & \mathbf{7 3} & \mathbf{7 3} & \mathbf{6 3} & \mathbf{6 3} & \mathbf{7 3} & \mathbf{8 2} & \mathbf{8 8} & \mathbf{9 5} & \mathbf{9 4}\end{array}$

\section{CUADRO 3}

Tasas de ilegitimidad en tantos por mil

$$
1595-1600 \quad 1645-1650 \quad 1695-1700 \quad 1745-1750 \quad 1795-1800
$$

$\begin{array}{lr}\text { Alcala G. } & 106 \\ \text { Bornos } & 75 \\ \text { Conil } & 23 \\ \text { Chiclana (1) } & 95 \\ \text { Gibraltar } & - \\ \text { Jerez F. (2) } & 199 \\ \text { Jerez F. (3) } & 81 \\ \text { Olvera } & 72 \\ \text { Sanlúcar } & 118 \\ \text { San Roque } & - \\ \text { (1) Par. S. Juan Bautista. } \\ \text { (2) Par. S. Dionisio. } \\ \text { (3) Par. Santiago. }\end{array}$

$\begin{array}{rrrr}73 & 15 & 23 & 26 \\ 28 & 12 & 23 & 11 \\ 52 & 18 & 20 & 11 \\ 71 & 25 & 32 & 37 \\ 139 & 78 & - & - \\ 200 & 60 & 4 & 26 \\ 54 & 19 & 8 & 4 \\ 75 & 38 & 23 & 16 \\ 131 & 99 & 81 & 62 \\ - & - & 49 & 71\end{array}$




\section{CUADRO 4 \\ Tipologias ilegitimas en números brutos}

1595-1600

Hijos de esclavos

Hijos de padres solteros

Hijos de padres desconocidos

Expósitos e hijos de la Iglesia

Otros

Muestra

\section{5-1650}

Hijos de esclavos

Hijos de padres solteros

Hijos de padres desconocidos

Expósitos e hijos de la Iglesia

Otros

Muestra

\section{5-1700}

Hijos de esclavos

Hijos de padres solteros

Hijos de padres desconocidos

Expósitos e hijos de la Iglesia

Otros

Muestra

\section{5-1750}

Hijos de esclavos

Hijos de padres solteros

Hijos de padres desconocidos

Expósitos e hijos de la Iglesia

Otros

Muestra

\section{5-1800}

Hijos de esclavos

Hijos de padres solteros

Hijos de padres desconocidos

Expósitos e hijos de la Iglesia

Otros

Muestra

$\begin{array}{rrrrrrrrr}1 . & 2 & 3 & 4 . & 5 & 6 & 7 & 8 . & 9 . \\ 11 & 10 & - & 12 & - & 3 & 4 & 24 & 64 \\ 52 & - & - & 31 & - & 25 & 3 & 4 & 6 \\ 4 & 13 & - & 12 & - & 46 & 66 & 21 & 216 \\ 5 & 2 & - & - & - & 10 & - & - & 21 \\ 9 & - & - & - & - & 1 & - & 13 & 3 \\ 81 & 25 & - & 55 & - & 85 & 73 & 62 & 310\end{array}$

$\begin{array}{rrrrrrrrr}4 & 5 & 2 & 5 & 28 & 3 & 5 & 25 & 107 \\ 43 & - & 5 & 33 & - & 2 & 10 & - & 11 \\ 8 & 2 & 18 & 15 & 29 & 36 & 26 & 10 & 56 \\ 5 & 7 & - & 2 & 29 & 50 & 5 & 7 & 402 \\ 3 & 2 & 4 & - & 6 & - & 1 & 9 & 1 \\ 63 & 16 & 29 & 55 & 92 & 91 & 47 & 51 & 577\end{array}$

$$
\begin{array}{rrrrrrrrr}
2 & 7 & - & 11 & 3 & 1 & 2 & 7 & 69 \\
6 & - & 6 & 8 & - & - & 4 & 4 & 17 \\
1 & - & 8 & 12 & - & 13 & 14 & - & 54 \\
8 & 7 & 1 & 7 & 21 & 1 & - & 19 & 231 \\
-17 & - & - & - & - & - & - & - & 9 \\
14 & 15 & 38 & 24 & 15 & 20 & 30 & 380
\end{array}
$$

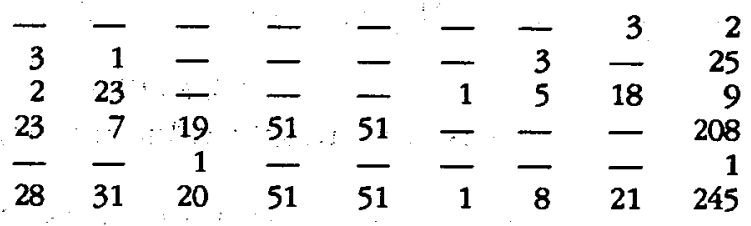

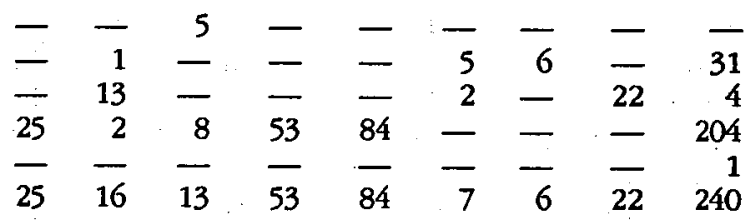

1.= Alcalá de los Gazules.

2.= Bornos.

3.= Conil.

$4 .=$ Chiclana (San Juan Bautista).

$5 .=$ Gibraltar (1645-1650 y 1695-1700) y San Roque (1745-1750 y 1795-1800).

$6 .=$ Jerez de la Frontera (San Dionisio).

7.= Jerez de la Frontera (Santiago).

8. $=$ Olvera.

9.= Sanlúcar de Barrameda. 
CUADRO 5

Estacionalidad de los matrimonios. Siglo XVII. Cifras en tanto por mil

$\begin{array}{lrrrrrrrrrrrr} & \text { E } & \text { F } & \text { M } & \text { A } & \text { M } & \text { J } & \text { J } & \text { A } & \text { S } & \text { O } & \text { N } & \text { D } \\ \text { Alcalá G. } & & & & & & & & & & & & \\ \text { (1650-99) } & 91 & 91 & 48 & 61 & 109 & 78 & 40 & 97 & 144 & 135 & 57 & 43 \\ \text { Bornos } & 109 & 95 & 41 & 67 & 94 & 67 & 45 & 85 & 106 & 136 & 93 & 57 \\ \begin{array}{l}\text { Conil } \\ \text { Chiclana }\end{array} & 91 & 73 & 34 & 72 & 74 & 39 & 58 & 105 & 148 & 161 & 79 & 61 \\ \begin{array}{l}(1650-99) \\ \text { Gibraltar }\end{array} & 72 & 64 & 44 & 96 & 104 & 68 & 58 & 77 & 86 & 115 & 79 & 131 \\ (1620-99) & 83 & 104 & 64 & 93 & 100 & 73 & 55 & 101 & 94 & 99 & 53 & 80 \\ \text { Jerez F. } & 95 & 101 & 53 & 71 & 100 & 67 & 57 & 54 & 122 & 89 & 85 & 101 \\ \text { Olvera } & 104 & 107 & 43 & 53 & 85 & 83 & 41 & 77 & 163 & 133 & 57 & 47 \\ \text { Sanlúcar } & 85 & 102 & 63 & 77 & 99 & 77 & 68 & 85 & 80 & 75 & 82 & 99\end{array}$

\section{CUADRO 6}

Estacionalidad de los matrimonios. Siglo XVIII

$\begin{array}{llllllllllll}\mathbf{E} & \mathbf{F} & \mathbf{M} & \mathbf{A} & \mathbf{M} & \mathbf{J} & \mathbf{J} & \mathbf{A} & \mathbf{S} & \mathbf{O} & \mathbf{N} & \mathbf{D}\end{array}$

$\begin{array}{lllllllllllll}\text { Alcalá G. } & 79 & 83 & 43 & 74 & 80 & 61 & 47 & 98 & 139 & 167 & 59 & 66\end{array}$

$\begin{array}{lllllllllllll}\text { Bornos } & 86 & 100 & 48 & 79 & 102 & 71 & 51 & 107 & 95 & 94 & 81 & 82\end{array}$

$\begin{array}{lllllllllllll}\text { Conil } & 62 & 53 & 48 & 61 & 62 & 45 & 68 & 112 & 134 & 168 & 77 & 103\end{array}$

$\begin{array}{lllllllllllll}\text { Chiclana } & 93 & 86 & 76 & 80 & 79 & 70 & 54 & 82 & 77 & 102 & 77 & 115\end{array}$

$\begin{array}{lllllllllllll}\text { Jerez F. } & 70 & 102 & 57 & 67 & 86 & 65 & 63 & 108 & 95 & 75 & 83 & 122\end{array}$

$\begin{array}{lllllllllllll}\text { Olvera } & 76 & 97 & 64 & 71 & 80 & 72 & 56 & 96 & 129 & 112 & 65 & 74\end{array}$

$\begin{array}{lllllllllllll}\text { Sanlúcar } & 62 & 95 & 59 & 70 & 91 & 68 & 71 & 87 & 77 & 84 & 106 & 124\end{array}$

San Roque

$\begin{array}{lllllllllllll}(1706-96) & 57 & 81 & 66 & 68 & 83 & 67 & 70 & 106 & 117 & 138 & 62 & 79\end{array}$

\section{CUADRO 7}

Estructura matrimonial. Cifras en tantos por mil

1. 2. 3. 4. $\quad$ 4. $\quad 6 . \quad 7 . \quad 8$.

1595-1600

Soltero-viuda

Soltera-viudo

Viudos

Solteros

Muestra

$\begin{array}{rrrrlrrr}- & 103 & 102 & 38 & - & 55 & 75 & 203 \\ - & 133 & 125 & 145 & - & 27 & 90 & 78 \\ - & 74 & 102 & 137 & - & 55 & 3 & 131 \\ - & 688 & 670 & 679 & - & 861 & 823 & 586 \\ - & 135 & 88 & 131 & - & 108 & 132 & 394\end{array}$

1645-1650

Soltero-viuda

Soltera-viudo

Viudos

Solteros

Muestra

$\begin{array}{rrrrrrrr}103 & 47 & 17 & 11 & 126 & 98 & 71 & 156 \\ 91 & 148 & 68 & 71 & 99 & 107 & 104 & 127 \\ 99 & 87 & 94 & 113 & 55 & 146 & 109 & 203 \\ 706 & 716 & 818 & 802 & 719 & 647 & 714 & 512 \\ 252 & 148 & 116 & 167 & 363 & 315 & 182 & 1.519\end{array}$


Soltero-viuda

Soltera-viudo

Viudos

Solteros

Muestra

$\begin{array}{rrrrrrrr}63 & 47 & 64 & 39 & 87 & 110 & 54 & 86 \\ 80 & 146 & 116 & 120 & 55 & 104 & 97 & 121 \\ 101 & 71 & 110 & 56 & 23 & 50 & 43 & 81 \\ 754 & 734 & 707 & 783 & 833 & 734 & 805 & 709 \\ 236 & 252 & 154 & 282 & 126 & 316 & 185 & 782\end{array}$

$1745-1750$

Soltero-viuda

$\begin{array}{rrrrrrrr}64 & 73 & 31 & 52 & 135 & 42 & 58 & 48 \\ 103 & 97 & 83 & 94 & 67 & 77 & 150 & 98 \\ 64 & 63 & 47 & 48 & 56 & 25 & 65 & 47 \\ 768 & 765 & 837 & 804 & 740 & 854 & 725 & 805 \\ 281 & 205 & 191 & 286 & 177 & 233 & 153 & 637\end{array}$

1795-1800

Soltero-viuda

Soltera-viudo

Viudos

Solteros

Muestra

$\begin{array}{rrrrrrrr}32 & 31 & 63 & 47 & 51 & 53 & 52 & 55 \\ 5 & 56 & 84 & 68 & 76 & 84 & 105 & 55 \\ 69 & 35 & 68 & 34 & 42 & 40 & 32 & 48 \\ 891 & 876 & 783 & 849 & 823 & 821 & 809 & 839 \\ 274 & 283 & 189 & 293 & 117 & 320 & 247 & 716\end{array}$

1.= Alcalá de los Gazules.

2.= Bornos.

3. $=$ Conil.

4.= Chiclana. Parroquia de San Juan Bautista.

$5 .=$ Gibraltar (1645-1650 y 1695-1696) y San Roque (1745-1750 y 1795-1797).

6.= Jerez de la Frontera. Parroquia de Santiago.

$7 .=$ Olvera.

8. = Sanlúcar de Barrameda.

\section{CUADRO 8}

\section{Estacionalidad de las defunciones en tantos por mil}

$$
\begin{array}{llllllllllll}
\mathbf{E} & \mathbf{F} & \mathbf{M} & \mathbf{A} & \mathbf{M} & \mathbf{J} & \mathbf{J} & \mathbf{A} & \mathbf{S} & \mathbf{O} & \mathbf{N} & \mathbf{D}
\end{array}
$$

Alcalá $G$.

$\begin{array}{lllllllllllll}(1700-99) & 75 & 71 & 75 & 65 & 74 & 68 & 82 & 105 & 101 & 98 & 86 & 90\end{array}$

Bornos

$\begin{array}{lllllllllllll}(1740-1789) & 81 & 65 & 80 & 78 & 73 & 64 & 77 & 102 & 87 & 93 & 98 & 94\end{array}$

Conil

$\begin{array}{lllllllllllll}(1700-1799) & 91 & 67 & 76 & 77 & 80 & 84 & 95 & 86 & 80 & 73 & 89 & 94\end{array}$

Chiclana

$\begin{array}{lllllllllllll}(1700-1799) & 77 & 65 & 77 & 76 & 80 & 84 & 94 & 102 & 89 & 86 & 82 & 82\end{array}$

Gibraltar

$\begin{array}{lllllllllllll}(1683-1690) & 73 & 70 & 74 & 70 & 86 & 78 & 106 & 112 & 89 & 90 & 76 & 71\end{array}$ 
Jerez F.

$\begin{array}{lllllllllllll}(1700-1799) & 87 & 70 & 80 & 79 & 83 & 83 & 83 & 89 & 80 & 83 & 87 & 91\end{array}$ Olvera adultos $\begin{array}{lllllllllllll}(1700-99) & 77 & 64 & 77 & 72 & 68 & 65 & 79 & 118 & 106 & 89 & 93 & 86\end{array}$ Olvera parv. $\begin{array}{lllllllllllll}(1674-1734) & 79 & 86 & 111 & 78 & 62 & 53 & 75 & 84 & 102 & 101 & 88 & 77\end{array}$ Sanlúcar

$\begin{array}{lllllllllllll}(1700-1799) & 96 & 77 & 85 & 79 & 81 & 78 & 82 & 84 & 76 & 77 & 85 & 94\end{array}$

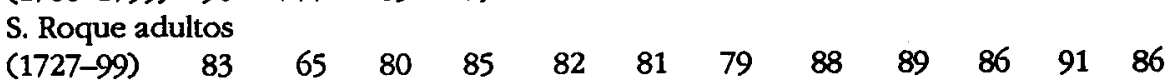
S. Roque parv. $\begin{array}{lllllllllllll}(1791-99) & 51 & 43 & 37 & 55 & 33 & 79 & 139 & 135 & 106 & 130 & 109 & 78\end{array}$

\section{CUADRO 9}

Estructura por edad y sexo. Conil

\begin{tabular}{|c|c|c|}
\hline & 1795 & -1800 \\
\hline . & V. & H. \\
\hline$-1 \quad$ año & 104 & 97 \\
\hline $1-7$ & 116 & 105 \\
\hline 8-14 & 8 & 10 \\
\hline $15-19$ & 7 & 8 \\
\hline $20-29$ & 20 & 10 \\
\hline $30-39$ & 18 & 8 \\
\hline $40-49$ & 37 & 24 \\
\hline $50-59$ & 19 & 13 \\
\hline $60-69$ & 42 & 38 \\
\hline+70 & 23 & 44 \\
\hline Indet. & 46 & 2 \\
\hline Total & 440 & 359 \\
\hline
\end{tabular}

CUADRO 10

Estructura por edad y sexo. San Roque

$\begin{array}{rrrr} & & & \text { 1795-1800 } \\ & & \text { V. } & \text { H. } \\ & & & \\ -1 & \text { año } & 130 & 81 \\ 1 & & 39 & 42 \\ 2 & & 34 & 29\end{array}$




$\begin{array}{rrr}3 & 26 & 29 \\ 4 & 19 & 21 \\ 5 & 5 & 13 \\ 6 & 5 & 7 \\ 7 & 2 & 3 \\ 8 & 4 & 3 \\ 9 & 3 & 2 \\ 10 & 5 & 1 \\ 11 & 2 & 1 \\ 12 & - & 1 \\ 13 & 1 & 2 \\ 14 & - & - \\ 15-19 & 10 & 6 \\ 20-29 & 25 & 27 \\ 30-39 & 46 & 37 \\ 40-49 & 38 & 34 \\ 50-59 & 49 & 35 \\ 60-69 & 41 & 45 \\ +70 & 33 & 54 \\ \text { Indet. } & 4 & 4 \\ \text { Total } & 521 & 477\end{array}$

\section{CUADRO 11}

Proporción de cónyuges inmigrantes en tantos por mil

$\begin{array}{lrrrrrr} & 1595- & 1645- & 1695- & 1745- & 1795- & \text { Media } \\ & 1600 & 1650 & 1700 & 1750 & 1800 & \\ \text { Alcalá G. } & - & 135 & 165 & 260 & 180 & 169 \\ \text { Bornos } & 325 & 80 & 199 & 83 & 75 & 135 \\ \text { Conil } & 136 & 80 & 177 & 165 & 135 & 143 \\ \text { Chiclana (1) } & 144 & 152 & 233 & 198 & 233 & 179 \\ \text { Gibraltar } & - & 173 & 212 & - & - & 183 \\ \text { Jerez F. (2) } & 111 & 163 & 343 & 272 & 244 & 210 \\ \text { Jerez F. (3) } & - & 196 & 170 & 208 & 168 & 184 \\ \text { Olvera } & 236 & 153 & 174 & 92 & 86 & 133 \\ \text { Sanlúcar } & 464 & 405 & 340 & 251 & 176 & 328 \\ \text { San Roque } & - & - & - & 488 & 244 & 389 \\ & & & & & & \\ \text { (1) S. Juan Bautista. } & & & & & & \\ \text { (2) S. Dionisio. } & & & & & & \\ \text { (3) Santiago. } & & & & & & \end{array}$




\section{CUADRO 12}

Procedencia geográfica de los cónyuges en tantos por mil

Varones

Localidad

R. Provincia

R. Andalucía

R. España

Extranjero
A1. Bo. Co

$\begin{array}{lll}775 & 793 & 807\end{array}$

$\begin{array}{lll}116 & 90 \quad 137\end{array}$

$60 \quad 61 \quad 24$

$37 \quad 42$

$9 \quad 12$
Co. Ch. Gi

$807 \quad 767$

146

$24 \quad 29$

$17 \quad 31$

$12 \quad 24$
Gi. Jf. Jf. ol. Sn. Sr.

$\begin{array}{llllll}722 & 697 & 720 & 813 & 561 & 515\end{array}$

$\begin{array}{llllll}77 & 74 & 71 & 60 & 82 & 103\end{array}$

$\begin{array}{llllll}87 & 56 & 78 & 93 & 151 & 264\end{array}$

$\begin{array}{llllll}61 & 113 & 74 & 25 & 110 & 96\end{array}$

$\begin{array}{llllll}43 & 56 & 55 & 6 & 93 & 20\end{array}$

Mujeres

$\begin{array}{lllllllllll}\text { Localidad } & 893 & 931 & 904 & 873 & 911 & 874 & 912 & 916 & 780 & 709\end{array}$ $\begin{array}{lllllllllll}\text { R. Provincia } & 76 & 38 & 81 & 105 & 31 & 66 & 36 & \mathbf{4 4} & 65 & 88\end{array}$ $\begin{array}{lllllllllll}\text { R. Andalucía } & 25 & 18 & 11 & 16 & 39 & 38 & 43 & 32 & 109 & 184\end{array}$

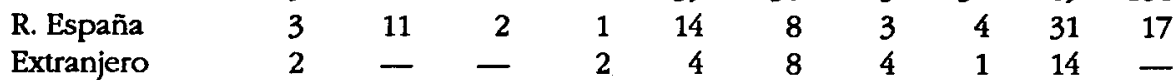

Chiclana: Parroquia de San Juan Bautista.

Jerez de la Frontera: Parroquias de San Dionisio y Santiago, respectivamente. Catas de 1595-1600, 1645-1650, 1695-1700, 1745-1750 y 1795-1800.

\section{CUADRO 13}

Procedencia geográfica de los cónyuges

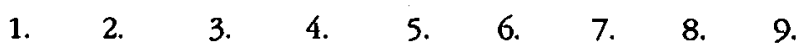

$\begin{array}{lrrrrrrrrr}\text { Alcalá de los Gazules } & 1.646 & 2 & 2 & 6 & 1 & 3 & 2 & - & 2 \\ \text { Alcalá del Valle } & - & - & - & - & - & 1 & 11 & - & - \\ \text { Algeciras } & - & - & 3 & 2 & - & - & 2 & 1 & 6 \\ \text { Algodonales } & - & 3 & - & - & - & - & 29 & - & - \\ \text { Arcos } & 12 & 34 & 2 & 4 & 5 & 11 & 1 & 20 & - \\ \text { Los Barrios } & - & - & - & 1 & - & - & - & - & 14 \\ \text { Benaocaz } & 10 & 3 & - & - & - & 1 & - & - & - \\ \text { Bornos } & 4 & 1.520 & 1 & - & - & 2 & - & 11 & 1 \\ \text { El Bosque } & - & 2 & - & - & - & - & - & - & - \\ \text { Cádiz } & 4 & 3 & 36 & 72 & 2 & 19 & - & 65 & 1 \\ \text { Castellar } & - & - & - & - & 2 & - & - & - & 1 \\ \text { Conil } & 1 & - & 1.208 & 39 & - & 1 & - & 4 & - \\ \text { Chiclana } & 4 & 1 & 14 & 1.760 & - & 2 & - & 2 & - \\ \text { Chipiona } & - & - & - & - & - & - & - & 29 & - \\ \text { Espera } & - & 9 & - & - & 1 & 3 & - & 6 & - \\ \text { El Gastor } & - & 1 & - & - & - & - & 1 & - & - \\ \text { Gibraltar } & 2 & 1 & - & 1 & 803 & - & - & 2 & 5 \\ \text { Grazalema } & 4 & 2 & 1 & 1 & - & 1 & 5 & 4 & - \\ & & & & & & & & & 5\end{array}$




\begin{tabular}{|c|c|c|c|c|c|c|c|c|c|}
\hline Jerez $F$. & 17 & 6 & 8 & 18 & 4 & .858 & - & 211 & - \\
\hline Jimena & 20 & 1 & 1 & 3 & 14 & 1 & 2 & - & 13 \\
\hline Medina Sidonia & 50 & 1 & 27 & 51 & 6 & 10 & - & 22 & 2 \\
\hline Olvera & - & 1 & - & - & - & 1 & 1.384 & - & - \\
\hline Paterna & 5 & - & - & 1 & - & - & - & - & - \\
\hline Puerto Real & 1 & 1 & 1 & 13 & - & 3 & - & 2 & - \\
\hline El Pto. Sta. María & 7 & 1 & 5 & 5 & - & 16 & 1 & 50 & 1 \\
\hline Puerto Serrano & - & 1 & - & - & - & - & 2 & - & - \\
\hline Rota & - & - & - & - & - & 5 & - & 32 & - \\
\hline San Fernando & 2 & - & 3 & 11 & - & 1 & 3 & 2 & - \\
\hline San Roque & 1 & - & - & - & - & 2 & - & 1 & 350 \\
\hline Sanlúcar & 1 & 1 & 3 & 4 & 1 & 24 & - & 1.834 & - \\
\hline Setenil & - & - & - & - & - & 1 & 7 & - & - \\
\hline Tarifa & 12 & 1 & 10 & 5 & 14 & - & - & 1 & 7 \\
\hline Torre Alháquime & - & - & - & - & - & - & 7 & - & - \\
\hline Trebujena & - & - & - & - & - & 6 & - & 48 & - \\
\hline Ubrique & 23 & 8 & 1 & 1 & 1 & 2 & - & 1 & 2 \\
\hline Vejer & 15 & 4 & 35 & 31 & 2 & 7 & - & 13 & - \\
\hline Villaluenga & 5 & - & - & - & - & - & - & - & - \\
\hline Villamartín & 1 & 25 & 1 & 1 & $\begin{array}{llll}1 & & & \\
\end{array}$ & - & 1 & 3 & - \\
\hline Zahara de la Sierra & - & - & - & - & - & - & 10 & - & - \\
\hline Almería & 2 & 1 & - & 3 & 1 & - & - & 8 & 1 \\
\hline Córdoba & - & 1 & 1 & 5 & 3 & 5 & 3 & 36 & 4 \\
\hline Granada & 7 & 5 & 3 & 3 & 6 & 9 & 1 & 21 & 9 \\
\hline Huelva & - & - & - & 3 & 1 & 10 & 2 & 160 & 1 \\
\hline Jaén & 2 & 2 & 2 & - & 4 & 2 & 3 & 24 & 1 \\
\hline Málaga & 30 & 20 & 8 & 12 & 40 & 19 & 29 & 34 & 100 \\
\hline Sevilla & 44 & 40 & 11 & 24 & 8 & 94 & 61 & 655 & 13 \\
\hline Aragón & 2 & - & - & 2 & - & - & - & 6 & 1 \\
\hline Asturias & 2 & - & - & 2 & - & 6 & 1 & 32 & 1 \\
\hline Baleares & - & - & - & - & - & - & - & 2 & - \\
\hline Canarias & 1 & - & - & 3 & 1 & - & - & 20 & - \\
\hline Castilla N. & 16 & 7 & - & 3 & 4 & 5 & 2 & 31 & 1 \\
\hline Castilla V. & 7 & 7 & 9 & 11 & 3 & 16 & 8 & 82 & 4 \\
\hline Cataluña & - & - & 1 & 3 & 2 & 1 & 1 & 6 & 6 \\
\hline Ceuta & 1 & - & - & 1 & 14 & - & - & 5 & 2 \\
\hline Extremadura & 1 & 7 & - & - & 5 & 17 & 3 & 62 & 2 \\
\hline Galicia & 8 & 15 & 3 & 5 & 2 & 40 & 6 & 198 & 8 \\
\hline León & - & 2 & - & 1 & 3 & 4 & 2 & 21 & - \\
\hline Melilla & - & - & - & - & - & - & - & 1 & - \\
\hline Murcia & 1 & 1 & - & - & 1 & - & - & 5 & 4 \\
\hline Navarra & 1 & 1 & 1 & 一 & 2 & - & 1 & 5 & 1 \\
\hline Valencia & - & 3 & - & 2 & - & - & - & 20 & 2 \\
\hline Vascongadas & - & 3 & - & 3 & 1 & - & - & 13 & 1 \\
\hline
\end{tabular}




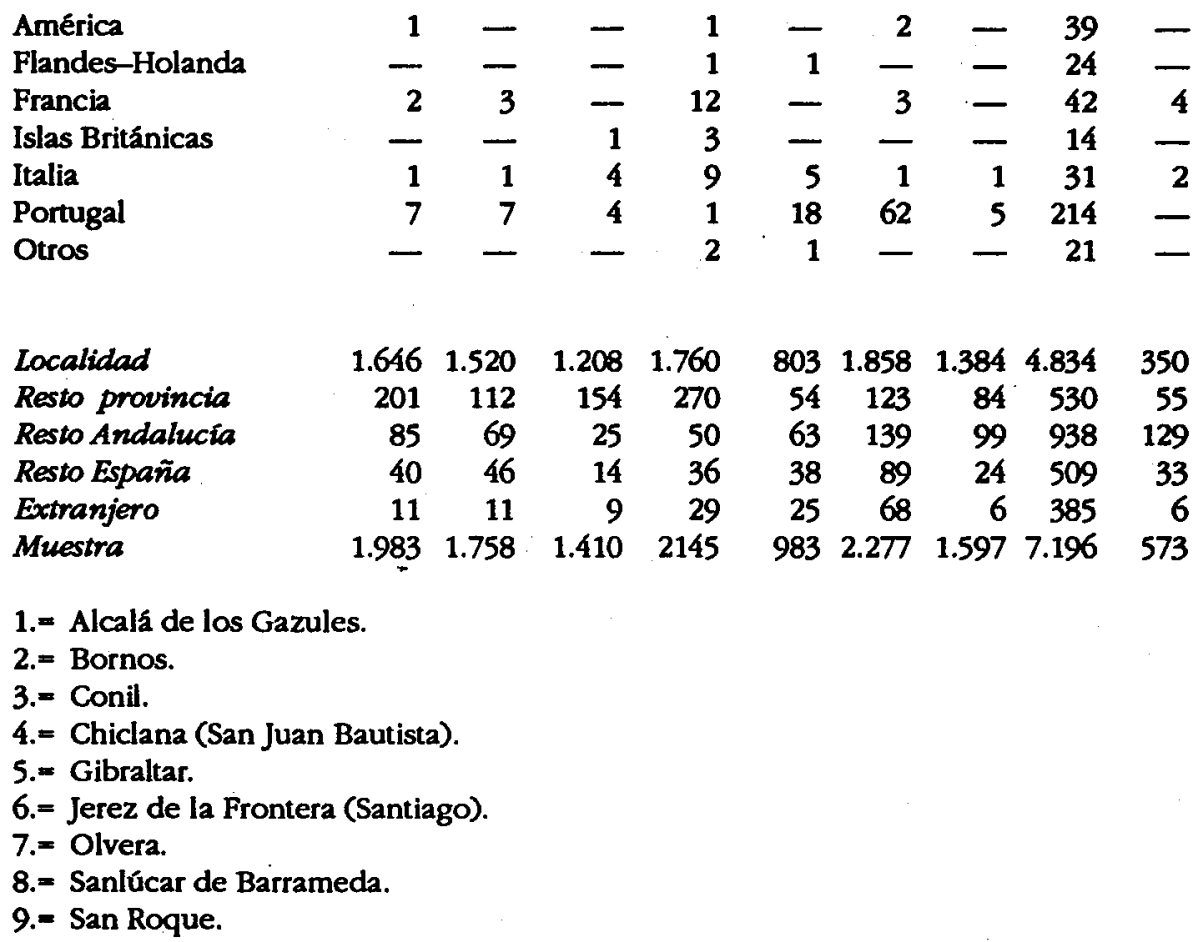

Catas de 1595-1600, 1645-1650, 1695-1700, 1745-1750, 1795-1800.

\section{CUADRO 14}

Evolución poblacional de algunas localidades

$\begin{array}{lrrrrr} & \mathbf{1 5 9 1} & \mathbf{1 6 4 0 - 1 6 4 7} & \mathbf{1 6 9 0 - 1 6 9 6} & \mathbf{1 7 5 1} & \mathbf{1 7 8 7} \\ \text { Alcalá G. } & 670 & - & 1.000 & - & 4.604 \\ \text { Arcos } & 1.162 & 1.879 & 814 & \mathbf{2 . 8 9 5} & 10.085 \\ \text { Bornos } & 491 & 423 & 384 & 1.164 & 4.820 \\ \text { Cádiz } & 900 & 1.492 & 5.625 & 9.842 & 71.080 \\ \text { Conil } & 325 & 583 & 653 & 835 & 3.504 \\ \text { Chiclana } & 627 & 700 & 626 & 1.290 & 7.450 \\ \text { Chipiona } & 117 & 79 & 76 & 168 & 1.008 \\ \text { Isla de León } & - & 180 & 121 & 650 & 28.138 \\ \text { Jerez F. } & 5.776 & 4.371 & 3.337 & 7.396 & 45.506 \\ \text { Jimena } & 1.203 & 920 & 1.038 & 1.313 & 4.968 \\ \text { Medina Sidonia } & 1.381 & 1.438 & 1.257 & 2.216 & 11.338 \\ \text { Puerto Real } & 377 & 740 & 426 & 1.292 & 8.438 \\ \text { El Pto. Sta. Maria } & 1.035 & 1.600 & 2.383 & 4.364 & 16.427 \\ \text { Rota } & 543 & 480 & 555 & 1.292 & 6.789\end{array}$




$\begin{array}{lrrrrr}\text { Sanlúcar B. } & 813 & 3.000 & 2.114 & 3.589 & 14.840 \\ \text { Vejer } & 884 & 948 & 695 & 1.358 & 5.191 \\ \text { Villamartín } & 709 & 600 & - & 406 & 1.667\end{array}$

Cifras en vecinos (en habitantes en 1787).

Fuente: P. Ponsot.

\section{CUADRO 15 \\ Evolución de los bautismos}

Alc. Bor. Con. Chi. Chp. Gib. Jer. Olv. Psm. San. SRo.

$\begin{array}{rrrrrrrrrrrr}1600-09 & 100 & 100 & 100 & 126 & 100 & 100 & 100 & 100 & 100 & 100 & - \\ 1610-19 & 80 & 113 & 97 & 88 & 151 & 118 & 102 & 103 & 116 & 106 & - \\ 1620-29 & 126 & 110 & 118 & 113 & 176 & 137 & 91 & 102 & 119 & 124 & - \\ 1630-39 & 131 & 129 & 113 & 93 & 125 & 122 & 92 & 106 & 108 & 151 & - \\ 1640-49 & 143 & 123 & 113 & 121 & 137 & 127 & 95 & 97 & 113 & 159 & - \\ 1650-59 & 145 & 135 & 116 & 99 & 145 & 100 & 94 & 92 & 120 & 124 & - \\ 1660-69 & 139 & 156 & 122 & 119 & 194 & 112 & 95 & 91 & 165 & 122 & - \\ 1670-79 & 155 & 161 & 135 & 144 & 239 & 117 & 94 & 109 & 196 & 127 & - \\ 1680-89 & 167 & 165 & 144 & 175 & 286 & 121 & 95 & 88 & 212 & 132 & - \\ 1690-99 & 176 & 215 & 158 & 188 & 268 & 142 & 107 & 91 & 210 & 137 & - \\ 1700-09 & 165 & 249 & 136 & 179 & 245 & 150 & 93 & 111 & 181 & 117 & 100 \\ 1710-19 & 147 & 241 & 155 & 187 & 209 & - & 96 & 110 & 162 & 104 & 368 \\ 1720-29 & 203 & 256 & 193 & 225 & 215 & - & 112 & 115 & 167 & 116 & 672 \\ 1730-39 & 185 & 237 & 161 & 214 & 218 & - & 111 & 117 & 188 & 117 & 777 \\ 1740-49 & 180 & 269 & 175 & 218 & 233 & - & 103 & 123 & 159 & 108 & 918 \\ 1750-59 & 188 & 255 & 218 & 263 & 237 & - & 118 & 114 & 181 & 116 & 1063 \\ 1760-69 & 180 & 261 & 188 & 256 & 248 & - & 117 & 131 & 177 & 115 & 917 \\ 1770-79 & 186 & 277 & 175 & 249 & 207 & - & 115 & 134 & 169 & 117 & 947 \\ 1780-89 & 194 & 268 & 188 & 251 & 189 & - & 106 & 139 & 188 & 114 & 1.203 \\ 1790-99 & 222 & 282 & 213 & 284 & 278 & - & 124 & 175 & 196 & 130 & 1.017\end{array}$

CUADRO 16 Superficie, población y densidad en 1787

$\begin{array}{lrrr} & \text { Superficie } & \text { Población } & \text { Densidad } \\ \text { Alcalá de los Gazules } & 478,5 & 4.604 & \\ \text { Alcalá del Valle } & 48,8 & 1.211 & 2,6 \mathrm{~h} / \mathrm{Km}^{2} \\ \text { Algeciras } & 83,7 & 6.346 & 75,8 \\ \text { Algodonales } & 135,9 & 3.402 & 25,0 \\ \text { Arcos de la Frontera } & 552,2 & 10.085 & 18,2 \\ \text { Los Barrios } & 328,1 & 2.357 & 7,1 \\ \text { Benaocaz } & 69,2 & 3.854 & 55,6 \\ \text { Bornos } & 54,3 & 4.820 & 88,7 \\ \text { El Bosque } & 30,6 & 1.430 & 46,7 \\ \text { Cádiz } & 10,6 & 71.080 & 6.705,6\end{array}$




$\begin{array}{lrrr}\text { Castellar de la F. } & & & 425 \\ \text { Conil de la F. } & 179,3 & 3.504 & 2,3 \\ \text { Chiclana de la F. } & 86,5 & 7.450 & 40,5 \\ \text { Chipiona } & 203,0 & 1.008 & 36,6 \\ \text { Espera } & 31,8 & 2.217 & 31,6 \\ \text { El Gastor } & 121,4 & 945 & 18,2 \\ \text { Grazalema } & 27,7 & 7.382 & 34,1 \\ \text { Jerez de la Frontera } & 122,3 & 45.506 & 60,3 \\ \text { Jimena de la F. } & 1.409,9 & 4.968 & 32,2 \\ \text { Medina Sidonia } & 345,2 & 11.338 & 14,3 \\ \text { Olvera } & 546,5 & 4.188 & 20,7 \\ \text { Paterna de la Rivera } & 191,9 & 986 & 21,8 \\ \text { Puerto Real } & 13,6 & 8.438 & 72,5 \\ \text { El Pto. de Sta. María } & 193,0 & 16.427 & 43,7 \\ \text { Puerto Serrano } & 154,4 & 873 & 106,3 \\ \text { Rota } & 80,2 & 6.789 & 10,8 \\ \text { San Fernando } & 83,9 & 28.138 & 80,9 \\ \text { San Roque } & 29,8 & 4.677 & 944,2 \\ \text { Sanlúcar de Barrameda } & 163,4 & 14.840 & 28,6 \\ \text { Setenil } & 165,2 & 1.482 & 89,8 \\ \text { Tarifa } & 82,4 & 7.548 & 17,9 \\ \text { Torre Alháquime } & 414,5 & 396 & 18,2 \\ \text { Trebujena } & 17,3 & 1.665 & 22,8 \\ \text { Ubrique } & 67,4 & 4.890 & 24,7 \\ \text { Vejer de la Frontera } & 69,3 & 5.191 & 70,5 \\ \text { Villaluenga del Rosario } & 404,0 & 2.157 & 12,8 \\ \text { Villamartín } & 59,8 & 1.667 & 36,0 \\ \text { Zahara de la Sierra } & 259,2 & 1.767 & 6,4 \\ \text { Tơral } & 71,3 & 306.051 & 24,7 \\ & 7.388,0 & & 41,4\end{array}$

Fuente: Reseña estadística de la provincia de Cádiz (Madrid, Instituto Nacional de Estadística, 1969, p. 5) y Censo de 1787 Floridablanca. Cádiz (Madrid, Instituto Nacional de Estadística, 1986, p. 146).

\section{CUADRO 17}

Estructura por edad, sexo y estado civil (1787)

$\begin{array}{lrrrrrrrr} & \begin{array}{r}\text { 1. } \\ \text { Sexo }\end{array} & \text { 2. } & \begin{array}{c}\text { 3. } \\ \text { Edad }\end{array} & \text { 4. } & \text { 5. } & \begin{array}{c}\text { 6. } \\ \text { Estado civil }\end{array} \\ \text { Alcalá Gaz. } & 110 & 467 & 480 & 52 & 590 & 335 & 73 \\ \text { Alcalá Val. } & 112 & 455 & 507 & 37 & 569 & 360 & 69 \\ \text { Algeciras } & 97 & 429 & 522 & 48 & 521 & 397 & \mathbf{8 1} \\ \text { Algodonales } & 105 & 437 & 506 & 56 & 592 & 342 & 64 \\ \text { Arcos } & 99 & 382 & 552 & 65 & 513 & 402 & 83 \\ \text { Los Barrios } & 112 & 413 & 535 & 51 & 555 & 367 & 77 \\ \text { Benaocaz } & 90 & 436 & 508 & 56 & 599 & 329 & 70\end{array}$




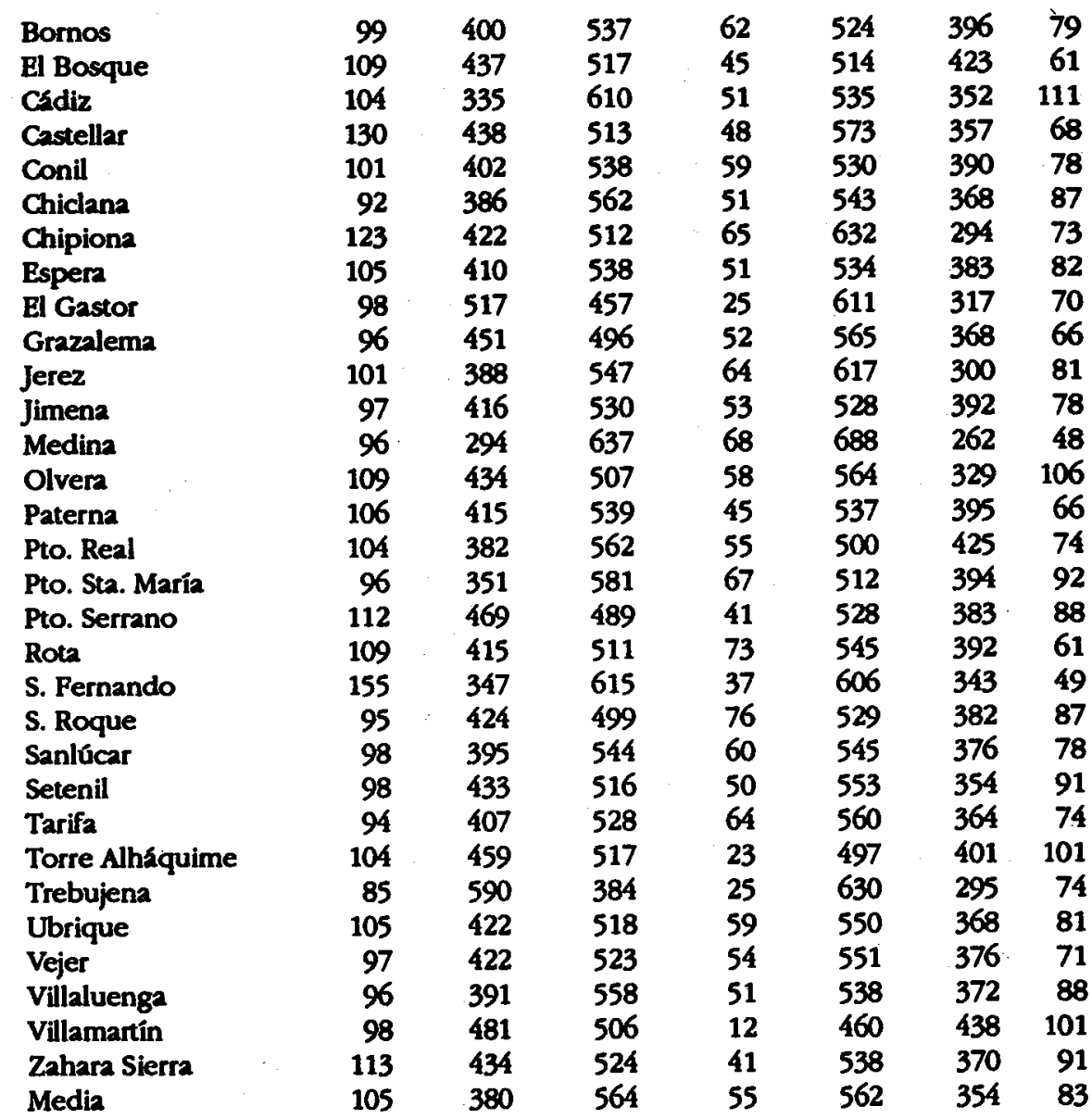

1. Relación de Masculinidad.

2. Población de 0-19 años en tantos por mil (sólo viviendas familiares).

3. Población de 20-59 años en tantos por mil (idem).

4. Población de más de 60 años en tantos por mil (idem).

5. Proporción de solteros en tantos por mil (idem).

6. Proporción de casados en tantos por mil (idem).

7. Proporción de viudos en tantos por mil (idem).

\section{CUADRO 18}

Bautismos

$\begin{array}{rrrrrrrr} & \text { Alc } & \text { Bor } & \text { Con } & \text { Chi } & \text { Gib } & \text { Olv } & \text { San } \\ 1600 & 121 & 23 & 95 & 128 & - & 125 & 416 \\ 1601 & 118 & 105 & 101 & 149 & 206 & 134 & 481 \\ 1602 & 130 & 98 & 84 & 143 & 199 & 119 & 464 \\ 1603 & 127 & 86 & 85 & 126 & 211 & 138 & 469\end{array}$




\begin{tabular}{|c|c|c|c|c|c|c|c|}
\hline 1604 & 103 & 89 & 101 & 107 & 173 & 99 & 493 \\
\hline 1605 & 115 & 58 & 79 & 132 & 200 & 131 & 442 \\
\hline 1606 & 109 & 103 & 95 & 123 & 192 & 116 & 513 \\
\hline 1607 & 85 & 66 & 85 & 95 & 202 & 94 & 449 \\
\hline 1608 & 96 & 89 & 77 & 121 & 224 & 120 & 570 \\
\hline 1609 & 82 & 91 & 79 & 139 & 216 & 126 & 515 \\
\hline 1610 & 102 & 99 & 82 & 115 & 214 & 113 & 513 \\
\hline 1611 & 126 & 84 & 85 & 116 & 254 & 99 & 534 \\
\hline 1612 & 122 & 99 & 86 & 135 & 220 & 138 & 514 \\
\hline 1613 & 123 & 86 & 81 & 117 & 240 & 120 & 519 \\
\hline 1614 & 135 & 86 & 90 & 125 & 242 & 128 & 479 \\
\hline 1615 & 67 & 81 & 76 & 135 & 228 & 131 & 492 \\
\hline 1616 & 63 & 102 & 85 & 68 & 245 & 147 & 496 \\
\hline 1617 & 23 & 102 & 107 & 23 & 256 & 119 & 534 \\
\hline 1618 & - & 102 & 71 & 148 & 246 & 128 & 508 \\
\hline 1619 & 117 & 78 & 96 & 137 & 248 & 124 & 551 \\
\hline 1620 & 115 & 79 & 96 & 123 & 249 & 127 & 534 \\
\hline 1621 & 146 & 96 & 92 & 138 & 278 & 124 & 624 \\
\hline 1622 & 109 & 82 & 110 & 111: & 271 & 125 & 504 \\
\hline 1623 & 147 & 82 & 103 & 126 & 258 & 108 & 553 \\
\hline 1624 & 137 & 89 & 96 & 159 & 362 & 130 & 591 \\
\hline 1625 & 150 & 110 & 124 & 159 & 274 & 133 & 631 \\
\hline 1626 & 137 & 73 & 104 & 145 & 281 & 103 & 581 \\
\hline 1627 & 151 & 99 & 101 & 148 & 264 & 127 & 598 \\
\hline 1628 & 150 & 96 & 106 & 167 & 267 & 136 & 771 \\
\hline 1629 & 133 & 88 & 114 & 156 & 274 & 119 & 607 \\
\hline 1630 & 134 & 94 & 107 & 144 & 271 & 124 & 733 \\
\hline 1631 & 150 & 102 & 85 & 145 & 248 & 129 & 691 \\
\hline 1632 & 149 & 98 & 108 & 142 & 278 & 126 & 700 \\
\hline 1633 & 122 & 109 & 90 & 151 & 240 & 117 & 763 \\
\hline 1634 & 124 & 106 & 109 & 73 & 262 & 130 & 780 \\
\hline 1635 & 142 & 101 & 96 & 51 & 240 & 130 & 773 \\
\hline 1636 & 141 & 98 & 99 & 62 & 230 & 130 & 792 \\
\hline 1637 & 130 & 96 & 106 & 105 & 231 & 116 & 659 \\
\hline 1638 & 166 & 121 & 84 & 171 & 235 & 133 & 707 \\
\hline 1639 & 173 & 118 & 113 & 132 & 248 & 149 & 713 \\
\hline 1640 & 162 & 109 & 122 & 156 & 214 & 126 & 769 \\
\hline 1641 & 173 & 108 & 95 & 167 & 306 & 128 & 809 \\
\hline 1642 & 176 & 117 & 107 & 148 & 258 & 118 & 807 \\
\hline 1643 & 157 & 85 & 93 & 165 & 257 & 120 & 778 \\
\hline 1644 & 165 & 103 & 110 & 161 & 295 & 115 & 763 \\
\hline 1645 & 164 & 97 & 88 & 159 & 261 & 109 & 813 \\
\hline 1646 & 177 & 111 & 112 & 158 & 285 & 128 & 839 \\
\hline 1647 & 159 & 98 & 89 & 157 & 263 & 105 & 730 \\
\hline 1648 & 125 & 75 & 81 & 113 & 224 & 119 & 768 \\
\hline 1649 & 102 & 91 & 105 & 148 & 226 & 102 & 582 \\
\hline 1650 & 133 & 91 & 82 & 33 & 184 & 117 & 662 \\
\hline 1651 & 176 & 101 & 103 & 99 & 179 & 112 & 643 \\
\hline 1652 & 149 & 92 & 87 & 136 & 204 & 95 & 640 \\
\hline
\end{tabular}




\begin{tabular}{|c|c|c|c|c|c|c|c|}
\hline 1653 & 170 & 99 & 111 & 118 & 208 & 132 & 608 \\
\hline 1654 & 184 & 119 & 104 & 146 & 233 & 125 & 581 \\
\hline 1655 & 181 & 114 & 111 & 159 & 207 & 109 & 660 \\
\hline 1656 & 178 & 127 & 119 & 139 & 236 & 103 & 596 \\
\hline 1657 & 173 & 120 & 115 & 153 & 222 & 123 & 610 \\
\hline 1658 & 167 & 126 & 119 & 139 & 196 & 88 & 556 \\
\hline 1659 & 68 & 102 & 73 & 139 & 168 & 108 & 435 \\
\hline 1660 & 134 & 132 & 130 & 121 & 204 & 105 & 549 \\
\hline 1661 & 131 & 116 & 115 & 109 & 193 & 105 & 483 \\
\hline 1662 & 167 & 138 & 102 & 138 & 217 & 115 & 551 \\
\hline 1663 & 156 & 115 & 99 & 153 & 213 & 91 & 472 \\
\hline 1664 & 116 & 121 & 91 & 165 & 245 & 104 & 569 \\
\hline 1665 & 160 & 156 & 107 & 185 & 239 & 123 & 672 \\
\hline 1666 & 144 & 115 & 102 & 169 & 248 & 110 & 625 \\
\hline 1667 & 160 & 121 & 102 & 151 & 233 & 108 & 632 \\
\hline 1668 & 168 & 116 & 111 & 150 & 240 & 126 & 690 \\
\hline 1669 & 180 & 132 & 122 & 162 & 238 & 118 & 634 \\
\hline 1670 & 165 & 114 & 124 & 176 & 254 & 125 & 599 \\
\hline 1671 & 197 & 132 & 116 & 201 & 225 & 135 & 708 \\
\hline 1672 & 175 & 128 & 117 & 166 & 256 & 125 & 636 \\
\hline 1673 & 207 & 129 & 119 & 167 & 272 & 139 & 591 \\
\hline 1674 & 171 & 153 & 124 & 199 & 267 & 141 & 709 \\
\hline 1675 & 179 & 147 & 141 & 195 & 246 & 152 & 659 \\
\hline 1676 & 173 & 126 & 114 & 182 & 257 & 121 & 568 \\
\hline 1677 & 187 & 145 & 162 & 196 & 252 & 158 & 716 \\
\hline 1678 & 125 & 125 & 99 & 186 & 168 & 99 & 518 \\
\hline 1679 & 107 & 105 & 79 & 152 & 192 & 116 & 422 \\
\hline 1680 & 150 & 152 & 126 & 236 & 224 & 112 & 733 \\
\hline 1681 & 167 & 134 & 127 & 199 & 224 & 115 & 622 \\
\hline 1682 & 155 & 135 & 105 & 194 & 227 & 97 & 612 \\
\hline 1683 & 175 & 170 & 156 & 210 & 259 & 132 & 705 \\
\hline 1684 & 180 & 108 & 106 & 214 & 228 & 81 & 610 \\
\hline 1685 & 195 & 73 & 112 & 233 & 260 & 80 & 502 \\
\hline 1686 & 188 & 157 & 130 & 209 & 247 & 86 & 587 \\
\hline 1687 & 200 & 117 & 139 & 249 & 250 & 114 & 683 \\
\hline 1688 & 207 & 126 & 141 & 228 & 273 & 108 & 602 \\
\hline 1689 & 200 & 167 & 131. & 250 & 259 & 140 & 739 \\
\hline 1690 & 213 & 157 & 150 & 280 & 282 & 111 & 688 \\
\hline 1691 & 216 & 195 & 156 & 68 & 282 & 137 & 594 \\
\hline 1692 & 198 & 160 & 134 & 245 & 270 & 111 & 740 \\
\hline 1693 & 220 & 172 & 158 & 265 & 280 & 118 & 696 \\
\hline 1694 & 173 & 180 & 146 & 293 & 279 & 99 & 691 \\
\hline 1695 & 188 & 164 & 155 & 266 & 319 & 78 & 771 \\
\hline 1696 & 179 & 153 & 112 & 233 & 264 & 139 & 626 \\
\hline 1697 & 186 & 213 & 148 & 265 & 323 & 142 & 567 \\
\hline 1698 & 165 & 153 & 122 & 204 & 314 & 142 & 626 \\
\hline 1699 & 174 & 193 & 118 & 267 & 277 & 148 & 621 \\
\hline 1700 & 185 & 209 & 154 & 233 & 298 & 139 & 625 \\
\hline 1701 & 185 & 178 & 141 & 242 & 312 & 155 & 632 \\
\hline
\end{tabular}




\begin{tabular}{|c|c|c|c|c|c|c|c|}
\hline 1702 & 185 & 211 & 140 & 260 & 303 & 144 & 631 \\
\hline 1703 & 203 & 203 & 126 & 252 & 301 & 116 & 590 \\
\hline 1704 & 206 & 219 & 122 & 245 & 163 & 143 & 634 \\
\hline 1705 & 187 & 209 & 123 & 248 & - & 119 & 608 \\
\hline 1706 & 170 & 213 & 121 & 218 & 7 & 148 & 561 \\
\hline 1707 & 188 & 220 & 99 & 263 & 20 & 145 & 506 \\
\hline 1708 & 155 & 214 & 111 & 178 & 22 & 120 & 500 \\
\hline 1709 & 138 & 142 & 62 & 127 & 25 & 115 & 347 \\
\hline 1710 & 143 & 177 & 88 & 158 & 29 & 132 & 467 \\
\hline 1711 & 162 & 234 & 132 & 241 & 49 & 130 & 468 \\
\hline 1712 & 153 & 172 & 131 & 213 & 56 & 144 & 508 \\
\hline 1713 & 154 & 175 & 118 & 243 & 51 & 110 & 473 \\
\hline 1714 & 139 & 195 & 129 & 238 & 58 & 136 & 532 \\
\hline 1715 & 158 & 193 & 136 & 206 & 50 & 129 & 478 \\
\hline 1716 & 159 & 205 & 144 & 246 & 63 & 149 & 484 \\
\hline 1717 & 176 & 185 & 168 & 262 & 64 & 143 & 513 \\
\hline 1718 & 190 & 219 & 163 & 282 & 63 & 120 & 541 \\
\hline 1719 & 164 & 193 & 165 & 278 & 88 & 134 & 554 \\
\hline 1720 & 214 & 220 & 170 & 298 & 70 & 149 & 538 \\
\hline 1721 & 209 & 209 & 189 & 296 & 99 & 117 & 567 \\
\hline 1722 & 187 & 223 & 151 & 283 & 128 & 142 & 598 \\
\hline 1723 & 223 & 186 & 164 & 291 & 76 & 152 & 552 \\
\hline 1724 & 225 & 200 & 165 & 287 & 108 & 105 & 518 \\
\hline 1725 & 226 & 184 & 164 & 299 & 121 & 149 & 563 \\
\hline 1726 & 231 & 221 & 197 & 263 & 128 & 159 & 595 \\
\hline 1727 & 238 & 209 & 171 & 269 & 231 & 130 & 541 \\
\hline 1728 & 270 & 206 & 168 & 279 & 149 & 155 & 565 \\
\hline 1729 & 187 & 211 & 170 & 277 & 135 & 127 & 569 \\
\hline 1730 & 218 & 178 & 160 & 298 & 152 & 145 & 584 \\
\hline 1731 & 191 & 236 & 167 & 275 & 127 & 129 & 604 \\
\hline 1732 & 191 & 198 & 123 & 220 & 158 & 150 & 526 \\
\hline 1733 & 197 & 195 & 156 & 263 & 143 & 147 & 552 \\
\hline 1734 & 227 & 236 & 148 & 262 & 175 & 169 & 622 \\
\hline 1735 & 201 & 180 & 170 & 253 & 128 & 133 & 549 \\
\hline 1736 & 203 & 175 & 120 & 299 & 128 & 142 & 575 \\
\hline 1737 & 177 & 195 & 135 & 264 & 153 & 162 & 564 \\
\hline 1738 & 185 & 127 & 97 & 257 & 117 & 101 & 475 \\
\hline 1739 & 181 & 198 & 150 & 313 & 158 & 139 & 627 \\
\hline 1740 & 187 & 183 & 111 & 272 & 182 & 154 & 533 \\
\hline 1741 & 181 & 189 & 123 & 284 & 170 & 140 & 563 \\
\hline 1742 & 210 & 238 & 164 & 311 & 159 & 134 & 523 \\
\hline 1743 & 202 & 216 & 169 & 290 & 166 & 164 & 554 \\
\hline 1744 & 223 & 226 & 172 & 310 & 187 & 155 & 559 \\
\hline 1745 & 218 & 225 & 173 & 268 & 180 & 190 & 516 \\
\hline 1746 & 184 & 235 & 153 & 271 & 153 & 151 & 478 \\
\hline 1747 & 176 & 208 & 150 & 257 & 168 & 124 & 494 \\
\hline 1748 & 194 & 240 & 145 & 247 & 168 & 152 & 518 \\
\hline 1749 & 187 & 214 & 182 & 244 & 166 & 122 & 462 \\
\hline 1750 & 222 & 217 & 175 & 292 & 190 & 145 & 555 \\
\hline
\end{tabular}




\begin{tabular}{|c|c|c|c|c|c|c|c|}
\hline 1751 & 166 & 151 & 126 & 230 & 166 & 100 & 458 \\
\hline 1752 & 156 & 152 & 205 & 340 & 161 & 78 & 548 \\
\hline 1753 & 204 & 241 & 187 & 323 & 190 & 157 & 558 \\
\hline 1754 & 191 & 166 & 189 & 321 & 190 & 113 & 537 \\
\hline 1755 & 186 & 215 & 200 & 342 & 210 & 133 & 525 \\
\hline 1756 & 250 & 245 & 210 & 385 & 216 & 145 & 666 \\
\hline 1757 & 245 & 195 & 242 & 372 & 224 & 159 & 631 \\
\hline 1758 & 232 & 259 & 189 & 387 & 224 & 174 & 567 \\
\hline 1759 & 192 & 225 & 201 & 331 & 196 & 169 & 574 \\
\hline 1760 & 234 & 226 & 164 & 333 & 201 & 145 & 523 \\
\hline 1761 & 214 & 222 & 218 & 392 & 175 & 167 & 608 \\
\hline 1762 & 195 & 235 & 185 & 322 & 199 & 155 & 603 \\
\hline 1763 & 190 & 227 & 173 & 339 & 194 & 179 & 524 \\
\hline 1764 & 204 & 185 & 155 & 322 & 155 & 163 & 606 \\
\hline 1765 & 204 & 214 & 145 & 296 & 157 & 139 & 539 \\
\hline 1766 & 192 & 200 & 150 & 319 & 160 & 146 & 554 \\
\hline 1767 & 183 & 208 & 165 & 303 & 160 & 179 & 558 \\
\hline 1768 & 186 & 217 & 144 & 309 & 159 & 151 & 514 \\
\hline 1769 & 154 & 176 & 165 & 303 & 138 & 154 & 531 \\
\hline 1770 & 196 & 213 & 145 & 293 & 141 & 148 & 537 \\
\hline 1771 & 176 & 220 & 150 & 311 & 188 & 166 & 581 \\
\hline 1772 & 199 & 213 & 166 & 317 & 159 & 168 & 575 \\
\hline 1773 & 184 & 195 & 165 & 309 & 167 & 164 & 553 \\
\hline 1774 & 218 & 247 & 141 & 298 & 193 & 168 & 584 \\
\hline 1775 & 195 & 214 & 154 & 334 & 177 & 153 & 587 \\
\hline 1776 & 207 & 243 & 153 & 306 & 190 & 143 & 525 \\
\hline 1777 & 231 & 215 & 171 & 333 & 185 & 177 & 575 \\
\hline 1778 & 200 & 229 & 162 & 326 & 162 & 152 & 514 \\
\hline 1779 & 214 & 256 & 143 & 320 & 191 & 177 & 603 \\
\hline 1780 & 191 & 201 & 160 & 330 & 239 & 164 & 552 \\
\hline 1781 & 192 & 190 & 155 & 297 & 272 & 154 & 471 \\
\hline 1782 & 241 & 235 & 168 & 303 & 242 & 173 & 534 \\
\hline 1783 & 225 & 273 & 176 & 312 & 283 & 193 & 539 \\
\hline 1784 & 263 & 239 & 187 & 330 & 241 & 178 & 606 \\
\hline 1785 & 195 & 207 & 189 & 302 & 242 & 175 & 535 \\
\hline 1786 & 205 & 214 & 119 & 336 & 176 & 156 & 544 \\
\hline 1787 & 184 & 175 & 172 & 302 & 185 & 154 & 525 \\
\hline 1788 & 234 & 245 & 178 & 336 & 195 & 170 & 621 \\
\hline 1789 & 181 & 190 & 158 & 329 & 152 & 157 & 575 \\
\hline 1790 & 217 & 248 & 212 & 346 & 197 & 174 & 647 \\
\hline 1791 & 229 & 222 & 171 & 349 & 182 & 194 & 659 \\
\hline 1792 & 228 & 246 & 212 & 400 & 185 & 221 & 688 \\
\hline 1793 & 264 & 233 & 187 & 344 & 183 & 186 & 622 \\
\hline 1794 & 234 & 208 & 159 & 311 & 169 & 203 & 438 \\
\hline 1795 & 278 & 227 & 199 & 396 & 185 & 227 & 691 \\
\hline 1796 & 248 & 267 & 185 & 355 & 199 & 217 & 620 \\
\hline 1797 & 249 & 206 & 172 & 368 & 184 & 234 & 618 \\
\hline 1798 & 257 & 194 & 197 & 355 & 198 & 213 & 662 \\
\hline 1799 & 214 & 235 & 189 & 366 & 200 & 235 & 612 \\
\hline
\end{tabular}


Alc. = Parroquia de San Jorge de Alcalá de los Gazules.

Bor. $=$ Parroquia de Santo Domingo de Bornos.

Con. = Parroquia de Santa Catalina de Conil.

Chi.= Parroquia de San Juan Bautista de Chiclana. Desde 1765, parroquia castrense; desde 1788, parroquia de San Sebastián.

Gib.= Iglesia mayor de Gibraltar. Los datos consignados desde 1705 corresponden a la parroquia de Santa María la Coronada de San Roque.

Olv.= Parroquia de Nuestra Señora de la Encarnación de Olvera.

San.= Parroquia de Nuestra Señora de la O de Sanlúcar.

CUADRO 19

Matrimonios

Alc Bor Con Chi Gib Olv San

\begin{tabular}{|c|c|c|c|c|c|c|c|}
\hline 1600 & - & 35 & 23 & 47 & - & 17 & 146 \\
\hline 1601 & - & 32 & 21 & 29 & 一 & 33 & 96 \\
\hline 1602 & - & 35 & 32 & 22 & - & 26 & 86 \\
\hline 1603 & - & 24 & 19 & 12 & - & 19 & 59 \\
\hline 1604 & - & 24 & 20 & - & - & 17 & 5 \\
\hline 1605 & - & 21 & 24 & - & - & 25 & 7 \\
\hline 1606 & - & 13 & 19 & - & - & 15 & 4 \\
\hline 1607 & - & 19 & 25 & - & - & 25 & 127 \\
\hline 1608 & - & 15 & 31 & - & - & 33 & 100 \\
\hline 1609 & - & 10 & 25 & - & - & 31 & 89 \\
\hline 1610 & - & 26 & 31 & - & - & 26 & 12 \\
\hline 1611 & - & 20 & 29 & - & - & 31 & 114 \\
\hline 1612 & - & 20 & 31 & 一 & - & 29 & 9 \\
\hline 1613 & - & 20 & 20 & - & - & 27 & \\
\hline 1614 & - & 11 & 21 & - & - & 22 & 1 \\
\hline 1615 & - & 29 & 23 & - & - & 27 & 89 \\
\hline 1616 & - & 28 & 15 & - & 一 & 34 & 98 \\
\hline 1617 & - & 18 & 33 & 一 & - & 19 & 12 \\
\hline 1618 & - & 18 & 25 & - & - & 39 & \\
\hline 1619 & 一 & 12 & 25 & - & - & 10 & 11 \\
\hline 1620 & - & 24 & 33 & - & 46 & 28 & 157 \\
\hline 1621 & 一 & 23 & 32 & 一 & 56 & 25 & \\
\hline 1622 & 35 & 16 & 24 & - & 61 & 37 & \\
\hline 1623 & 41 & 13 & 16 & - & 79 & 28 & \\
\hline 1624 & 27 & 22 & 34 & - & 86 & 21 & 1 \\
\hline 1625 & 35 & 25 & 24 & - & 57 & 18 & \\
\hline 1626 & 23 & 28 & 22 & 一 & 44 & 27 & \\
\hline 1627 & 29 & 12 & 14 & - & 53 & 23 & 175 \\
\hline 1628 & 22 & 19 & 16 & - & 46 & 30 & \\
\hline 1629 & 37 & 18 & 16 & - & 41 & 34 & \\
\hline 1630 & 39 & 22 & 13 & - & 48 & 33 & \\
\hline
\end{tabular}




\begin{tabular}{|c|c|c|c|c|c|c|c|}
\hline 1631 & 33 & 23 & 29 & - & 60 & 34 & 152 \\
\hline 1632 & 22 & 25 & 22 & - & 57. & 43 & 191 \\
\hline 1633 & 30 & 17 & 26 & - & 51 & 21 & 146 \\
\hline 1634 & 33 & 32 & .35 & - & 48 & 24 & 179 \\
\hline 1635 & 36 & 21 & 29 & 14 & 46 & 31 & 152 \\
\hline 1636 & 39 & 21 & 38 & 25 & 50 & 24 & 86 \\
\hline 1637 & 42 & 14 & 27. & 31 & .54 & 20 & 129 \\
\hline 1638 & 50 & 34 & 21 & 36 & 50 & 30 & 168 \\
\hline 1639 & 65 & 28 & 24 & 31 & 54 & 29 & 168 \\
\hline 1640 & 37 & 19 & 29 & 21 & 70 & 18 & 268 \\
\hline 1641 & 26 & 19 & 17 & 39 & 57 & 32 & 189 \\
\hline 1642 & 36 & 19 & 23 & 30 & 67 & 33 & 209 \\
\hline 1643 & 31 & 30 & 18 & 32 & 60 & 17 & 198 \\
\hline 1644 & 32 & 25 & 13 & 35 & 56 & 20 & 196 \\
\hline 1645 & 47 & 14 & 13 & 33 & 63 & 30 & 196 \\
\hline 1646 & 33 & 20 & 21 & 29 & 64 & 47 & 217 \\
\hline 1647 & 27 & 21 & 16 & 31 & 56 & 29 & 167 \\
\hline 1648 & 18 & 11 & 17 & 20 & 40 & 23 & 203 \\
\hline 1649 & 38 & 34 & 21 & 24 & 55 & 24 & 395 \\
\hline 1650 & 89 & 48 & 28 & 30 & 85 & 29 & 341 \\
\hline 1651 . & 59 & 37. & 22 & 28 & 77 & 28 & 228 \\
\hline 1652 & 43 & 14 & 20 & 38 & 77 & 33 & 173 \\
\hline 1653 & 52 & 33 & 32 & 29 & 59 & 37 & 162 \\
\hline 1654 & 35 & 40 & 30 & 27 & 59 & 24 & 147 \\
\hline 1655 & 42 & 37 & 18 & 27 & 43 & 22 & 169 \\
\hline 1656 & 41 & 24 & 36 & 38 & 49 & 25 & 162 \\
\hline 1657: & 32 & 24 & 21 & 14 & 32 & 29 & 151 \\
\hline 1658 & 23 & 17 & 13 & 19 & 26 & 28 & 93 \\
\hline 1659 & 26 & 24 & 21 & 19 & 36 & 22 & 81 \\
\hline 1660 & 40 & 22 & 30 & 37 & 35 & 20 & 123 \\
\hline 1661 & 32 & 18 & 22 & 34 & 38 & 23 & 119 \\
\hline 1662 & 49 & 29 & 22 & 40 & 58 & 34 & 136 \\
\hline 1663 & 26 & 30 & 21 & 31 & 52 & 39 & 122 \\
\hline 1664 & 46 & 25 & 29 & 24 & 16 & 28 & 173 \\
\hline 1665 & 42 & 12 & 26 & 26 & - & 38 & 159 \\
\hline 1666 & 33 & 22 & 38 & 38 & - & 23 & 129 \\
\hline 1667 & 49 & 9 & 29 & 31 & 43 & 15 & 126 \\
\hline 1668 & 36 & 19 & 32 & 35 & 52 & 32 & 191 \\
\hline 1669 & 44 & 14 & 38 & 39 & 50 & 18 & 110 \\
\hline 1670 & 47 & 31 & 21 & 41 & 48 & 26 & 200 \\
\hline 1671 & 44 & 30 & 29 & 30 & 55 & 33 & 163 \\
\hline 1672 & 34 & 37 & 24 & 27 & 37 & 25 & 142 \\
\hline 1673 & 41 & 26 & 25 & 35 & 43 & 29 & 170 \\
\hline 1674 & 44 & 29 & 29 & 41 & 35 & 27 & 139 \\
\hline 1675 & 40 & 34 & 33 & 34 & 48 & 24 & 153 \\
\hline 1676 & 45 & 27 & 37 & 45 & 54 & 21 & 135 \\
\hline 1677 & 39 & 34 & 37 & 50 & 60 & 18 & 158 \\
\hline 1678 & 22 & 27 & 22 & 30 & 28 & 28 & 88 \\
\hline 1679 & 32 & 26 & 28 & 41 & 38 & 18 & 151 \\
\hline
\end{tabular}




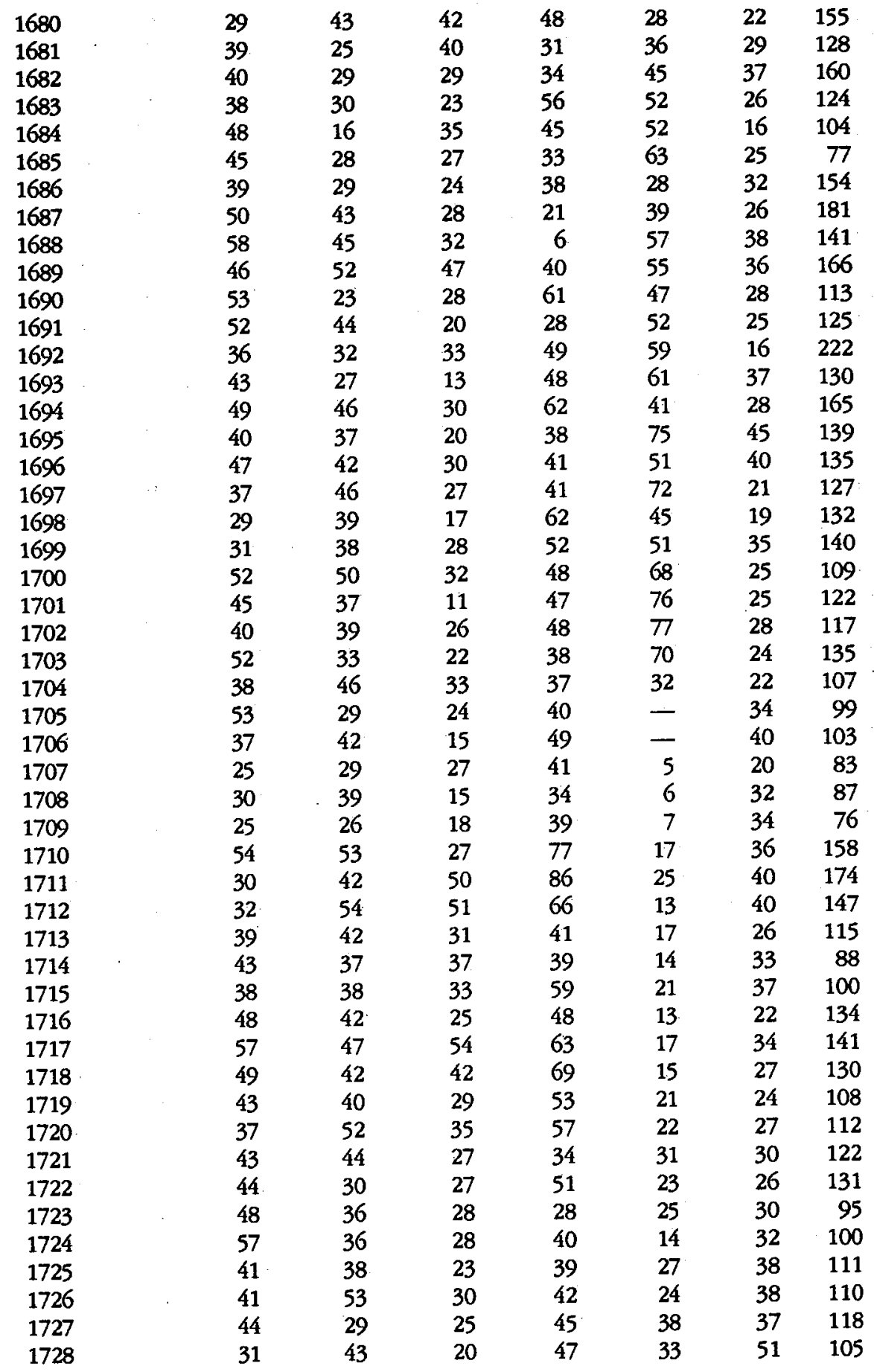




\begin{tabular}{|c|c|c|c|c|c|c|c|}
\hline 1729 & 32 & 21 & 27 & 54 & 26 & 31 & 122 \\
\hline 1730 & 49 & 39 & 32 & 59 & 28 & 21 & 147 \\
\hline 1731 & 45 & 39 & 21 & 47 & 29 & 26 & 96 \\
\hline 1732 & 36 & 47 & 25 & 53 & 35 & 33 & 130 \\
\hline 1733 & 42 & 49 & 33 & 44 & 30 & 37 & 118 \\
\hline 1734 & 56 & 34 & 23 & 55 & 28 & 42 & 104 \\
\hline 1735 & 38 & 25 & 27 & 49 & 34 & 29 & 99 \\
\hline 1736 & 62 & 21 & 33 & 48 & 27 & 34 & 104 \\
\hline 1737 & 32 & 24 & 10 & 32 & 14 & 24 & 120 \\
\hline 1738 & 25 & 33 & 28 & 54 & 28 & 20 & 114 \\
\hline 1739 & 68 & 50 & 39 & 57 & 34 & 46 & 135 \\
\hline 1740 & 72 & 45 & 29 & 55 & 28 & 32 & 114 \\
\hline 1741 & 47 & 41 & 40 & 66 & 35 & 25 & 114 \\
\hline 1742 & 50 & 45 & 48 & 59 & 38 & 40 & 132 \\
\hline 1743 & 51 & 61 & 56 & 55 & 43 & 55 & 121 \\
\hline 1744 & 62 & 58 & 43 & 41 & 35 & 33 & 113 \\
\hline 1745 & 50 & 31 & 36 & 57 & 44 & 25 & 118 \\
\hline 1746 & 31 & 34 & 25 & 26 & 19 & 18 & 81 \\
\hline 1747 & 40 & 34 & 27 & 39 & 29 & 41 & 99 \\
\hline 1748 & 33 & 43 & 35 & 57 & 20 & 26 & 105 \\
\hline 1749 & 71 & 35 & 47 & 56 & 33 & 26 & 120 \\
\hline 1750 & 56 & 28 & 21 & 51 & 32 & 18 & 114 \\
\hline 1751 & 21 & 35 & 43 & 63 & 41 & 15 & 122 \\
\hline 1752 & 55 & 44 & 40 & 83 & 30 & 36 & 147 \\
\hline 1753 & 51 & 52 & 56 & 64 & 46 & 49 & 131 \\
\hline 1754 & 44 & 44 & 43 & 65 & 53 & 33 & 150 \\
\hline 1755 & 70 & 75 & 39 & 52 & 51 & 38 & 155 \\
\hline 1756 & 62 & 58 & 46 & 64 & 68 & 50 & 184 \\
\hline 1757 & 35 & 51 & 34 & 63 & 32 & 41 & 119 \\
\hline 1758 & 33 & 44 & 23 & 56 & 33 & 23 & 97 \\
\hline 1759 & 36 & 47 & 35 & 79 & 40 & 36 & 113 \\
\hline 1760 & 45 & 38 & 37 & 61 & 42 & 31 & 141 \\
\hline 1761 & 38 & 44 & 43 & 74 & 41 & 29 & 127 \\
\hline 1762 & 64 & 76 & 39 & 63 & 47 & 48 & 137 \\
\hline 1763 & 33 & 33 & 33 & 31 & 25 & 26 & 94 \\
\hline 1764 & 34 & 37 & 30 & 34 & 27 & 18 & 102 \\
\hline 1765 & 44 & 46 & 27 & 58 & 28 & 20 & 121 \\
\hline 1766 & 41 & 31 & 43 & 44 & 39 & 29 & 85 \\
\hline 1767 & 44 & 44 & 46 & 60 & 43 & 30 & 121 \\
\hline 1768 & 40 & 33 & 35 & 105 & 40 & 15 & 106 \\
\hline 1769 & 52 & 45 & 30 & 61 & 37 & 16 & 108 \\
\hline 1770 & 42 & 53 & 34 & 83 & 37 & 42 & 173 \\
\hline 1771 & 54 & 57 & 37 & 70 & 60 & 38 & 131 \\
\hline 1772 & 38 & 44 & 37 & 84 & 50 & 25 & 113 \\
\hline 1773 & 56 & 37 & 34 & 59 & 70 & 23 & 122 \\
\hline 1774 & 42 & 44 & 21 & 70 & 64 & 17 & 105 \\
\hline 1775 & 36 & 70 & 52 & 57 & 68 & 23 & 115 \\
\hline 1776 & 41 & 51 & 45 & 79 & 37 & 46 & 149 \\
\hline 1777 & 41 & 37 & 31 & 68 & 26 & 24 & 115 \\
\hline
\end{tabular}




$\begin{array}{rrrrrrrr}1778 & 26 & 52 & 24 & 67 & 38 & 43 & 104 \\ 1779 & 50 & 60 & 30 & 57 & 57 & 36 & 127 \\ 1780 & 46 & 40 & 29 & 44 & 53 & 20 & 93 \\ 1781 & 37 & 33 & 30 & 53 & 61 & 32 & 94 \\ 1782 & 65 & 69 & 35 & 74 & 82 & 69 & 130 \\ 1783 & 50 & 69 & 61 & 92 & 79 & 47 & 141 \\ 1784 & 37 & 42 & 29 & 79 & 55 & 24 & 153 \\ 1785 & 41 & 30 & 26 & 61 & 31 & 20 & 116 \\ 1786 & 27 & 32 & 25 & 89 & 28 & 24 & 108 \\ 1787 & 52 & 58 & 45 & 75 & 47 & 36 & 137 \\ 1788 & 44 & 42 & 39 & 81 & 45 & 33 & 145 \\ 1789 & 43 & 49 & 37 & 76 & 63 & 37 & 132 \\ 1790 & 54 & 48 & 49 & 99 & 55 & 61 & 150 \\ 1791 & 66 & 43 & 40 & 78 & 49 & 37 & 130 \\ 1792 & 51 & 38 & 34 & 105 & 37 & 49 & 141 \\ 1793 & 67 & 52 & 30 & 62 & 38 & 35 & 92 \\ 1794 & 60 & 25 & 56 & 78 & 37 & 59 & 101 \\ 1795 & 55 & 70 & 32 & 82 & 50 & 30 & 139 \\ 1796 & 40 & 44 & 38 & 89 & 42 & 44 & 130 \\ 1797 & 36 & 29 & 26 & 76 & - & 47 & 103 \\ 1798 & 43 & 30 & 34 & 69 & - & 54 & 109 \\ 1799 & 52 & 66 & 36 & 95 & - & 41 & 150\end{array}$

Alc.= Parroquia de San Jorge de Alcalá de los Gazules.

Bor. = Parroquia de Santo Domingo de Bornos.

Con. $=$ Parroquia de Santa Catalina de Conil.

Chi. = Parroquia de San Juan Bautista de Chiclana. Desde 1765, parroquia castrense; desde 1788, parroquia de San Sebastián.

Gib.= Iglesia mayor de Gibraltar. Los datos consignados desde 1705 corresponden a la parroquia de Santa María la Coronada de San Roque.

Olv.= Parroquia de Nuestra Señora de la Encarnación de Olvera.

San.= Parroquia de Nuestra Señora de la $O$ de Sanlúcar.

\section{CUADRO 20}

\section{Defunciones}

Alc Bor Con Chi Gib OlvA OlvP San SROA SRoP

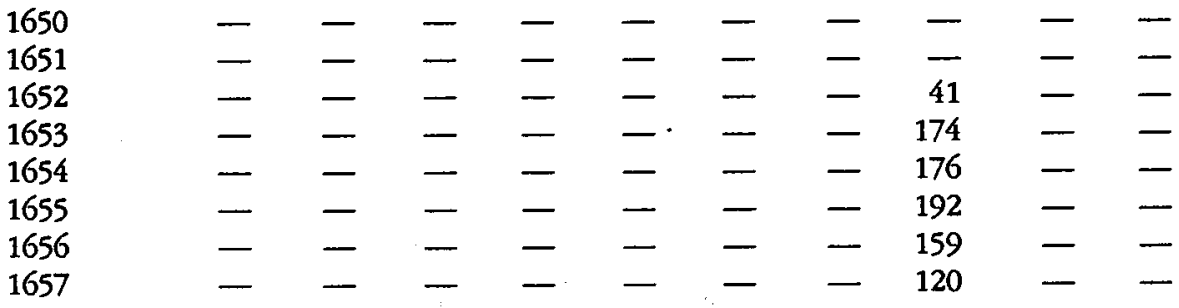




\begin{tabular}{|c|c|c|c|c|c|c|c|c|c|c|}
\hline 1658 & - & - & - & - & - & - & - & 156 & - & - \\
\hline 1659 & - & - & - & - & - & - & - & 173 & - & - \\
\hline 1660 & - & - & - & - & - & - & - & 157 & - & - \\
\hline 1661 & - & - & - & - & - & - & - & 151 & - & - \\
\hline 1662 & - & - & - & - & - & - & - & 150 & - & - \\
\hline 1663 & - & - & - & - & - & - & - & 154 & - & - \\
\hline 1664 & - & - & - & - & - & - & - & 191 & - & - \\
\hline 1665 & - & - & - & - & - & - & - & 165 & - & - \\
\hline 1666 & - & - & - & - & - & - & - & 155 & - & - \\
\hline 1667 & - & - & - & - & - & - & - & 222 & - & - \\
\hline 1668 & - & - & - & - & - & - & - & 249 & - & - \\
\hline 1669 & - & - & - & - & - & - & - & 179 & - & - \\
\hline 1670 & - & - & - & - & - & - & - & 131 & - & - \\
\hline 1671 & - & - & - & - & - & - & - & 205 & - & - \\
\hline 1672 & - & - & - & - & - & - & - & 167 & - & - \\
\hline 1673 & - & - & - & - & - & - & - & 168 & - & - \\
\hline 1674 & - & - & - & - & - & 26 & 89 & 240 & - & - \\
\hline 1675 & - & - & - & - & - & 48 & 63 & 241 & - & - \\
\hline 1676 & - & - & - & - & - & 75 & 52 & 211 & - & - \\
\hline 1677 & - & - & - & - & - & 55 & 31 & 299 & - & - \\
\hline 1678 & - & - & - & - & - & 76 & 43 & 450 & - & - \\
\hline 1679 & - & 81 & - & - & - & 60 & 36 & 209 & - & - \\
\hline 1680 & - & 87 & - & - & - & 98 & 55 & 191 & - & - \\
\hline 1681 & - & 123 & - & - & - & 79 & 41 & 130 & - & - \\
\hline 1682 & - & 122 & - & - & - & 63 & 62 & 121 & - & - \\
\hline 1683 & - & 86 & - & - & 78 & 88 & 67 & 150 & - & - \\
\hline 1684 & 52 & 141 & - & - & 160 & 116 & 42 & 243 & - & - \\
\hline 1685 & 46 & 169 & - & - & 136 & 97 & 30 & 196 & - & - \\
\hline 1686 & 74 & - & - & - & 102 & 53 & 26 & 119 & - & - \\
\hline 1687 & 101 & - & - & - & 119 & 49 & 42 & 130 & - & - \\
\hline 1688 & 64 & - & - & - & 98 & 40 & 23 & 151 & - & - \\
\hline 1689 & 109 & - & - & - & 127 & 35 & 31 & 227 & - & - \\
\hline 1690 & 104 & - & 30 & - & 195 & 43 & 58 & 159 & - & - \\
\hline 1691 & 78 & - & 14 & - & 121 & 47 & 31 & 211 & - & - \\
\hline 1692 & 90 & - & 44 & - & 148 & 34 & 26 & 215 & - & - \\
\hline 1693 & 113 & - & 40 & - & 131 & 52 & 23 & 215 & - & - \\
\hline 1694 & 146 & - & 45 & - & 143 & 63 & 50 & 272 & - & - \\
\hline 1695 & 118 & - & 42 & 一 & 220 & 58 & 56 & 379 & - & - \\
\hline 1696 & 107 & 156 & 41 & - & 116 & 51 & 63 & 387 & - & - \\
\hline 1697 & 67 & 98 & 45 & - & - & 39 & 43 & 352 & - & - \\
\hline 1698 & 144 & 85 & 43 & - & - & 38 & 23 & 259 & - & - \\
\hline 1699 & 84 & 133 & 39 & 133 & - & 42 & 43 & 227 & - & - \\
\hline 1700 & 71 & 89 & 29 & 153 & - & 57 & 46 & 195 & - & - \\
\hline 1701 & 91 & 79 & 26 & 154 & - & 65 & 121 & 181 & - & - \\
\hline 1702 & 66 & 81 & 24 & 100 & - & 60 & 35 & 193 & - & 一 \\
\hline 1703 & 78 & 175 & 30 & 175 & - & 46 & 21 & 199 & - & - \\
\hline 1704 & 82 & 86 & 22 & 171 & - & 50 & 23 & 206 & - & - \\
\hline 1705 & 80 & 104 & 43 & 163 & - & 53 & 28 & 271 & - & - \\
\hline 1706 & 43 & 92 & 26 & 160 & - & 44 & 34 & 192 & - & - \\
\hline
\end{tabular}




\begin{tabular}{|c|c|c|c|c|c|c|c|c|c|c|}
\hline 1707 & 62 & 108 & 30 & 228 & - & 71 & 41 & 199 & - & - \\
\hline 1708 & 104 & 96 & 78 & 281 & - & 71 & 49 & 231 & - & - \\
\hline 1709 & 145 & 159 & 153 & 291 & - & 136 & 66 & 498 & 一 & - \\
\hline 1710 & 57 & 107 & 42 & 137 & - & 77 & 70 & 244 & - & - \\
\hline 1711 & 53 & 43 & 45 & 118 & - & 71 & 80 & 129 & - & - \\
\hline 1712 & 80 & 66 & 53 & 204 & - & 66 & 36 & 183 & - & - \\
\hline 1713 & 62 & 56 & 24 & 116 & - & 61 & 49 & 164 & - & - \\
\hline 1714 & 63 & 61 & 27 & 156 & - & 89 & 39 & 168 & - & - \\
\hline 1715 & 47 & 75 & 27 & 136 & - & 44 & 35 & 182 & - & - \\
\hline 1716 & 60 & 14 & 22 & 249 & - & 50 & 97 & 142 & - & - \\
\hline 1717 & 17 & - & 32 & 115 & - & 63 & 35 & 182 & - & - \\
\hline 1718 & 38 & - & 18 & 125 & - & 45 & 24 & 174 & 一 & - \\
\hline 1719 & 64 & 一 & 38 & 168 & - & 40 & 31 & 240 & - & - \\
\hline 1720 & 93 & - & 39 & 339 & - & 53 & 38 & 203 & - & - \\
\hline 1721 & 75 & 一 & 24 & 125 & - & 123 & 41 & 188 & - & - \\
\hline 1722 & 85 & - & 32 & 151 & - & 67 & 125 & 173 & - & - \\
\hline 1723 & 81 & - & 36 & 131 & - & 64 & 35 & 173 & - & - \\
\hline 1724 & 97 & - & 45 & 240 & - & 87 & 47 & 205 & - & - \\
\hline 1725 & 76 & - & 27 & 107 & - & 68 & 38 & 211 & - & - \\
\hline 1726 & 114 & - & 31 & 133 & - & 62 & 58 & 180 & - & 一 \\
\hline 1727 & 158 & - & 35 & 155 & - & 54 & 37 & 183 & 234 & 一 \\
\hline 1728 & 98 & - & 36 & 142 & - & 68 & 36 & 186 & 85 & - \\
\hline 1729 & 83 & - & 31 & 176 & - & 58 & 37 & 219 & 81 & - \\
\hline 1730 & 87 & - & 41 & 211 & - & 33 & 30 & 183 & 54 & - \\
\hline 1731 & 95 & - & 47 & 254 & - & 42 & 47 & 173 & 100 & - \\
\hline 1732 & 110 & 15 & 60 & 286 & - & 42 & 25 & 216 & 78 & - \\
\hline 1733 & 101 & 70 & 46 & 265 & - & 60 & 113 & 222 & 57 & - \\
\hline 1734 & 109 & 48 & 65 & 164 & 一 & 53 & 14 & 221 & 94 & - \\
\hline 1735 & 144 & 82 & 49 & 242 & - & 66 & - & 229 & 65 & - \\
\hline 1736 & 117 & 77 & 39 & 165 & - & 70 & 一 & 229 & 62 & - \\
\hline 1737 & 148 & 83 & 69 & 180 & - & 67 & - & 248 & 67 & - \\
\hline 1738 & 195 & 126 & 128 & 267 & - & 144 & - & 307 & 60 & - \\
\hline 1739 & 185 & 72 & 72 & 270 & - & 107 & - & 242 & 49 & - \\
\hline 1740 & 93 & 64 & 59 & 218 & - & 44 & - & 210 & 48 & - \\
\hline 1741 & 75 & 69 & 51 & 257 & - & 49 & - & 231 & 68 & - \\
\hline 1742 & 69 & 70 & 27 & 198 & - & 54 & - & 185 & 64 & - \\
\hline 1743 & 153 & 42 & 35 & 268 & - & 46 & - & 195 & 49 & - \\
\hline 1744 & 65 & 59 & 49 & 233 & - & 63 & - & 234 & 66 & - \\
\hline 1745 & 74 & 79 & 31 & 197 & - & 72 & - & 252 & 52 & - \\
\hline 1746 & 79 & 93 & 75 & 241 & - & 80 & 一 & 270 & 42 & - \\
\hline 1747 & 104 & 112 & 54 & 320 & - & 61 & - & 193 & 41 & - \\
\hline 1748 & 101 & 79 & 54 & 255 & - & 41 & - & 168 & 62 & - \\
\hline 1749 & 155 & 85 & 43 & 244 & - & 56 & - & 230 & 38 & - \\
\hline 1750 & 66 & 83 & 68 & 205 & 一 & 58 & - & 267 & 66 & - \\
\hline 1751 & 128 & 99 & 51 & 343 & - & 114 & - & 223 & 57 & - \\
\hline 1752 & 53 & 74 & 47 & 189 & - & 182 & - & 244 & 58 & 一 \\
\hline 1753 & 66 & 78 & 28 & 198 & - & 34 & - & 228 & 57 & - \\
\hline 1754 & 61 & 79 & 37 & 215 & - & 21 & - & 258 & 57 & - \\
\hline 1755 & 43 & 86 & 48 & 217 & - & 39 & - & 201 & 56 & 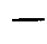 \\
\hline
\end{tabular}




\begin{tabular}{|c|c|c|c|c|c|c|c|c|c|c|}
\hline 1756 & 35 & 72 & 26 & 184 & - & 46 & - & 217 & 48 & - \\
\hline 1757 & 37 & 66 & 30 & 384 & - & 38 & - & 285 & 46 & - \\
\hline 1758 & 72 & 72 & 54 & 251 & - & 45 & - & 278 & - & - \\
\hline 1759 & 64 & 77 & 62 & 206 & - & 63 & - & 312 & - & - \\
\hline 1760 & 74 & 101 & 117 & 363 & - & 72 & - & 257 & - & - \\
\hline 1761 & 94 & 164 & 46 & 278 & - & 56 & - & 257 & - & - \\
\hline 1762 & 84 & 77 & 70 & 280 & - & 54 & - & 229 & - & - \\
\hline 1763 & 93 & 79 & 73 & 319 & - & 42 & - & 179 & - & - \\
\hline 1764 & 93 & 83 & 117 & 363 & - & 51 & - & 236 & - & - \\
\hline 1765 & 110 & 67 & 68 & 278 & - & 47 & - & 240 & 68 & - \\
\hline 1766 & 117 & 80 & 53 & 248 & - & 64 & - & 266 & 87 & - \\
\hline 1767 & 122 & 82 & 69 & 366 & - & 64 & - & 214 & 94 & - \\
\hline 1768 & 157 & 70 & 67 & 307 & - & 67 & - & 276 & 107 & - \\
\hline 1769 & 129 & 76 & 132 & 381 & - & 59 & - & 211 & 81 & - \\
\hline 1770 & 87 & 123 & 89 & 263 & - & 71 & - & 240 & 72 & - \\
\hline 1771 & 74 & 101 & 91 & 339 & - & 60 & - & 193 & 65 & - \\
\hline 1772 & 85 & 92 & 134 & 199 & - & 59 & - & 246 & 69 & - \\
\hline 1773 & 125 & 96 & 65 & 228 & - & 56 & - & 206 & 80 & - \\
\hline 1774 & 56 & 75 & 181 & 292 & - & 56 & - & 191 & 67 & - \\
\hline 1775 & 58 & 81 & 73 & 197 & - & 53 & - & 185 & 62 & - \\
\hline 1776 & 64 & 87 & 158 & 285 & - & 46 & - & 239 & 69 & - \\
\hline 1777 & 65 & 86 & 127 & 227 & - & 50 & - & 200 & 64 & - \\
\hline 1778 & 80 & 138 & 120 & 248 & - & 49 & - & 240 & 59 & - \\
\hline 1779 & 95 & 94 & 153 & 356 & - & 48 & 110 & 276 & 70 & - \\
\hline 1780 & 106 & 109 & 122 & 258 & - & 50 & 55 & 292 & 102 & - \\
\hline 1781 & 77 & 129 & 137 & 193 & - & 64 & 72 & 234 & 107 & - \\
\hline 1782 & 99 & 128 & 128 & 248 & - & 75 & 52 & 288 & 139 & - \\
\hline 1783 & 69 & 98 & 145 & 202 & - & 91 & 52 & 258 & 82 & - \\
\hline 1784 & 85 & 104 & 122 & 212 & - & 46 & 52 & 244 & 66 & - \\
\hline 1785 & 83 & 200 & 110 & 411 & - & 39 & 52 & 318 & 93 & - \\
\hline 1786 & 177 & 267 & 203 & 505 & - & 63 & 140 & 498 & 109 & - \\
\hline 1787 & 99 & 114 & 127 & 292 & - & 113 & 34 & 250 & 114 & - \\
\hline 1788 & 83 & 66 & 119 & 276 & - & 54 & 44 & 192 & 72 & - \\
\hline 1789 & 114 & 63 & 118 & 259 & - & 49 & 104 & 264 & 93 & - \\
\hline 1790 & 74 & 72 & 89 & 230 & - & 67 & 67 & 203 & 77 & - \\
\hline 1791 & 74 & 68 & 127 & 366 & - & 47 & 48 & 212 & 69 & 67 \\
\hline 1792 & 64 & 64 & 162 & 244 & - & 50 & 37 & 167 & 63 & 55 \\
\hline 1793 & 74 & 68 & 112 & 277 & - & 50 & 36 & 223 & 64 & 87 \\
\hline 1794 & 89 & 87 & 91 & 325 & - & 46 & 34 & 274 & 70 & 83 \\
\hline 1795 & 75 & 80 & 91 & 197 & - & 78 & 84 & 203 & 75 & 53 \\
\hline 1796 & 92 & 76 & 72 & 262 & - & 69 & 116 & 168 & 64 & 36 \\
\hline 1797 & 90 & 94 & 202 & 312 & - & 77 & 53 & 222 & 92 & 62 \\
\hline 1798 & 119 & 84 & 197 & 302 & - & 76 & 75 & 290 & 103 & 117 \\
\hline 1799 & 170 & 82 & 107 & 286 & - & 64 & 61 & 331 & 94 & 106 \\
\hline \multicolumn{11}{|c|}{$\begin{array}{l}\text { Alc. = Parroquia de San Jorge de Alcalá de los } \\
\text { Bor.= Parroquia de Santo Domingo de Borno } \\
\text { Con. = Parroquia de Santa Catalina de Conil. }\end{array}$} \\
\hline
\end{tabular}


Gib.= Iglesia Mayor de Gibraltar.

OlvA. = Parroquia de Nuestra Señora de la Encarnación de Olvera. Adultos.

OlvP.= Ibídem. Párvulos.

San.= Parroquia de Nuestra Señora de la $O$ de Sanlúcar.

SRoA.= Parroquia de Nuestra Señora la Coronada de San Roque. Adultos.

SroP.= Ibídem. Párvulos.

\section{CUADRO 21}

Bautismos. Jerez de la Frontera

\begin{tabular}{|c|c|c|c|c|c|c|c|c|c|}
\hline & 1. & 2. & 3. & 4. & 5. & 6. & 7. & 8. & Total \\
\hline 1600 & 61 & 27 & 28 & 61 & 36 & 384 & 54 & 107 & 758 \\
\hline 1601 & 81 & 33 & 32 & 50 & 36 & 395 & 71 & 137 & 835 \\
\hline 1602 & 72 & 38 & 39 & 49 & 47 & 457 & 71 & 164 & 937 \\
\hline 1603 & 70 & 29 & 33 & 53 & 33 & 454 & 69 & 172 & 913 \\
\hline 1604 & 78 & 27 & 35 & 49 & 51 & 476 & 67 & 121 & 904 \\
\hline 1605 & 63 & 24 & 43 & 38 & 52 & 357 & 79 & 143 & 799 \\
\hline 1606 & 70 & 28 & 34 & 44 & 40 & 432 & 71 & 160 & 879 \\
\hline 1607 & 93 & 25 & 35 & 30 & 41 & 351 & 69 & 133 & 777 \\
\hline 1608 & 96 & 28 & 29 & 50 & 52 & 427 & 64 & 155 & 901 \\
\hline 1609 & 119 & 24 & 29 & 52 & 56 & 401 & 77 & 146 & 904 \\
\hline 1610 & 90 & 16 & 37 & 36 & 53 & 422 & 82 & 160 & 896 \\
\hline 1611 & 109 & 36 & 32 & 66 & 50 & 417 & 91 & 131 & 932 \\
\hline 1612 & 105 & 34 & 32 & 38 & 66 & 448 & 92 & 166 & 981 \\
\hline 1613 & 78 & 25 & 47 & 54 & 27 & 395 & 75 & 153 & 854 \\
\hline 1614 & 93 & 36 & 32 & 49 & 50 & 418 & 86 & 130 & 894 \\
\hline 1615 & 99 & 33 & 36 & 53 & 60 & 390 & 88 & 149 & 908 \\
\hline 1616 & 97 & 28 & 37 & 58 & 58 & 409 & 84 & 157 & 928 \\
\hline 1617 & 90 & 23 & 28 & 42 & 54 & 369 & 84 & 136 & 826 \\
\hline 1618 & 104 & 34 & 32 & 35 & 58 & 382 & 70 & 113 & 828 \\
\hline 1619 & 85 & 39 & 33 & 39 & 55 & 327 & 81 & 119 & 778 \\
\hline 1620 & 81 & 27 & 30 & 42 & 62 & 349 & 67 & 116 & 774 \\
\hline 1621 & 84 & 31 & 25 & 51 & 39 & 345 & 73 & 104 & 752 \\
\hline 1622 & 73 & 33 & 36 & 33 & 92 & 324 & 67 & 101 & 759 \\
\hline 1623 & 86 & 30 & 31 & 43 & 54 & 354 & 75 & 127 & 800 \\
\hline 1624 & 66 & 30 & 39 & 40 & 50 & 356 & 64 & 110 & 755 \\
\hline 1625 & 82 & 35 & 22 & 44 & 62 & 366 & 87 & 149 & 847 \\
\hline 1626 & 56 & 27 & 37 & 43 & 46 & 325 & 60 & 103 & 697 \\
\hline 1627 & 87 & 36 & 29 & 30 & 52 & 356 & 80 & 137 & 807 \\
\hline 1628 & 63 & 44 & 36 & 47 & 82 & 357 & 97 & 128 & 854 \\
\hline 1629 & 81 & 32 & 36 & 45 & 57 & 353 & 77 & 134 & 815 \\
\hline 1630 & 74 & 42 & 38 & 30 & 60 & 339 & 92 & 146 & 821 \\
\hline 1631 & 67 & 25 & 29 & 40 & 54 & 296 & 67 & 133 & 711 \\
\hline 1632 & 109 & 20 & 34 & 50 & 48 & 331 & 91 & 108 & 791 \\
\hline 1633 & 84 & 31 & 32 & 53 & 57 & 343 & 87 & 132 & 819 \\
\hline 1634 & 90 & 46 & 25 & 35 & 53 & 342 & 110 & 162 & 863 \\
\hline
\end{tabular}




\begin{tabular}{|c|c|c|c|c|c|c|c|c|}
\hline 1635 & 72 & 44 & 27 & 47 & 54 & 359 & 83 & 128 \\
\hline 1636 & 91 & 37 & 35 & 42 & 54 & 339 & 85 & 128 \\
\hline 1637. & 70 & 33 & 32 & 37 & 51 & 300 & 78 & 93 \\
\hline 1638 & 84 & 42 & 24 & 38 & 58 & 375 & 73 & 143 \\
\hline 1639 & 85 & 32 & 30 & 39 & 47 & 365 & 87 & 158 \\
\hline 1640 & 93 & 34 & 37 & 46 & 55 & 345 & 83 & 137 \\
\hline 1641 & 98 & 37 & 28 & 45 & 61 & 408 & 94 & 152 \\
\hline 1642 & 83 & 32 & 28 & 51 & 59 & 366 & 80 & 167 \\
\hline 1643 & 64 & 35 & 31 & 48 & 54 & 372 & 94 & 137 \\
\hline 1644 & 79 & 30 & 21 & 54 & 56 & 341 & 87 & 134 \\
\hline 1645 & 78 & 37 & 25 & 57 & 55 & 348 & 87 & 152 \\
\hline 1646 & 86 & 30 & 25 & 44 & 50 & 363 & 71 & 166 \\
\hline 1647 & 81 & 34 & 32 & 48 & 50 & 331 & 68 & 139 \\
\hline 1648 & 63 & 35 & 28 & 50 & 44 & 320 & 58 & 128 \\
\hline 1649 & 67 & 23 & 31 & 55 & 55 & 328 & 63 & 142 \\
\hline 1650 & 80 & 36 & 19 & 25 & 51 & 316 & 61 & 134 \\
\hline 1651 & 92 & 35 & 36 & 55 & 53 & 352 & 69 & 157 \\
\hline 1652 & 72 & 31 & 33 & 43 & 55 & 340 & 65 & 157 \\
\hline 1653 & 79 & 32 & 38 & 36 & 48 & 352 & 109 & 131 \\
\hline 1654 & 80 & 30 & 31 & 54 & 55 & 317 & 90 & 136 \\
\hline 1655 & 102 & 47 & 26 & 29 & 50 & 379 & 88 & 169 \\
\hline 1656 & 97 & 9 & 28 & 49 & 69 & 378 & 84 & 143 \\
\hline 1657 & 85 & 25 & 40 & 45 & 61 & 382 & 88 & 124 \\
\hline 1658 & 103 & 29 & 28 & 48 & 58 & 314 & 74 & 135 \\
\hline 1659 & 94 & 27 & 25 & 42 & 43 & 299 & 72 & 133 \\
\hline 1660 & 113 & 31 & 35 & 43 & 65 & 363 & 68 & 130 \\
\hline 1661 & 100 & 22 & 29 & 40 & 70 & 316 & 81 & 140 \\
\hline 1662 & 98 & 29 & 21 & 33 & 77 & 378 & 58 & 152 \\
\hline 1663 & 92 & 30. & 41 & 43 & 76 & 323 & 77 & 155 \\
\hline 1664 & 101 & 31 & 29 & 33 & 53 & 364 & 88 & 122 \\
\hline 1665 & 82 & 29 & 35 & 30 & 64 & 366 & 80 & 160 \\
\hline 1666 & 74 & 23 & 33 & 44 & 63 & 308 & 75 & 119 \\
\hline 1667 & 97 & 28 & 29 & 40 & 66 & 365 & 69 & 126 \\
\hline 1668 & 70 & 22 & 26 & 44 & 82 & 379 & 85 & 163 \\
\hline 1669 & 67 & 31 & 33 & 39 & 56 & 382 & 70 & 127 \\
\hline 1670 & 74 & 24 & 29 & 42 & 55 & 342 & 88 & 154 \\
\hline 1671 & 59 & 26 & 32 & 52 & 83 & 401 & 87. & 179 \\
\hline 1672 & 71 & 27 & 24 & 46 & 61 & 323 & 80 & 138 \\
\hline 1673 & 58 & 22 & 25 & 28 & 52 & 383 & 85 & 159 \\
\hline 1674 & 86 & 28 & 32 & 45 & 60 & 405 & 85 & 168 \\
\hline 1675 & 88 & 26 & 27 & 45 & 57 & 351 & 83 & 163 \\
\hline 1676 & 79 & 31 & 38 & 27 & 57 & 386 & 70 & 161 \\
\hline 1677 & 70 & 25 & 33 & 40 & 56 & 382 & 97 & 172 \\
\hline 1678 & 71 & 24 & 22 & 22 & 44 & 299 & 63 & 143 \\
\hline 1679 & 61 & 24 & 18 & 30 & 46 & 284 & 62 & 117 \\
\hline 1680 & 71 & 29 & 27 & 31 & 66 & 390 & 74 & 150 \\
\hline 1681 & 70 & 23 & 21 & 24 & 49 & 353 & 70 & 151 \\
\hline 1682 & 88 & 22 & 32 & 37 & 53 & 390 & 73 & 165 \\
\hline 1683 & 79 & 28 & 19 & 36 & 60 & 386 & 95 & 194 \\
\hline
\end{tabular}




\begin{tabular}{|c|c|c|c|c|c|c|c|c|c|c|}
\hline 1684 & & 80 & 21 & 30 & 40 & 53 & 359 & 83 & 145 & \\
\hline 1685 & $\therefore$ & 60 & 24 & 18 & 25 & 51 & 265 & 61 & 118 & 622 \\
\hline 1686 & & 52 & 20 & 27 & 29 & 50 & 383 & 57 & 152 & 770 \\
\hline 1687 & & 47 & 16 & 33 & 23 & 62 & 399 & 78 & 166 & 824 \\
\hline 1688 & $\therefore$ & 57 & 20 & 31 & 37 & 58 & 412 & 93 & 164 & 872 \\
\hline 1689 & & 68 & 28 & 26 & 29 & 59 & 481 & 68 & 172 & 931 \\
\hline 1690 & & 56 & 29 & 32 & 27 & 66 & 486 & 94 & 202 & 992 \\
\hline 1691 & & 50 & 20 & 22 & 23 & 61 & 524 & 70 & 175 & 945 \\
\hline 1692 & & 50 & 28 & 25 & 30 & 58 & 453 & 78 & 196 & 918 \\
\hline 1693 & & 70 & 25 & 24 & 37 & 72 & 519 & 92 & 179 & 1.018 \\
\hline 1694 & & 53 & 28 & 27 & 25 & 71 & 461 & 87 & 214 & 966 \\
\hline 1695 & & 71 & 24 & 33 & 36 & 68 & 502 & 95 & 179 & 1.008 \\
\hline 1696 & & 51. & 31 & 33 & 40 & 52 & 404 & 73 & 168 & 852 \\
\hline 1697 & & 58 & 32 & 23 & 23 & 58 & 445 & 75 & 193 & 907 \\
\hline 1698 & & .52 & 18 & 25 & 27 & 60 & 412 & 73 & 164 & 831 \\
\hline 1699 & & 36 & 30 & 28 & 26 & 46 & 400 & 77 & 159 & 802 \\
\hline 1700 & & 61 & 18 & 25 & 30 & 49 & 454 & 57 & 180 & 874 \\
\hline 1701 & $\cdot$ & 49 & 21 & 32 & 25 & 62 & 500 & 75 & 168 & 932 \\
\hline 1702 & & 62 & 24 & 27 & 35 & 61 & 459 & 73 & 197 & 938 \\
\hline 1703 & : & 56 & 17 & 17 & 25 & 52 & 454 & 79 & 168 & 868 \\
\hline 1704 & & 45 & 34 & 25 & 22 & 54 & 414 & 83 & 188 & 865 \\
\hline 1705 & & 61 & 21 & 25 & 23 & 64 & 418 & 57 & 153 & 822 \\
\hline 1706 & & 46 & 27 & 23 & 26 & 62 & 424 & 62 & 145 & 815 \\
\hline 1707 & & 41 & 19. & 20 & 27 & 59 & 398 & 54 & 140 & 758 \\
\hline 1708 & & 40 & 18 & 28 & 11 & 58 & 373 & 63 & 140 & 731 \\
\hline 1709 & & 27 & 3 & 17 & 17 & 29 & 217 & 35 & 65 & 410 \\
\hline 1710 & & 50 & 19 & 21 & 21 & 43 & 349 & 58 & 125 & 686 \\
\hline 1711 & & 52 & 15 & 24 & 19 & 50 & 387 & 70 & 143 & 760 \\
\hline 1712 & & 54 & 20 & 24 & 21 & 53 & 383 & 59 & 144 & 758 \\
\hline 1713 & & 50 & 15 & 25 & 25 & 55 & 413 & 71 & 194 & 848 \\
\hline 1714 & & 53 & 22 & 26 & 25 & 51 & 416 & 71 & 166 & 830 \\
\hline 1715 & & 53 & 15. & 26 & 29 & 46 & 423 & 78 & 156 & 826 \\
\hline 1716 & & 56 & 16 & 32 & 27 & 61 & 466 & 76 & 192 & 926 \\
\hline 1717 & & 52 & 25 & 21 & 24 & 68 & 433 & 84 & 169 & 876 \\
\hline 1718 & & 63 & 18 & 32 & 27 & 51 & 484 & 73 & 193 & 941 \\
\hline 1719 & & 36 & 15 & 34 & 22 & 71 & 474 & 89 & 158 & 899 \\
\hline 1720 & & 65 & 24 & 22 & 33 & 63 & 510 & 66 & 204 & 987. \\
\hline 1721 & & 46 & 27 & 38 & 25 & 69 & 494 & 91 & 180 & 970 \\
\hline 1722 & & 63 & 24 & 30 & 35 & 64 & 504 & 69 & 195 & 984 \\
\hline 1723 & & 41 & 18 & 32 & 26 & 48 & 479 & 77 & 198 & 919 \\
\hline 1724 & & 58 & 20 & 30 & 25 & 53 & 446 & 87. & 170 & 889 \\
\hline 1725 & & 55 & 29 & 28 & 30 & 66 & 466 & 70 & 161 & 905 \\
\hline 1726 & & 46 & 19 & 25 & 28 & 57 & 526 & 71 & 204 & 976 \\
\hline 1727 & & 53. & 23 & 38 & 27 & 60 & 522 & 80 & 166 & 969 \\
\hline 1728 & & 52 & 32 & 42 & 36 & 51 & 567. & 90 & 214 & 1.084 \\
\hline 1729 & & 47 & 22 & 36 & 24 & 61 & 522 & 77 & 185 & 974 \\
\hline 1730 & & 58 & 21 & 45 & 36 & 62 & 548 & 92 & 179 & 1.041 \\
\hline 1731 & & 56 & 19 & 36 & 28 & 65 & 549. & 104 & 200 & 1.057 \\
\hline 1732 & & 48 & 28 & 34 & 38 & 58 & 571 & 88 & 196 & 1.061 \\
\hline
\end{tabular}




\begin{tabular}{|c|c|c|c|c|c|c|c|c|c|}
\hline $\begin{array}{l}1733 \\
1734\end{array}$ & $\begin{array}{l}45 \\
41\end{array}$ & $\begin{array}{l}22 \\
30\end{array}$ & $\begin{array}{l}35 \\
36\end{array}$ & $\begin{array}{l}33 \\
35\end{array}$ & $\begin{array}{l}70 \\
60\end{array}$ & $\begin{array}{l}510 \\
538\end{array}$ & $\begin{array}{l}92 \\
91\end{array}$ & $\begin{array}{l}176 \\
200\end{array}$ & $\begin{array}{r}983 \\
1.031\end{array}$ \\
\hline 1735 & 32 & 31 & 24 & 33 & 44 & 478 & 82 & 184 & 908 \\
\hline 1736 & 54 & 20 & 31 & 38 & 62 & 512 & 83 & 173 & 973 \\
\hline 1737 & 41 & 27 & 30 & 27 & 45 & 469 & 78 & 152 & 869 \\
\hline 1738 & 35 & 18 & 23 & 17 & 58 & 425 & 73 & 116 & 765 \\
\hline 1739 & 43 & 21 & 28 & 35 & 57 & 497 & 72 & 161 & 914 \\
\hline 1740 & 32 & 25 & 26 & 36 & 56 & 466 & 84 & 152 & 877 \\
\hline 1741 & 43 & 18 & 30 & 26 & 47 & 468 & 74 & 168 & 874 \\
\hline 1742 & 40 & 18 & 37 & 23 & 53 & 530 & 70 & 182 & 953 \\
\hline 1743 & 47 & 28 & 29 & 35 & 51 & 558 & 73 & 194 & 1.015 \\
\hline 1744 & 51 & 27 & 37 & 31 & 50 & 548 & 80 & 179 & 1.003 \\
\hline 1745 & 38 & 23 & 36 & 27 & 48 & 532 & 78 & 173 & 955 \\
\hline 1746 & 35 & 20 & 30 & 26 & 50 & 456 & 64 & 142 & 823 \\
\hline 1747 & 32 & 14 & 18 & 35 & 48 & 438 & 56 & 150 & 791 \\
\hline 1748 & 37 & 22 & 33 & 32 & 45 & 483 & 59 & 155 & 866 \\
\hline 1749 & 23 & 18 & 26 & 33 & 43 & 454 & 55 & 141 & 793 \\
\hline 1750 & 37 & 29 & 34 & 27 & 42 & 554 & 63 & 194 & 980 \\
\hline 1751 & 20 & 22 & 17 & 24 & 32 & 400 & 43 & 116 & 674 \\
\hline 1752 & 21 & 19 & 30 & 34 & 58 & 532 & 58 & 168 & 920 \\
\hline 1753 & 27 & 19 & 23 & 36 & 49 & 574 & 55 & 180 & 963 \\
\hline 1754 & 26 & 30 & 27 & 35 & 47 & 558 & 62 & 148 & 933 \\
\hline 1755 & 33 & 20 & 26 & 31 & 58 & 539 & 75 & 187 & 969 \\
\hline 1756 & 42 & 26 & 32 & 40 & 64 & 692 & 76 & 247 & 1.219 \\
\hline 1757 & 40 & 29 & 28 & 33 & 64 & 729 & 75 & 231 & 1.229 \\
\hline 1758 & 44 & 28 & 35 & 40 & 53 & 629 & 73 & 225 & 1.127 \\
\hline 1759 & 49 & 38 & 35 & 38 & 47 & 647 & 80 & 253 & 1.187 \\
\hline 1760 & 39 & 25 & 23 & 28 & 53 & 596 & 81 & 183 & 1.028 \\
\hline 1761 & 52 & 38 & 36 & 55 & 60 & 584 & 73 & 179 & 1.077 \\
\hline 1762 & 39 & 25 & 31 & 35 & 55 & 656 & 99 & 225 & 1.165 \\
\hline 1763 & 50 & 15 & 30 & 33 & 55 & 579 & 79 & 196 & 1.037 \\
\hline 1764 & 43 & 16 & 21 & 26 & 55 & 551 & 71 & 185 & 968 \\
\hline 1765 & 48 & 25 & 25 & 26 & 60 & 623 & 71 & 210 & 1.088 \\
\hline 1766 & 31 & 18 & 19 & 33 & 53 & 494 & 59 & 191 & 898 \\
\hline 1767 & 56 & 26 & 25 & 24 & 49 & 564 & 74 & 198 & 1.016 \\
\hline 1768 & 33 & 20 & 22 & 29 & 43 & 491 & 67 & 172 & 877 \\
\hline 1769 & 37 & 21 & 14 & 27 & 38 & 540 & 70 & 179 & 926 \\
\hline 1770 & 32 & 23. & 24 & 26 & 45 & 526 & 63 & 171 & 910 \\
\hline 1771 & 42 & 19 & 26 & 20 & 49 & 583 & 76 & 188 & 1.003 \\
\hline 1772 & 35 & 23 & 22 & 28 & 48 & 604 & 66 & 199 & 1.025 \\
\hline 1773 & 44 & 25 & 16 & 31 & 45 & 587 & 70 & 219 & 1.037 \\
\hline 1774 & 37 & 15 & 19 & 26 & 47 & 523 & 74 & 205 & 946 \\
\hline 1775 & 51 & 22 & 15 & 33 & 50 & 581 & 66 & 196 & 1.014 \\
\hline 1776 & 49 & 18 & 17 & 27 & 43 & 561 & 62 & 196 & 973 \\
\hline 1777 & 54 & 23 & 21 & 33 & 51 & 568 & 82 & 216 & 1.048 \\
\hline 1778 & 41 & 23 & 21 & 29 & 56 & 563 & 70 & 165 & 968 \\
\hline 1779 & 53 & 33 & 26 & 28 & 60 & 523 & 68 & 223 & 1.014 \\
\hline 1780 & 39 & 18 & 24 & 27 & 50 & 516 & 63 & 182 & 919 \\
\hline 1781 & 50 & 27 & 26 & 33 & 51 & 484 & 70 & 174 & 915 \\
\hline
\end{tabular}




\begin{tabular}{|c|c|c|c|c|c|c|c|c|c|}
\hline 1782 & 31 & 22 & 28 & 37 & 63 & 514 & 58 & 189 & 942 \\
\hline 1783 & 35 & 38 & 26 & 28 & 58 & 545 & 77 & 210 & 1.017 \\
\hline 1784 & 44 & 19 & 28 & 35 & 65 & 552 & 92 & 217 & 1.052 \\
\hline 1785 & 34 & 28 & 20 & 23 & 45 & 474 & 49 & 176 & 849 \\
\hline 1786 & 41 & 17 & 25 & 24 & 56 & 414 & 66 & 201 & 844 \\
\hline 1787 & 39 & 15 & 24 & 27 & 38 & 375 & 60 & 138 & 716 \\
\hline 1788 & 39 & 24 & 48 & 41 & 55 & 526 & 68 & 198 & 999 \\
\hline 1789 & 33 & 30 & 54 & 26 & 39 & 464 & 74 & 192 & 912 \\
\hline 1790 & 64 & 33 & 68 & 40 & 60 & 547 & 89 & 240 & 1.141 \\
\hline 1791 & 43 & 22 & 81 & 42 & 59 & 611 & 86 & 221 & 1.165 \\
\hline 1792 & 35 & 34 & 85 & 35 & 57 & 525 & 74 & 254 & 1.099 \\
\hline 1793 & 41 & 24 & 85 & 33 & 57 & 526 & 68 & 203 & 1.037 \\
\hline 1794 & 36 & 20 & 65 & 33 & 42 & 475 & 60 & 185 & 916 \\
\hline 1795 & 37 & 25 & 79 & 31 & 72 & 582 & 79 & 246 & 1.151 \\
\hline 1796 & 44 & 28 & 71 & 34 & 54 & 573 & 75 & 237 & 1.116 \\
\hline 1797 & 42 & 18 & 77 & 31 & 51 & 513 & 74 & 229 & 1.035 \\
\hline 1798 & 36 & 27 & 63 & 22 & 54 & 485 & 57 & 198 & 942 \\
\hline 1799 & 54 & 28 & 64 & 29 & 59 & 595 & 55 & 241 & 1.125 \\
\hline \multicolumn{10}{|c|}{$\begin{array}{l}\text { 1.= Parroquia de San Dionisio. } \\
\text { 2.= Parroquia de San Juan de los Caballeros. } \\
\text { 3.= Parroquia de San Lucas. } \\
\text { 4.= Parroquia de San Marcos. } \\
\text { 5.= Parroquia de San Mateo. } \\
\text { 6.= Parroquia de San Miguel. } \\
\text { 7.= Parroquia de San Salvador. } \\
\text { 8.= Parroquia de Santiago. }\end{array}$} \\
\hline
\end{tabular}

\section{CUADRO 22}

Matrimonios. Jerez de la Frontera

$\begin{array}{lrrrrrrrrr} & \mathbf{1 .} & \mathbf{2 .} & \mathbf{3 .} & \mathbf{4 .} & \mathbf{5 .} & \mathbf{6 .} & \mathbf{7} & \mathbf{8 .} & \text { Total } \\ 1600 & 25 & 11 & 15 & 25 & 3 & 44 & 35 & 30 & \mathbf{1 8 8} \\ 1601 & 23 & 6 & 11 & 40 & 2 & 57 & 42 & 79 & 260 \\ 1602 & 41 & 10 & 9 & 22 & 3 & 146 & 26 & 51 & 308 \\ 1603 & 19 & 4 & 13 & 14 & 5 & 142 & 17 & 36 & 250 \\ 1604 & 17 & 5 & 6 & 5 & 12 & 70 & 20 & 20 & 155 \\ 1605 & 18 & - & 14 & 7 & 12 & 101 & 18 & 29 & 199 \\ 1606 & 13 & 5 & 8 & 11 & 7 & 53 & 15 & 37 & 159 \\ 1607 & 13 & 2 & 11 & 10 & 17 & 78 & 19 & 28 & 178 \\ 1608 & 27 & 11 & 9 & 11 & 7 & 124 & 25 & 25 & 239 \\ 1609 & 27 & 3 & 12 & 17 & 17 & 118 & 28 & 26 & 248 \\ 1610 & 26 & 6 & 12 & 11 & 14 & 130 & 21 & 21 & 241 \\ 1611 & 20 & 31 & 17 & 17 & 18 & 122 & 30 & 11 & 266 \\ 1612 & 25 & 19 & 10 & 15 & 12 & 115 & 30 & 13 & 239 \\ 1613 & 15 & 1 & 10 & 19 & 20 & 97 & 10 & 10 & 182\end{array}$




\begin{tabular}{|c|c|c|c|c|c|c|c|c|c|}
\hline 1614 & 20 & 14 & 10 & 18 & 14 & 93 & 35 & 14 & 218 \\
\hline 1615 & 20 & 6 & 14 & 14 & 12 & 133 & 13 & 9 & 221 \\
\hline 1616 & 23 & 6 & 4 & 14 & 6 & 123 & 24 & 19 & 219 \\
\hline 1617 & 18 & 5 & 11 & 13 & 11 & 122 & 22 & 2 & 204 \\
\hline 1618 & 17 & 12 & 10 & 11 & 7 & 115 & 27 & 22 & 221 \\
\hline 1619 & 20 & 10 & 11 & 19 & 10 & 117 & 25 & 28 & 240 \\
\hline 1620 & 25 & 13 & 8 & 16 & 14 & 71 & 33 & 40 & 220 \\
\hline 1621 & 13 & 11 & 11 & 18 & 13 & 35 & 33 & 30 & 164 \\
\hline 1622 & 23 & 8 & 10 & 16 & 11 & 73 & 22 & 23 & 186 \\
\hline 1623 & 16 & 8 & 10 & 20 & 9 & 69 & 21 & 34 & 187 \\
\hline 1624 & 22 & 12 & 8 & 15 & 9 & 121 & 30 & 35 & 252 \\
\hline 1625 & 17 & 8 & 5 & 14 & 14 & 90 & 30 & 37 & 215 \\
\hline 1626 & 29 & 5 & 10 & 15 & 12 & 63 & 15 & 32 & 181 \\
\hline 1627 & 22 & 7 & 14 & 11 & 18 & 44 & 30 & 37 & 183 \\
\hline 1628 & 28 & 5 & 6 & 14 & 12 & 77 & 19 & 40 & 201 \\
\hline 1629 & 19 & 9 & 9 & 7 & 4 & 64 & 25 & 33 & 170 \\
\hline 1630 & 23 & 8 & 5 & 21 & 13 & 55 & 26 & 34 & 185 \\
\hline 1631 & 22 & 9 & 7 & 8 & 11 & 54 & 21 & 28 & 160 \\
\hline 1632 & 21 & 4 & 10 & 13 & 17 & 73 & 19 & 42 & 199 \\
\hline 1633 & 19 & 7 & 13 & 6 & 16 & 81 & 24 & 49 & 215 \\
\hline 1634 & 15 & 17 & 10 & 17 & 9 & 76 & 26 & 51 & 221 \\
\hline 1635 & 21 & 13 & 11 & 13 & 16 & 110 & 20 & 52 & 256 \\
\hline 1636 & 14 & 11 & 8 & 10 & 7 & 107 & 12 & 33 & 202 \\
\hline 1637 & 19 & 8 & 8 & 11 & 6 & 107 & 12 & 31 & 202 \\
\hline 1638 & 25 & 7 & 10 & 13 & 10 & 119 & 25 & 52 & 261 \\
\hline 1639 & 36 & 12 & 13 & 19 & 19 & 157 & 28 & 41 & 325 \\
\hline 1640 & 24 & 13 & 10 & 15 & 14 & 149 & 24 & 45 & 294 \\
\hline 1641 & 21 & 8 & 5 & 10 & 13 & 142 & 28 & 63 & 290 \\
\hline 1642 & 14 & 10 & 6 & 19 & 12 & 132 & 20 & 42 & 255 \\
\hline 1643 & 16 & 6 & 12 & 8 & 12 & 100 & 17 & 41 & 212 \\
\hline 1644 & 17 & 6 & 10 & 11 & 15 & 113 & 13 & 43 & 228 \\
\hline 1645 & 25 & 16 & 6 & 10 & 9 & 114 & 14 & 46 & 240 \\
\hline 1646 & 18 & 12 & 8 & 13 & 19 & 179 & 19 & 47 & 315 \\
\hline 1647 & 18 & 10 & 16 & 12 & 11 & 111 & 21 & 43 & 242 \\
\hline 1648 & 7 & 7 & 8 & 11 & 18 & 124 & 16 & 33 & 224 \\
\hline 1649 & 22 & 17 & 11 & 12 & 16 & 189 & 25 & 63 & 355 \\
\hline 1650 & 20 & 10 & 15 & 15 & 24 & 207 & 55 & 83 & 429 \\
\hline 1651 & 26 & 10 & 13 & 21 & 18 & 159 & 35 & 62 & 346 \\
\hline 1652 & 13 & 4 & 7 & 16 & 16 & 133 & 29 & 53 & 271 \\
\hline 1653 & 20 & 8 & 9 & 12 & 12 & 180 & 28 & 52 & 321 \\
\hline 1654 & 19 & 11 & 7 & 9 & 14 & 139 & 24 & 60 & 283 \\
\hline 1655 & 16 & 6 & 8 & 10 & 17 & 126 & 23 & 65 & 271 \\
\hline 1656 & 10 & 8 & 12 & 12 & 19 & 157 & 23 & 52 & 293 \\
\hline 1657 & 27 & 3 & 7 & 9 & 23 & 139 & 17 & 54 & 279 \\
\hline 1658 & 10 & 6 & 5 & 7 & 5 & 84 & 11 & 35 & 163 \\
\hline 1659 & 16 & 7 & 5 & 6 & 8 & 111 & 17 & 42 & 212 \\
\hline 1660 & 19 & 6 & 8 & 14 & 16 & 129 & 13 & 33 & 238 \\
\hline 1661 & 11 & 5 & 13 & 9 & 19 & 178 & 14 & 51 & 300 \\
\hline 1662 & 23 & 8 & 11 & 9 & 11 & 160 & 23 & 66 & 311 \\
\hline
\end{tabular}




\begin{tabular}{|c|c|c|c|c|c|c|c|c|c|}
\hline 1663 & 12 & 10 & 3 & 12 & 9 & 133 & 19 & 47 & 245 \\
\hline 1664 & 17 & 5 & 7 & 11 & 7 & 164 & 27 & 51 & 289 \\
\hline 1665 & 23 & 10 & 9 & 12 & 11 & 135 & 16 & 46 & 262 \\
\hline 1666 & 14 & 8 & 2 & 11 & 12 & 141 & 27 & 39 & 254 \\
\hline 1667 & 10 & 17 & 6 & 8 & 10 & 115 & 27 & 53 & 246 \\
\hline 1668 & 11 & 2 & 7 & 13 & 15 & 124 & 8 & 57 & 237 \\
\hline 1669 & 8 & 11 & 10 & 4 & 7 & 134 & 18 & 56 & 248 \\
\hline 1670 & 17 & 12 & 1 & 10 & 19 & 156 & 20 & 45 & 280 \\
\hline 1671 & 17 & 8 & 8 & 14 & 9 & 169 & 20 & 57 & 302 \\
\hline 1672 & 18 & 10 & 4 & 11 & 12 & 119 & 24 & 47 & 245 \\
\hline 1673 & 10 & 7 & 9 & 5 & 19 & 136 & 18 & 43 & 247 \\
\hline 1674 & 12 & 11 & 8 & 19 & 8 & 133 & 14 & 63 & 268 \\
\hline 1675 & 19 & 8 & 6 & 13 & 9 & 154 & 16 & 52 & 277 \\
\hline 1676 & 20 & 8 & 8 & 12 & 19 & 137 & 19 & 69 & 292 \\
\hline 1677 & 25 & 9 & 10 & 8 & 20 & 176 & 24 & 68 & 340 \\
\hline 1678 & 14 & 4 & 7 & 15 & 6 & 98 & 11 & 26 & 181 \\
\hline 1679 & 12 & 5 & 13 & 11 & 9 & 118 & 31 & 50 & 249 \\
\hline 1680 & 14 & 12 & 9 & 14 & 11 & 147 & 24 & 52 & 283 \\
\hline 1681 & 18 & 8 & 5 & 13 & 14 & 180 & 24 & 57 & 319 \\
\hline 1682 & 19 & 10 & 9 & 18 & 16 & 191 & 28 & 64 & 355 \\
\hline 1683 & 13 & 4 & 7 & 14 & 13 & 145 & 11 & 48 & 255 \\
\hline 1684 & 11 & 7 & 6 & 3 & 8 & 100 & 14 & 32 & 181 \\
\hline 1685 & 10 & 8 & 4 & 9 & 8 & 121 & 12 & 39 & 211 \\
\hline 1686 & 13 & 6 & 8 & 7 & 2 & 152 & 14 & 55 & 257 \\
\hline 1687 & 12 & 8 & 11 & 11 & 22 & 177 & 19 & 68 & 328 \\
\hline 1688 & 13 & 9 & 9 & 10 & 16 & 150 & 19 & 51 & 277 \\
\hline 1689 & 22 & 9 & 9 & 15 & 14 & 162 & 20 & 68 & 319 \\
\hline 1690 & 20 & 5 & 13 & 9 & 12 & 157 & 22 & 46 & 284 \\
\hline 1691 & 15 & 2 & 9 & 9 & 8 & 150 & 16 & 55 & 264 \\
\hline 1692 & 17 & 10 & 10 & 8 & 11 & 142 & 16 & 53 & 267 \\
\hline 1693 & 16 & 10 & 7. & 12 & 13 & 154 & 21 & 51 & 284 \\
\hline 1694 & 13 & 6 & 9 & 7 & 19 & 138 & 31 & 46 & 269 \\
\hline 1695 & 13 & 5 & 8 & 9 & 11 & 120 & 26 & 45 & 237 \\
\hline 1696 & 19 & 10 & 11 & 12 & 17 & 187 & 17 & 61 & 334 \\
\hline 1697 & 17 & 2 & 12 & 2 & 8 & 143 & 16 & 35 & 235 \\
\hline 1698 & 9 & 2 & 5 & 10 & 12 & 149 & 20 & 58 & 265 \\
\hline 1699 & 15 & 12 & 7 & 11 & 11 & 162 & 20 & 55 & 293 \\
\hline 1700 & 9 & 8 & 13 & 4 & 14 & 140 & 21 & 62 & 271 \\
\hline 1701 & 8 & 7 & 7 & 10 & 13 & 148 & 24 & 74 & 291 \\
\hline 1702 & 10 & 5 & 6 & 4 & 14 & 150 & 20 & 49 & 258 \\
\hline 1703 & 10 & 5 & 10 & 12 & 17 & 151 & 12 & 54 & 271 \\
\hline 1704 & 6 & 7 & 10 & 9 & 17 & 138 & 17 & 55 & 259 \\
\hline 1705 & 7 & 7 & 10 & 7 & 11 & 139 & 22 & 26 & 229 \\
\hline 1706 & 9 & 8 & 11 & 6 & 14 & 156 & 19 & 59 & 282 \\
\hline 1707 & 13 & 2 & 5 & 6 & 8 & 164 & 17 & 39 & 254 \\
\hline 1708 & 8 & 3 & 7 & 5 & 9 & 101 & 18 & 43 & 194 \\
\hline 1709 & 16 & 2 & 10 & 5 & 6 & 104 & 13 & 38 & 194 \\
\hline 1710 & 21 & 10 & 18 & 19 & 23 & 211 & 23 & 84 & 409 \\
\hline 1711 & 14 & 9 & 14 & 10 & 22 & 203 & 30 & 97 & 399 \\
\hline
\end{tabular}




\begin{tabular}{|c|c|c|c|c|c|c|c|c|c|}
\hline 1712 & 20 & 5 & 4 & 10 & 16 & 183 & 20 & 72 & 330 \\
\hline 1713 & 11 & 5 & 8 & 8 & 9 & 172 & 25 & 74 & 312 \\
\hline 1714 & 10 & 6 & 12 & 6 & 10 & 142 & 18 & 44 & 248 \\
\hline 1715 & 10 & 8 & 9 & 11 & 8 & 125 & 14 & 43 & 228 \\
\hline 1716 & 20 & 8 & 11 & 11 & 9 & 165 & 17 & 44 & 285 \\
\hline 1717 & 15 & 3 & 13 & 5 & 16 & 164 & 18 & 52 & 286 \\
\hline 1718 & 18 & 6 & 10 & 8 & 14 & 189 & 26 & 75 & 346 \\
\hline 1719 & 10 & 6 & 5 & 12 & 12 & 148 & 16 & 54 & 263 \\
\hline 1720 & 6 & 7 & 8 & 7 & 9 & 160 & 24 & 63 & 284 \\
\hline 1721 & 17 & 7 & 7 & 13 & 6 & 140 & 16 & 43 & 249 \\
\hline 1722 & 12 & 7 & 12 & 16 & 14 & 117 & 16 & 58 & 252 \\
\hline 1723 & 6 & 3 & 7 & 5 & 11 & 108 & 17 & 55 & 212 \\
\hline 1724 & 12 & 5 & 9 & 6 & 11 & 114 & 15 & 35 & 207 \\
\hline 1725 & 10 & 3 & 13 & 5 & 8 & 131 & 16 & 34 & 220 \\
\hline 1726 & 19 & 8 & 10 & 8 & 12 & 139 & 18 & 59 & 273 \\
\hline 1727 & 10 & 8 & 8 & 16 & 14 & 120 & 26 & 49 & 251 \\
\hline 1728 & 9 & 9 & 8 & 10 & 17 & 153 & 25 & 46 & 277 \\
\hline 1729 & 15 & 7 & 9 & 11 & 13 & 145 & 17 & 45 & 262 \\
\hline 1730 & 12 & 2 & 14 & 8 & 11 & 123 & 26 & 49 & 245 \\
\hline 1731 & 12 & 4 & 5 & 10 & 14 & 118 & 22 & 43 & 228 \\
\hline 1732 & 12 & 11 & 5 & 11 & 20 & 137 & 24 & 59 & 279 \\
\hline 1733 & 6 & 5 & 9 & 6 & 15 & 171 & 25 & 50 & 287 \\
\hline 1734 & 4 & 7 & 14 & 6 & 16 & 130 & 14 & 42 & 233 \\
\hline 1735 & 13 & 6 & 8 & 7 & 2 & 155 & 12 & 35 & 238 \\
\hline 1736 & 11 & 3 & 9 & 9 & 8 & 124 & 11 & 42 & 217 \\
\hline 1737 & 13 & 7 & 6 & 7 & 5 & 95 & 12 & 42 & 187 \\
\hline 1738 & 4 & 2 & 5 & 3 & 8 & 90 & 13 & 43 & 168 \\
\hline 1739 & 12 & 9 & 13 & 17 & 19 & 182 & 15 & 43 & 310 \\
\hline 1740 & 10 & 5 & 10 & 10 & 8 & 152 & 13 & 55 & 263 \\
\hline 1741 & 10 & 7 & 11 & 6 & 11 & 149 & 18 & 59 & 270 \\
\hline 1742 & 14 & 14 & 6 & 11 & 18 & 193 & 30 & 69 & 355 \\
\hline 1743 & 19 & 7 & 9 & 18 & 24 & 232 & 23 & 69 & 401 \\
\hline 1744 & 11 & 4 & 7 & 8 & 18 & 148 & 23 & 45 & 264 \\
\hline 1745 & 8 & 7 & 13 & 7 & 7 & 125 & 17 & 34 & 218 \\
\hline 1746 & 10 & 5 & 4 & 7 & 8 & 104 & 12 & 29 & 179 \\
\hline 1747 & 10 & 3 & 8 & 7 & 8 & 102 & 20 & 45 & 203 \\
\hline 1748 & 8 & 7 & 6 & 7 & 8 & 111 & 12 & 33 & .192 \\
\hline 1749 & 3 & 6 & 5 & 7 & 19 & 134 & 12 & 56 & 242 \\
\hline 1750 & 5 & 4 & 8 & 10 & 7 & 132 & 11 & 39 & 216 \\
\hline 1751 & 5 & 6 & 7 & 11 & 21 & 145 & 22 & 40 & 257 \\
\hline 1752 & 13 & 6 & 10 & 9 & 15 & 155 & 13 & 39 & 260 \\
\hline 1753 & 10 & 9 & 6 & 8 & 7 & 168 & 23 & 40 & 271 \\
\hline 1754 & 11 & 5 & 8 & 11 & 10 & 133 & 13 & 59 & 250 \\
\hline 1755 & 13 & 12 & 10 & 15 & 16 & 211 & 26 & 51 & 354 \\
\hline 1756 & 10 & 6 & 13 & 11 & 16 & 244 & 28 & 55 & 383 \\
\hline 1757 & 13 & 16 & 16 & 14 & 18 & 211 & 29 & 70 & 387 \\
\hline 1758 & 10 & 13 & 11 & 3 & 15 & 161 & 21 & 60 & 294 \\
\hline 1759 & 16 & 9 & 9 & 4 & 9 & 159 & 23 & 74 & 303 \\
\hline 1760 & 17 & 9 & 6 & 8 & 17 & 143 & 17 & 31 & 248 \\
\hline
\end{tabular}




\begin{tabular}{|c|c|c|c|c|c|c|c|c|c|}
\hline 1761 & 4 & 5 & 8 & 6 & 13 & 157 & 27 & 46 & 266 \\
\hline 1762 & 16 & 4 & 4 & 11 & 15 & 191 & 19 & 50 & 310 \\
\hline 1763 & 10 & 2 & 9 & 10 & 10 & 120 & 21 & 50 & 232 \\
\hline 1764 & 7 & 8 & 8 & 15 & 12 & 148 & 11 & 52 & 261 \\
\hline 1765 & 11 & 7 & 7 & 8 & 4 & 108 & 15 & 34 & 194 \\
\hline 1766 & 4 & 4 & 3 & 10 & 8 & 137 & 15 & 41 & 222 \\
\hline 1767 & 10 & 7 & 4 & 8 & 8 & 131. & 10 & 44 & 222 \\
\hline 1768 & 5 & 5 & 5 & 5 & 9 & 129 & 8 & 52 & 218 \\
\hline 1769 & 4 & 4 & 5 & 8 & 6 & 127 & 14 & 26 & 194 \\
\hline 1770 & 7 & 6 & 4 & 10 & 14 & 162 & 15 & 60 & 278 \\
\hline 1771 & 8 & 8 & 8 & 15 & 21 & 211 & 22 & 65 & 358 \\
\hline 1772 & 11 & 10 & 4 & 8 & 14 & 183 & 29 & 55 & 314 \\
\hline 1773 & 11 & 5 & 6 & 7 & 15 & 141 & 19 & 56 & 260 \\
\hline 1774 & 10 & 7 & 5 & 10 & 7 & 141 & 7 & 41 & 228 \\
\hline 1775 & 18 & 10 & 6 & 16 & 12 & 167 & 15 & 48 & 292 \\
\hline 1776 & 13 & 13 & 8 & 5 & 10 & 201 & 22 & 52 & 324 \\
\hline 1777 & 6 & 11 & 5 & 12 & 6 & 146 & 20 & 35 & 241 \\
\hline 1778 & 5 & 7 & 2 & 6 & 9 & 122 & 17 & 48 & 216 \\
\hline 1779 & 13 & 3 & 7 & 13 & 10 & 115 & 14 & 46 & 221 \\
\hline 1780 & 11 & 9 & 5 & 7 & 13 & 129 & 18 & 47 & 239 \\
\hline 1781 & 10 & 5 & 1 & 5 & 7 & 121 & 19 & 38 & 206 \\
\hline 1782 & 10 & 8 & 4 & 9 & 18 & 204 & 12 & 72 & 337 \\
\hline 1783 & 6 & 7 & 11 & 8 & 10 & 181 & 21 & 56 & 300 \\
\hline 1784 & 15 & 8 & 6 & 11 & 16 & 166 & 21 & 55 & 298 \\
\hline 1785 & 6 & 4 & 11 & 4 & 2 & 105 & 20 & 34 & 186 \\
\hline 1786 & 15 & 6 & 5 & 2 & 11 & 110 & 16 & 27 & 192 \\
\hline 1787 & 13 & 8 & 7 & 12 & 15 & 136 & 17 & 53 & 261 \\
\hline 1788 & 10 & 6 & 5 & 8 & 16 & 163 & 9 & 43 & 260 \\
\hline 1789 & 9 & 4 & 4 & 15 & 12 & 153 & 20 & 66 & 283 \\
\hline 1790 & 17 & 10 & 9 & 13 & 14 & 197 & 25 & 85 & 370 \\
\hline 1791 & 7 & 8 & 12 & 4 & 11 & 215 & 9 & 68 & 334 \\
\hline 1792 & 11 & 3 & 7 & 7 & 9 & 214 & 22 & 64 & 337 \\
\hline 1793 & 11 & 4 & 8 & 10 & 11 & 158 & 16 & 65 & 283 \\
\hline 1794 & 11 & 4 & 5 & 17 & 18 & 168 & 21 & 55 & 299 \\
\hline 1795 & 6 & 8 & 10 & 10 & 8 & 185 & 18 & 60 & 305 \\
\hline 1796 & 7 & 6 & 7 & 11 & 9 & 141 & 13 & 51 & 245 \\
\hline 1797 & 5 & 3 & 10 & 8 & 11 & 142 & 16 & 52 & 247 \\
\hline 1798 & 6 & 2 & 5 & 2 & 12 & 135 & 23 & 70 & 255 \\
\hline 1799 & 14 & 10 & 5 & 3 & 16 & 172 & 19 & 65 & 304 \\
\hline \multicolumn{10}{|c|}{$\begin{array}{l}\text { 1.= Parroquia de San Dionisio. } \\
\text { 2.= Parroquia de San Juan de los Caballeros. } \\
\text { 3.= Parroquia de San Lucas. } \\
\text { 4.= Parroquia de San Marcos. } \\
\text { 5.= Parroquia de San Mateo. } \\
\text { 6.= Parroquia de San Miguel. } \\
\text { 7.= Parroquia de San Salvador. } \\
\text { 8.= Parroquia de Santiago. }\end{array}$} \\
\hline
\end{tabular}




\section{CUADRO 23}

Defunciones. Jerez de la Frontera

$\begin{array}{llllllll}\text { 1. } & \text { 2. } & \text { 3. } & \text { 4. } & \text { 5. } & \text { 6. } & \text { 7. } & \text { 8. }\end{array}$

1640

1641

1642

1643

1644

1645

1646

1647

1648

1649

1650

1651

1652

1653

1654

1655

1656

1657

1658

1659

1660

1661

1662

1663

1664

1665

1666

1667

1668

1669

1670

1671

1672

1673

1674

1675

1676

1677

1678

1679

1680

1681
5

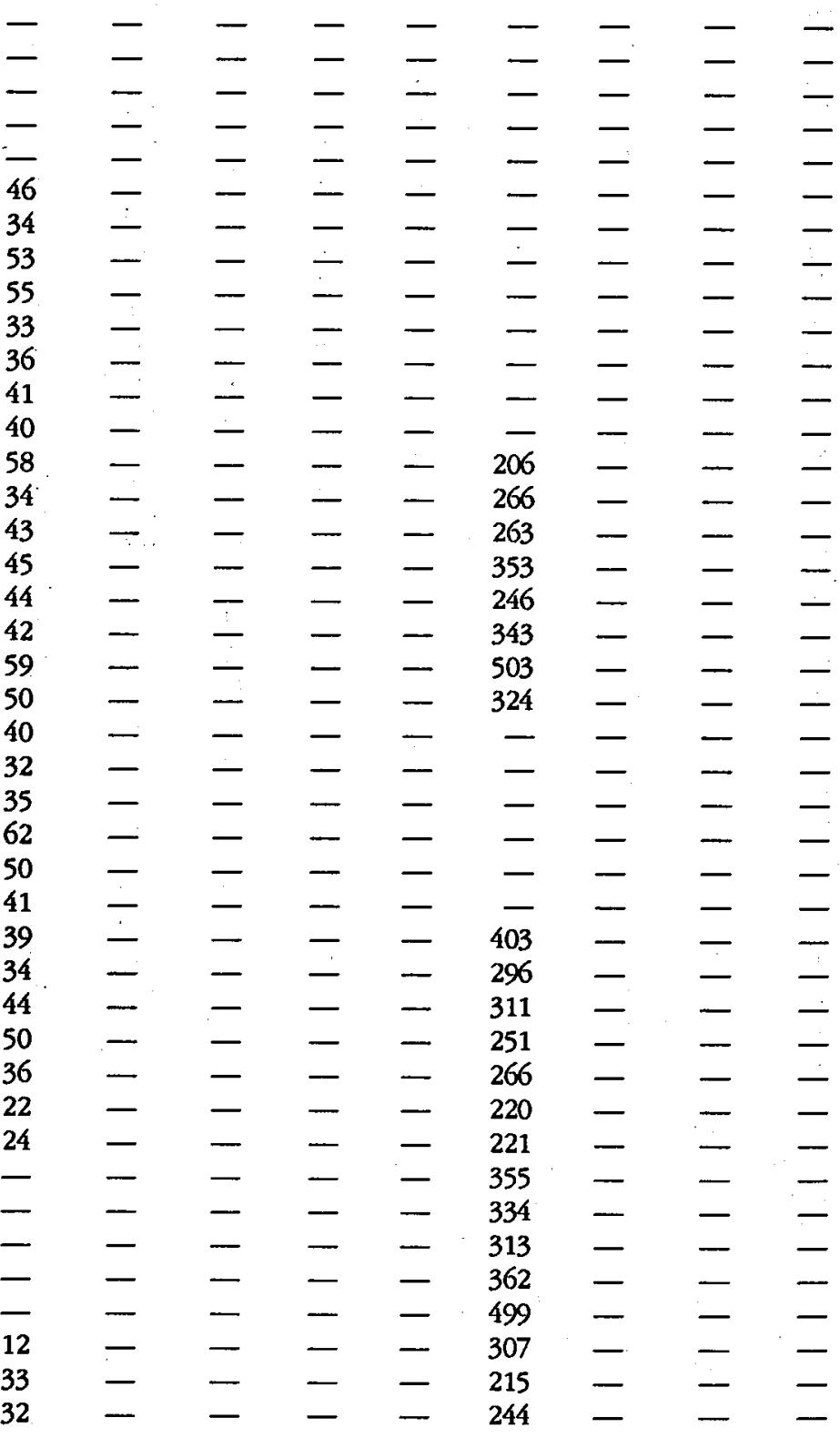




\begin{tabular}{|c|c|c|c|c|c|c|c|c|c|}
\hline 1682 & 36 & - & - & - & - & 210 & - & - & - \\
\hline 1683 & 35 & - & - & - & - & 316 & - & - & - \\
\hline 1684 & 37 & - & - & - & - & 528 & - & - & - \\
\hline 1685 & 41 & - & - & - & - & 428 & - & - & - \\
\hline 1686 & 29 & - & - & - & - & 205 & - & - & - \\
\hline 1687 & 16 & - & - & - & - & 159 & - & - & - \\
\hline 1688 & 16 & - & - & - & - & 195 & - & - & - \\
\hline 1689 & 30 & - & - & - & - & 222 & - & - & - \\
\hline 1690 & 21 & - & - & - & - & 162 & - & - & - \\
\hline 1691 & 25 & - & - & - & - & 196 & - & - & - \\
\hline 1692 & 33 & - & 9 & - & 一 & 230 & - & - & - \\
\hline 1693 & 44 & 5 & 17 & 24 & 31 & 214 & 39 & 95 & 469 \\
\hline 1694 & 38 & 16 & 12 & 26 & 30 & 248 & 43 & 105 & 518 \\
\hline 1695 & 52 & 17 & 23 & 32 & 50 & 535 & 109 & 202 & 1.020 \\
\hline 1696 & 47 & 24 & 28 & 45 & 45 & 508 & 110 & 224 & 1.031 \\
\hline 1697 & 57 & 23 & 22 & 26 & 38 & 439 & 86 & 165 & 856 \\
\hline 1698 & 31 & 18 & 20 & 14 & 18 & 278 & 51 & 91 & 521 \\
\hline 1699 & 23 & 13 & 20 & 23 & 17 & 220 & 54 & 102 & 472 \\
\hline 1700 & 24 & 12 & 20 & 12 & 10 & 211 & 37 & 75 & 401 \\
\hline 1701 & 21 & 6 & 14 & 18 & 11 & 177 & 41 & 67 & 355 \\
\hline 1702 & 22 & 10 & 12 & 24 & 11 & 187 & 19 & 73 & 358 \\
\hline 1703 & 24 & 14 & 24 & 17. & 17 & 218 & 25 & 83 & 422 \\
\hline 1704 & 14 & 12 & 14 & 18 & 21 & 193 & 26 & 76 & 374 \\
\hline 1705 & 42 & 19 & 31 & 31 & 22 & 297 & 54 & 116 & 612 \\
\hline 1706 & 20 & 14 & 20 & 8 & 20 & 206 & 24 & 96 & 408 \\
\hline 1707 & 19 & 22 & 19 & 20 & 26 & 197 & 28 & 61 & 392 \\
\hline 1708 & 22 & 14 & 28 & 22 & 36 & 277 & 29 & 114 & 542 \\
\hline 1709 & 105 & 65 & 106 & 44 & 83 & 853 & 129 & 510 & 1.895 \\
\hline 1710 & 15 & 11 & 11 & 6 & 22 & 97 & 26 & 101 & 289 \\
\hline 1711 & 15 & 8 & 10 & 9 & 26 & 145 & 38 & 56 & 307 \\
\hline 1712 & 27 & 8 & 19 & 20 & 38 & 241 & 42 & 79 & 474 \\
\hline 1713 & 19 & 8 & 18 & 17 & 19 & 193 & 31 & 54 & 359 \\
\hline 1714 & 16 & 9 & 12 & 16 & 28 & 216 & 36 & 75 & 408 \\
\hline 1715 & 26 & 16 & 14 & 15 & 15 & 220 & 16 & 69 & 391 \\
\hline 1716 & 29 & 7 & 15 & 16 & 20 & 179 & 30 & 75 & 371 \\
\hline 1717 & 17 & 15 & 8 & 14 & 19 & 161 & 21 & 55 & 310 \\
\hline 1718 & 24 & 12 & 19 & 22 & 17 & 184 & 25 & 84 & 387 \\
\hline 1719 & 23 & 15 & 13 & 15 & 23 & 182 & 36 & 76 & 383 \\
\hline 1720 & 16 & 10 & 22 & 18 & 25 & 227 & 24 & 92 & 434 \\
\hline 1721 & 25 & 4 & 17 & 19 & 28 & 230 & 23 & 81 & 427 \\
\hline 1722 & 24 & 15 & 19 & 16 & 17 & 188 & 14 & 77 & 370 \\
\hline 1723 & 28 & 14 & 18 & 7 & 25 & 213 & 24 & 86 & 415 \\
\hline 1724 & 28 & 18 & 23 & 19 & 22 & 215 & 36 & 88 & 449 \\
\hline 1725 & 27 & 12 & 12 & 19 & 22 & 186 & 24 & 59 & 361 \\
\hline 1726 & 32 & 13 & 17 & 14 & 27 & 208 & 39 & 85 & 435 \\
\hline 1727 & 23 & 29 & 14 & 23 & 22 & 213 & 29 & 66 & 419 \\
\hline 1728 & 24 & 11 & 18 & 17 & 23 & 172 & 24 & 68 & 357 \\
\hline 1729 & 32 & 9 & 13 & 20 & 27 & 210 & 38 & 74 & 423 \\
\hline 1730 & 27 & 18 & 17 & 16 & 27 & 245 & 39 & 84 & 473 \\
\hline
\end{tabular}




\begin{tabular}{|c|c|c|c|c|c|c|c|c|c|}
\hline 1731 & 32 & 15 & 23 & 23 & 32 & 250 & 39 & 81 & 495 \\
\hline 1732 & 24 & 12 & 20 & 25 & 29 & 261 & 41 & 102 & 514 \\
\hline 1733 & 23 & 17 & 19 & 21 & 39 & 275 & 36 & 97 & 527 \\
\hline 1734 & 31 & 21 & 15 & 13 & 19 & 335 & 31 & 74 & 539 \\
\hline 1735 & 26 & 19 & 10 & 18 & 28 & 244 & 36 & 92 & 473 \\
\hline 1736 & 22 & 21 & 16 & 26 & 33 & 322 & 36 & 105 & 581 \\
\hline 1737 & 42 & 24 & 24 & 34 & 39 & 382 & 38 & 178 & 761 \\
\hline 1738 & 30 & 19 & 25 & 43 & 40 & 411 & 42 & 146 & 756 \\
\hline 1739 & 18 & 8 & 22 & 16 & 15 & 232 & 36 & 91 & 438 \\
\hline 1740 & 21 & 12 & 21 & 19 & 20 & 237 & 29 & 104 & 463 \\
\hline 1741 & 26 & 16 & 16 & 26 & 19 & 258 & 25 & 90 & 476 \\
\hline 1742 & 21 & 15 & 13 & 22 & 19 & 282 & 45 & 104 & 521 \\
\hline 1743 & 35 & 13 & 14 & 12 & 24 & 234 & 33 & 91 & 456 \\
\hline 1744 & 32 & 7 & 17 & 20 & 19 & 239 & 32 & 92 & 458 \\
\hline 1745 & 34 & 14 & 27 & 29 & 24 & 308 & 46 & 127 & 609 \\
\hline 1746 & 26 & 8 & 10 & 24 & 19 & 355 & 43 & 125 & 610 \\
\hline 1747 & 31 & 15 & 20 & 28 & 43 & 276 & 28 & 128 & 549 \\
\hline 1748 & 31 & 20 & 17 & 17 & 15 & 296 & 56 & 105 & 557 \\
\hline 1749 & 34 & 16 & 24 & 25 & 21 & 223 & 46 & 82 & 471 \\
\hline 1750 & 25 & 13 & 21 & 15 & 21 & 257 & 32 & 90 & 474 \\
\hline 1751 & 24 & 10 & 17 & 16 & 23 & 293 & 43 & 119 & 545 \\
\hline 1752 & 18 & 8 & 19 & 19 & 18 & 269 & 31 & 108 & 490 \\
\hline 1753 & 25 & 21 & 15 & 21 & 17 & 330 & 36 & 106 & 571 \\
\hline 1754 & 34 & 18 & 16 & 32 & 20 & 306 & 52 & 114 & 592 \\
\hline 1755 & 24 & 12 & 17 & 31 & 19 & 247 & 49 & 130 & 529 \\
\hline 1756 & 34 & 19 & 13 & 27 & 18 & 257 & 37 & 150 & 555 \\
\hline 1757 & 36 & 15 & 13 & 21 & 27 & 289 & 43 & 148 & 592 \\
\hline 1758 & 39 & 24 & 18 & 20 & 33 & 335 & 49 & 145 & 663 \\
\hline 1759 & 27 & 11 & 10 & 28 & 22 & 404 & 50 & 173 & 725 \\
\hline 1760 & 37 & 31 & 15 & 32 & 37 & 455 & 50 & 198 & 855 \\
\hline 1761 & 19 & 18 & 18 & 19 & 28 & 371 & 40 & 193 & 706 \\
\hline 1762 & 26 & 19 & 14 & 32 & 25 & 278 & 42 & 87 & 523 \\
\hline 1763 & 25 & 19 & 14 & 18 & 21 & 280 & 52 & 132 & 561 \\
\hline 1764 & 24 & 10 & 10 & 25 & 19 & 288 & 49 & 143 & 568 \\
\hline 1765 & 32 & 21 & 18 & 27 & 19 & 305 & 49 & 135 & 606 \\
\hline 1766 & 34 & 15 & 16 & 31 & 21 & 416 & 67 & 156 & 756 \\
\hline 1767 & 41 & 15 & 17 & 25 & 37 & 389 & 45 & 156 & 725 \\
\hline 1768 & 32 & 19 & 23 & 29 & 39 & 412 & 56 & 191 & 801 \\
\hline 1769 & 20 & 21 & 26 & 24 & 32 & 393 & 42 & 182 & 740 \\
\hline 1770 & 24 & 18 & 21 & 25 & 30 & 350 & 51 & 143 & 662 \\
\hline 1771 & 28 & 15 & 16 & 22 & 24 & 300 & 28 & 121 & 554 \\
\hline 1772 & 18 & 16 & 18 & 19 & 15 & 261 & 43 & 122 & 512 \\
\hline 1773 & 24 & 14 & 8 & 23 & 22 & 250 & 38 & 120 & 499 \\
\hline 1774 & 33 & 13 & 17 & 20 & 25 & 218 & 29 & 132 & 487 \\
\hline 1775 & 28 & 13 & 4 & 14 & 13 & 247 & 30 & 149 & 498 \\
\hline 1776 & 24 & 17 & 17 & 23 & 20 & 285 & 41 & 99 & 526 \\
\hline 1777 & 30 & 16 & 9 & 27 & 22 & 251 & 30 & 97 & 482 \\
\hline 1778 & 58 & 21 & 14 & 23 & 30 & 344 & 72 & 193 & 755 \\
\hline 1779 & 39 & 19 & 18 & 26 & 20 & 245 & 43 & 96 & 506 \\
\hline
\end{tabular}




$\begin{array}{rrrrrrrrrr}1780 & 44 & 23 & 21 & 30 & 24 & 362 & 62 & 130 & 696 \\ 1781 & 38 & 16 & 23 & 21 & 33 & 297 & 35 & 127 & 590 \\ 1782 & 46 & 20 & 18 & 30 & 41 & 323 & 53 & 121 & 652 \\ 1783 & 40 & 19 & 15 & 29 & 23 & 283 & 44 & 110 & 563 \\ 1784 & 30 & 16 & 18 & 20 & 17 & 305 & 48 & 111 & 565 \\ 1785 & 55 & 22 & 17 & 29 & 60 & 532 & 55 & 261 & 1.031 \\ 1786 & 41 & 16 & 23 & 30 & 51 & 774 & 84 & 265 & 1.284 \\ 1787 & 22 & 21 & 17 & 20 & 43 & 467 & 43 & 189 & \mathbf{8 2 2} \\ 1788 & 27 & 12 & 5 & 14 & 24 & 294 & 30 & 170 & 576 \\ 1789 & 28 & 21 & 8 & 27 & 28 & 355 & 64 & 126 & 657 \\ 1790 & 27 & 18 & 15 & 24 & 29 & 320 & 60 & 173 & 666 \\ 1791 & 22 & 21 & 10 & 18 & 24 & 270 & 43 & 122 & 530 \\ 1792 & 29 & 14 & 13 & 23 & 29 & 307 & 41 & 135 & 591 \\ 1793 & 31 & 22 & 18 & 25 & 24 & 295 & 42 & 144 & 601 \\ 1794 & 24 & 15 & 26 & 20 & 28 & 272 & 32 & 141 & 558 \\ 1795 & 17 & 16 & 20 & 17 & 28 & 292 & 36 & 131 & 557 \\ 1796 & 31 & 15 & 12 & 19 & 23 & 276 & 52 & 168 & 596 \\ 1797 & 32 & 18 & 27 & 19 & 26 & 386 & 37 & 164 & 709 \\ 1798 & 22 & 23 & 22 & 24 & 52 & 414 & 76 & 209 & 842 \\ 1799 & 24 & 22 & 20 & 25 & 26 & 321 & 46 & 166 & 650\end{array}$

1.= Parroquia de San Dionisio.

2.= Parroquia de San Juan de los Caballeros.

3.= Parroquia de San Lucas.

4.= Parroquia de San Marcos.

5.= Parroquia de San Mateo.

6.= Parroquia de San Miguel.

7.= Parroquia de San Salvador.

8.= Parroquia de Santiago. 